\title{
Accessing adolescent friendly health clinics in India: The perspectives of adolescents and youth
}

\author{
K.G. Santhya \\ Population Council \\ Ravi Prakash \\ Population Council \\ Shireen J. Jejeebhoy \\ Population Council \\ Santosh Kumar Singh \\ Population Council
}

Follow this and additional works at: https://knowledgecommons.popcouncil.org/departments_sbsr-pgy

Part of the Demography, Population, and Ecology Commons, Family, Life Course, and Society Commons, and the International Public Health Commons How does access to this work benefit you? Let us know!

\section{Recommended Citation}

Santhya, K.G., Ravi Prakash, Shireen J. Jejeebhoy, and Santosh Kumar Singh. 2014. "Accessing adolescent friendly health clinics in India: The perspectives of adolescents and youth." New Delhi: Population Council. 


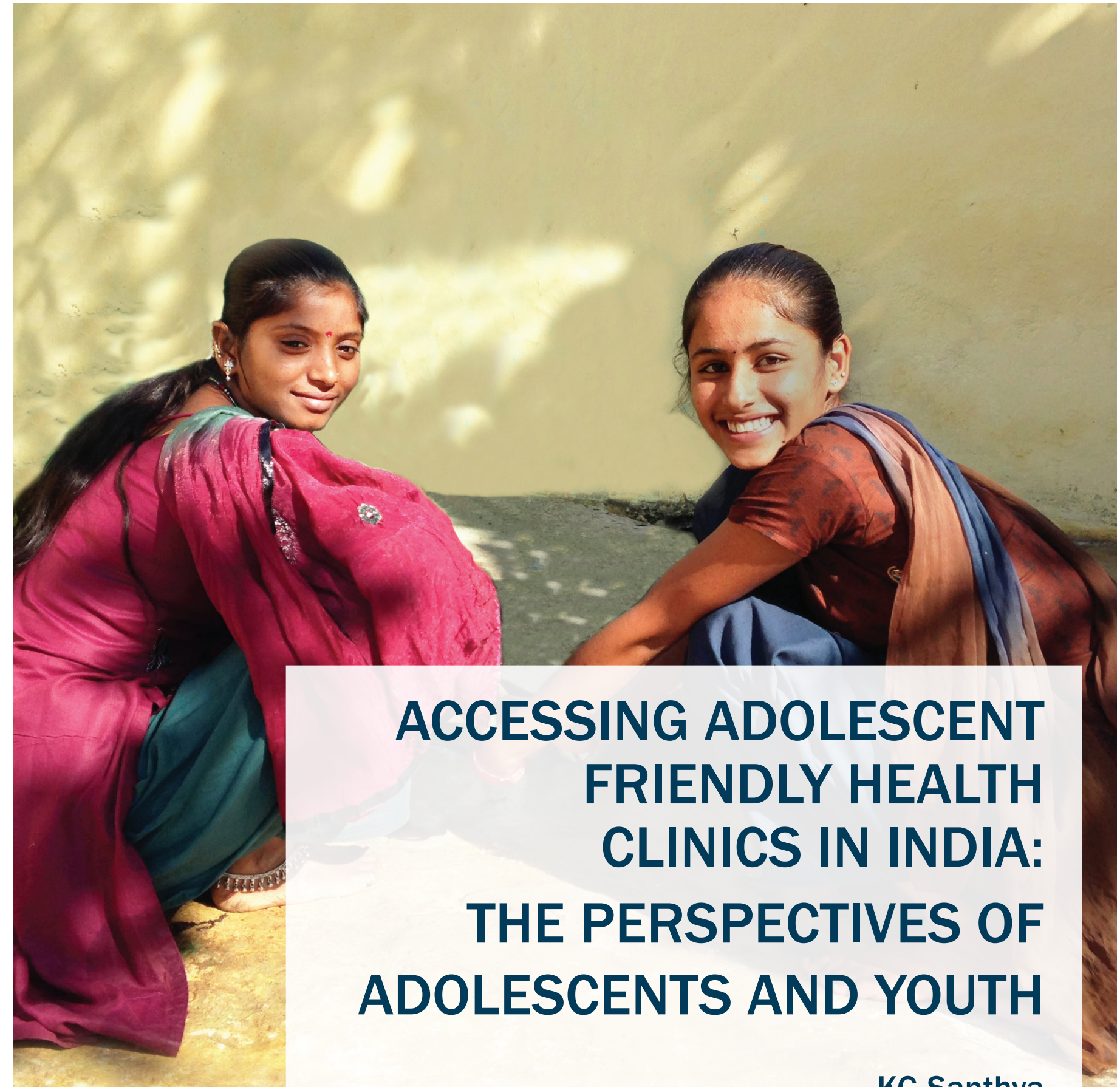




\section{POPULATION
COUNCIL
Ideas. Evidence. Impact.}

The Population Council confronts critical health and development issues-from stopping the spread of HIV to improving reproductive health and ensuring that young people lead full and productive lives. Through biomedical, social science, and public health research in 50 countries, we work with our partners to deliver solutions that lead to more effective policies, programs, and technologies that improve lives around the world. Established in 1952 and headquartered in New York, the Council is a nongovernmental, nonprofit organization governed by an international board of trustees.

\section{Population Council}

Zone 5A, Ground Floor

India Habitat Centre, Lodi Road

New Delhi, India 110003

Phone: 91-11-24642901

Email: info.india@popcouncil.org

Website: www.popcouncil.org

Suggested citation: Santhya, K. G., R. Prakash, S. J. Jejeebhoy and S. K. Singh. 2014. Accessing Adolescent Friendly Health Clinics in India: The Perspectives of Adolescents and Youth. New Delhi: Population Council. 


\section{ACCESSING ADOLESCENT FRIENDLY HEALTH CLINICS IN INDIA: \\ THE PERSPECTIVES OF ADOLESCENTS AND YOUTH}

KG Santhya

Ravi Prakash

Shireen J Jejeebhoy

Santosh Kumar Singh

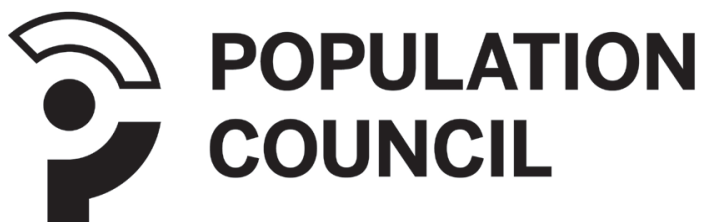

Ideas. Evidence. Impact. 


\section{Table of Contents}

List of Tables

Acknowledgements vii

Chapter 1 Introduction 1

Chapter 2 Health problems and concerns experienced by adolescents and youth and treatment-seeking

Chapter 3 Awareness about and experiences at Adolescent Friendly Health Clinics

Chapter 4 Preferences of adolescents and youth about health care providers and facilities

Chapter 5 Summary and recommendations

References

Authors 


\section{List of Tables}

Table 1.1: Profile of the study districts and states

Table 1.2: Description of study components

Table 1.3: Selected background characteristics of adolescents and youth who participated in the survey by sex and marital status

Table 1.4: Selected background characteristics of adolescents and youth who participated in the survey by state of residence

Table 2.1: Percentage of adolescents and youth reporting recent experiences of selected sexual and reproductive health problems and mental health concerns by sex and marital status

Table 2.2: Percentage of adolescents and youth reporting recent experiences of selected sexual and reproductive health problems and mental health concerns by state of residence

Table 2.3: Percentage of adolescents and youth who experienced selected sexual and reproductive health problems and mental health concerns by reported advice and/or treatment-seeking

Table 2.4: Percentage of adolescents and youth who experienced selected sexual and reproductive health problems and mental health concerns by reported advice and/or treatment-seeking, according to state of residence

Table 2.5: Percentage of adolescents and youth who sought advice and/or treatment for selected sexual and reproductive health problems and mental health concerns by type of provider, according to marital status

Table 2.6: Percentage of adolescents and youth who sought advice and/or treatment for selected sexual and reproductive health problems and mental health concerns by type of provider, according to state of residence

Table 2.7: Percentage of adolescents and youth who did not seek advice and/or treatment for selected sexual and reproductive health problems and mental health concerns by reasons for not seeking care, according to sex and marital status

Table 2.8: Percentage of adolescents and youth who did not seek advice and/or treatment for selected sexual and reproductive health problems and mental health concerns by reasons for not seeking care, according to state of residence

Table 2.9: Percentage of adolescents and youth reporting interaction with ANMs in the year preceding the interview by selected background characteristics

Table 2.10: Percentage of adolescents and youth who interacted with ANMs by the nature of their interaction, according to sex and marital status

Table 2.11: Percentage of young women who interacted with ANMs by the nature of their interaction, according to state of residence

Table 2.12: Percentage of adolescents and youth reporting interactions with Community Health Workers by selected background characteristics 
Table 2.13: Percentage of adolescents and youth who interacted with Community Health Workers by the nature of their interaction

Table 2.14: Percentage of young women who interacted with Community Health Workers by the nature of their interaction, according to state of residence

Table 3.1: Percentage of adolescents and youth who were aware of and had sought services from AFHCs by selected characteristics

Table 3.2: Services provided to mystery clients visiting AFHCs

Table 4.1: Percentage of adolescents and youth by preferred health care provider for selected health services, according to sex and marital status

Table 4.2: Percentage of adolescents and youth by preferred health care provider for selected health services, according to state of residence

Table 4.3: Percentage of adolescents and youth by preferred health facility for selected health services, according to sex and marital status

Table 4.4: Percentage of adolescents and youth by preferred health facility for selected health services, according to state of residence

Table 4.5: Percentage of adolescents and youth by reasons for preferring government or private health facilities, according to sex and marital status

Table 4.6: Percentage of adolescents and youth by reasons for preferring government or private health facilities, according to sex and state of residence 


\section{Acknowledgements}

This study has benefited immeasurably from the inputs of many. We are extremely grateful to the John D. and Catherine T. MacArthur Foundation for their financial support which made this study possible.

The Population Council undertook this study at the request of the Ministry of Health and Family Welfare, Government of India. We are grateful for this opportunity and for the unstinting support that we received from the Ministry at all stages of the study. We take this opportunity to express our special thanks to Dr. Suresh Mohammed, IPS, formerly Director, Reproductive and Child Health, Ministry of Health and Family Welfare, Government of India, New Delhi; Dr. Kiran Sharma, formerly National Professional Officer, World Health Organization India Country Office, New Delhi, and Ms. Medha Gandhi, formerly Consultant Adolescent Reproductive and Sexual Health, Ministry of Health and Family Welfare, Government of India, New Delhi.

We could not have successfully completed this study without the support of the Departments of Health and Family Welfare in Jharkhand, Maharashtra and Rajasthan. We would like to acknowledge with gratitude the support that we received from Shri Aboobacker Siddique P., IAS, formerly Mission Director, Jharkhand Rural Health Mission Society, Government of Jharkhand; Dr. Vinod Kumar Saha, formerly Chief Medical Officer, Jamtara District, Government of Jharkhand; Dr. Gopal Srivastava, formerly Chief Medical Officer, Palamu District, Government of Jharkhand; Shri Vikas Kharge (IAS), Commissioner (Family Welfare) \& Director (National Rural Health Mission), Government of Maharashtra; Smt. Gayatari Rathore, formerly Mission Director (National Rural Health Mission), Directorate of Medical and Health Services, Government of Rajasthan, and Ms. Archana Sharma, State NGO Coordinator/ Consultant (Adolescent Reproductive and Sexual Health), Directorate of Medical, Health \& Family Welfare, Government of Rajasthan. We would also like to acknowledge the contribution of various officials at the health facilities in which the study was conducted in Jharkhand, Maharashtra and Rajasthan.

We are grateful to Dr. Dinesh Agarwal, Policy Lead - Health and Disease Control, IPE Global Private Limited, New Delhi, and Dr. Jaya Jaya, India Programme Officer, UNFPA, New Delhi, for reviewing the earlier draft of this report and providing insightful comments and suggestions.

At the Population Council, several colleagues have supported us in both the technical and administrative aspects of this study. We are grateful to Rajib Acharya for reviewing the study design and helping with the training of field investigators, Shagun Sabarwal (formerly Programme Officer, Population Council) for analysing the survey data, Komal Saxena and Shilpi Rampal for analysing qualitative data, and M.A. Jose for ably managing the administrative aspects of the project. We would like to thank Jyoti Moodbidri for her editorial contributions and Komal Saxena for ably coordinating the printing of the report. We also appreciate the efforts of our investigators and the mystery clients who painstakingly collected the data and Monika Bindra, Sandeep Sharma, Anakshi Ummat Upadhyay and Samiha Grewal who diligently translated the transcripts.

Finally, and most importantly, we would like to thank the adolescents and youth who generously gave us their time and shared their views and experiences with us.

K G Santhya

Ravi Prakash

Shireen J. Jejeebhoy

Santosh Kumar Singh 


\section{Chapter 1 Introduction}

The recently launched Rashtriya Kishor Swasthya Karyakram (RKSK) seeks to enable all adolescents and youth to realise their full potential by making informed and responsible decisions concerning their health and well-being and by accessing the services and support they need to implement their decisions (Ministry of Health and Family Welfare, 2014). In order to realise this vision, the RKSK framework acknowledges the strengthening of Adolescent Friendly Health Clinics (AFHCs) and providing correct knowledge and information through counselling services as two of its seven critical components (7Cs). As the government makes efforts to roll out the RKSK programme at scale across the country, reviewing the experiences of the AFHCs established under the National Adolescent Reproductive and Sexual Health Strategy, the predecessor of the RKSK, can provide useful lessons. With this in view, at the request of the Ministry of Health and Family Welfare, the Population Council conducted an assessment of AFHCs from the perspectives of adolescents and youth, and health care providers in three states in India. This report presents the findings of the assessment conducted among adolescents and youth. Findings describing the perspectives of health care providers are presented in a separate report (Jejeebhoy et al., 2014).

\section{Study objectives}

The goal of this study was to identify, from the perspectives of adolescents and youth aged 15-24 and health care providers ranging from frontline workers to those based at AFHCs, the key components of sexual and reproductive health services that are responsive to the needs of adolescents and youth, and feasible at community and facility levels as well as to make recommendations regarding refinements in content and approaches for training various cadres of health care providers to better address these needs. Specifically, the study sought to

- Explore the perspectives of adolescents and youth about their health needs, the obstacles they face in obtaining sexual and reproductive health information, supplies and services, and their preferences about how and by whom information and services should be provided; and

- Explore the perspectives of health care providers, including Accredited Social Health Activists (ASHAs), Auxiliary Nurse Midwives (ANMs), Counsellors and Medical Officers (MOs), about their role in responding to the sexual and reproductive health needs of adolescents and youth, and the factors that facilitate or constrain them from providing information and services and effectively reaching out to adolescents and youth.

\section{Background and rationale for the study}

One of the key objectives of the RKSK is to increase the accessibility of quality counselling and health services for as well as their utilisation by adolescents and youth; consequently, strengthening AFHCs and providing quality counselling services are among the seven critical components (7Cs) identified in the RKSK to achieve this objective (Ministry of Health and Family Welfare, 2014). The RKSK seeks to develop community-based interventions that will offer information and commodities such as sanitary napkins, iron and folic acid tablets and non-clinical contraceptives, and strengthen facility-based services that will provide need-based counselling, and specialised medical and paramedical services to adolescents and youth.

With regard to facility-based services, the RKSK promises to establish at the sub-centre level, routine sub-centre clinics that will provide counselling on common health concerns of adolescents and youth and haemoglobin testing by ANMs or male multi-purpose workers. At the Primary Health Centre (PHC) level, it will run weekly AFHCs that will offer counselling services by ANMs, and management of common health problems and referrals by MOs. At the Community Health Centre $(\mathrm{CHC})$ level, it will establish daily AFHCs that will provide counselling services by dedicated counsellors and management of common health problems and referrals by MOs and Staff Nurses. At the District Hospital (DH) level, in addition to what is being promised at the CHCs, biweekly speciality AFHCs (S-AFHCs) will be conducted to offer management of speciality problems and referrals by gynaecologists and paediatricians. Finally, at the medical college level, S-AFHCs for speciality care will be conducted five days a week. 
Adolescent Friendly Health Clinics have been established as part of the earlier National Adolescent Reproductive and Sexual Health Strategy to provide preventive, promotive, curative and referral services to adolescents (Ministry of Health and Family Welfare, 2006a). Although known as 'adolescent' friendly clinics, these clinics are designed to meet the specific needs of young people, that is, adolescents (10-19 year-olds) and youth (15-24 year-olds). As of 2013, a total of 6,220 AFHCs have been established (Kumar, 2014). The AFHCs, however, have not made significant inroads into providing services for young people as evident from the study, Youth in India: Situation and Needs, and other evaluations. For example, in the Youth in India study, just seven percent of young men and three percent of young women reported that they had ever received information on sexual matters from a health care provider (International Institute for Population Sciences and Population Council, 2010). Likewise, of those who were aware of contraceptive methods, just 13-14 percent had received information on contraception from a health care provider. Besides, as many as 43 percent and 52 percent of young men and women, respectively, reported that they would be uncomfortable to obtain contraceptive supplies from any health care provider. Additionally, married youth were just somewhat more likely to report contact with health care providers than were the unmarried.

Moreover, a few evaluations of AFHCs, conducted in the early days of their establishment, have noted their uneven distribution, the limited utilisation of services by young people and the poor quality of services provided at these clinics (Centre for Operations Research and Training, 2009; International Institute of Health Management Research, 2010). Even in Gujarat, one of the states in which AFHCs are concentrated, evidence from an evaluation of 21 Adolescent Reproductive and Sexual Health (ARSH) clinics observes that not all were functional, and very few of those that were working had separate OPD (Out-Patient Department) hours and days designated for adolescents and youth or provided auditory and visual privacy. Additionally, few young people were aware of these clinics and even fewer would use them because of lack of privacy, fear of attending clinics located in health centres and hospitals, and fear of service provider attitudes (Centre for Operations Research and Training, 2009).

The need for training programmes to orient various categories of health care providers about the special needs of adolescents and youth has also been reiterated in the RKSK. The programme promises to provide both preservice training and continuing education, including refresher courses, and has revised or newly prepared orientation modules to enhance the capacity of various cadres, including peer educators, ANMs/Lady Health Visitors (LHVs), Counsellors and MOs (Ministry of Health and Family Welfare, 2014). Under the earlier National Adolescent Reproductive and Sexual Health Strategy, orientation modules were developed and training programmes were conducted to orient ANMs and MOs in the provision of various sexual and reproductive health services to adolescents and youth (Ministry of Health and Family Welfare, 2006b; 2006c). Likewise, the needs of adolescents and youth were also incorporated into ASHA training programmes (Ministry of Health and Family Welfare, 2006d).

Although training programmes in adolescent reproductive and sexual health have been imparted to various cadres of health care providers, not all ASHAs, ANMs, Staff Nurses, MOs and other personnel have been trained or sensitised to the unique needs of adolescents and youth (Ministry of Health and Family Welfare, 2009). Moreover, training has not always combined a focus on the content of information to be imparted with strategies for imparting the information or attention to the clarification of values. Evidence from a small-scale study in Andhra Pradesh and Madhya Pradesh indicates that a major factor that might hinder the ability of health care providers to provide sexual and reproductive health services to young people is their discomfort in doing so. While most stakeholders were comfortable discussing such matters with married young women, sizeable proportions reported discomfort in addressing young men and even unmarried young women. Male health care providers were less uncomfortable providing information and services to young women than were female providers about providing such services to young men (Santhya, Jejeebhoy and Ghosh, 2007). Evaluations of AFHCs in Maharashtra and Gujarat also observe that the training of health care providers in adolescent reproductive and sexual health service delivery is inadequate (Centre for Operations Research and Training, 2009; International Institute of Health Management Research, 2010).

Likewise, although the guidelines for ASHAs do highlight, in general terms, the vulnerability of young women and although over four-fifths (81\%) of the 8.5 lakh enlisted ASHAs have received training in adolescent and youth issues (Ministry of Health and Family Welfare, 2012), the need still remains to provide more specific information on possible strategies for delivering services to young people. Indeed, the mid-term appraisal of the Eleventh Five Year Plan noted that ASHAs were inadequately trained, and because of their focus on the Janani Suraksha Yojana (a conditional cash transfer programme to promote institutional delivery and safe motherhood under the National Rural Health Mission), their activities have largely concentrated on facilitating institutional deliveries (Planning Commission, 2011). Evidence from a recent study of some 150 ASHAs in two districts of Rajasthan indicates that 
their interactions with adolescent girls and young women remain limited; for example, just one-third of ASHAs reported that they had counselled newly married women about contraceptives (Santhya, Jejeebhoy and Zavier, 2011). Similarly, a companion study of women who had delivered in the one year preceding the interview reports that while just a quarter of young mothers had received assistance from the ASHA during pregnancy, even fewer had received assistance during delivery and the postpartum period (Santhya et al., 2011).

Clearly, there exists a need to identify approaches to enhance service delivery through AFHCs on the one hand and to generate demand for such services among adolescents and youth on the other. There is also a need to identify what services adolescents and youth require, what is feasible at community and facility levels, and what is feasible for implementation by different cadres of health care providers.

\section{Study setting}

The study was conducted in three states-Jharkhand, Maharashtra and Rajasthan-selected jointly with the Ministry of Health and Family Welfare, Government of India.

The states reflect heterogeneity both geographically as well as in terms of the situation of young people, and their social, economic and demographic characteristics. Maharashtra is among the more economically progressive states in the country, while Jharkhand and Rajasthan are among the lesser developed states (Ministry of Statistics and Programme Implementation, 2008). Similarly, while Maharashtra is among the most urbanised states, Jharkhand and Rajasthan are characterised by large rural populations (Office of the Registrar General and Census Commissioner, 2011). The literacy rate ranged from a low of 67-68 percent in Jharkhand and Rajasthan to a high of 83 percent in Maharashtra.

Evidence from the Youth in India: Situation and Needs study indicates that sexual and reproductive health services have not reached most young people in these states (International Institute for Population Sciences and Population Council, 2010). For example, few young men and young women had ever practised contraception within marriage: between 22 percent (Jharkhand) and 36-38 percent (Maharashtra and Rajasthan) among married young men and between 24 percent (Jharkhand and Rajasthan) and 30 percent (Maharashtra) among married young women. Consistent condom use within pre-marital relationships was even less frequent-6-7 percent of young men who had engaged in a pre-marital relationship in Jharkhand and Rajasthan and 22 percent in Maharashtra reported consistent condom use; the corresponding percentages among young women were $2-4$ and seven, respectively. Just 11-15 percent of young men in these states reported a health care provider as a source of information on contraception; among young women, 8-11 percent in Jharkhand and Rajasthan and 23 percent in Maharashtra so reported. A total of 180 AFHCs were functional in Jharkhand and 140 in Maharashtra (State National Rural Health Mission office in Jharkhand and Maharashtra, personal communication).

The present study was located in two districts in each selected state. First, districts that were close to the state averages on such indicators as literacy rate of young women aged 15-24 and percentage of married young women aged 15-24 currently using contraceptive methods were listed. Subsequently, as suggested by the Ministry of Health and Family Welfare, from the district list of each state, we selected one district in which the AFHCs had been functional for quite some time and one in which such clinics had recently been launched, for locating the study. These districts namely, Jamtara and Palamu in Jharkhand, Chandrapur and Nashik in Maharashtra, and Bhilwara and Karauli in Rajasthan, represented districts with long- and recently-established AFHCs, respectively, in the three states. A few key indicators of the study districts and states are presented in Table 1.1.

The study was fielded in rural areas of the study districts. Within each district, in consultation with the district health department, and using the records made available to us by the state health department, we prepared a list of all the $\mathrm{CHCs}$ (in Jharkhand and Rajasthan) and sub-district/rural hospitals (in Maharashtra) which had an AFHC. We restricted our study to AFHCs located in $\mathrm{CHCs}$ or sub-district/rural hospitals because at the time of our fieldwork, AFHCs had not been established at PHCs or those that existed were not functional. Based on the date of establishment of the AFHC and whether or not it was functional, one AFHC established before 2010 and one established in $\mathbf{2 0 1 0}$ or later were selected randomly. In total, therefore, the facility-based components of this assessment were conducted in $12 \mathrm{AFHCs}$ from the three states taken together. In Rajasthan, there was no designated facility or fixed timings for providing services specifically to adolescents and youth in the $\mathrm{CHC}$. The $\mathrm{CHCs}$, however, were shown as housing AFHCs in the records of the state health department, and provided services for adolescents and youth in the general OPD. 


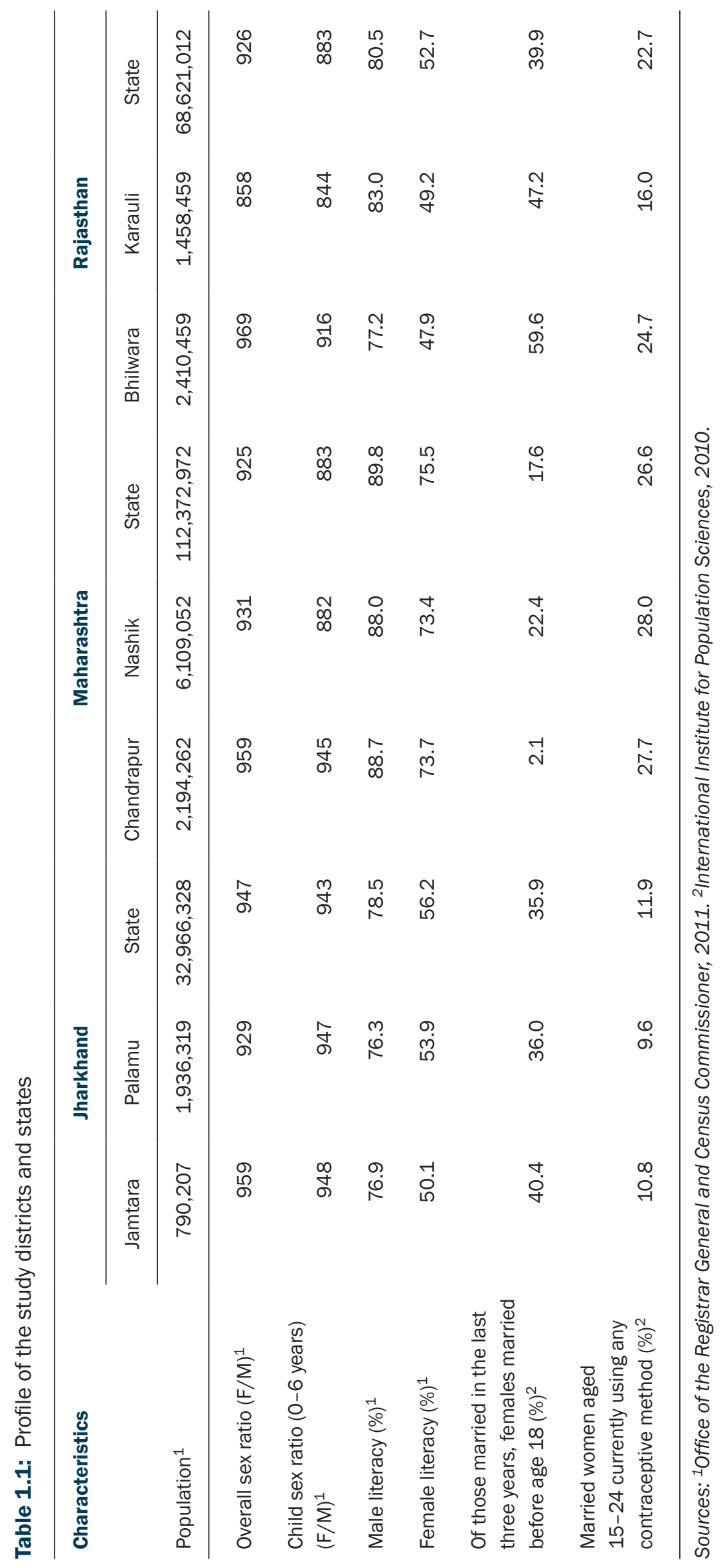


For the community-based survey of adolescents and youth, we selected four villages systematically from among the villages surrounding each AFHC, that is, within a distance of 5-10 kilometres from the AFHC. Specifically, we first collected information about all the villages surrounding the selected AFHCs. We then arranged these villages by their population size in ascending order, cumulated their population and selected four villages systematically, using probability proportional to size. Thus, the community-based survey was located in a total of 48 villages from the three states taken together.

\section{Study design}

A community- and facility-based multi-component study, using both quantitative and qualitative methods, was conducted between September, 2012 and January, 2013. The study comprised seven components in all, as summarised in Table 1.2 and described in detail below. The first three components are explored in detail in this report; the latter four are explored in a companion report (Jejeebhoy et al., 2014).

Observation of service delivery at AFHCs using mystery clients: Mystery client visits were undertaken to better understand facility-based interactions between young people and MOs and other health care providers, including nurses and ANMs. We followed the procedure for conducting mystery client visits as suggested in the guide published by Pathfinder International (Boyce and Neale, 2006). The study team identified young women and young men to serve as mystery clients, with the help of local NGOs, from villages that were not located in close proximity to the AFHCs selected for the study. A young person was considered eligible to serve as a mystery client if she/he was aged between 18 and 24 years, she/he resided in a village that was not located in close proximity to the AFHC, she/ he had not been to the AFHC before, she/he demonstrated a talent for role playing and she/he displayed openness about discussing sexual and reproductive matters. The study team recruited four youth-two females and two malesper clinic to serve as mystery clients.

The mystery clients were trained by the study coordinators. During the training, the study coordinators familiarised the mystery clients with the scenarios they were expected to act out at the AFHC, helped them phrase their question(s) to the health care provider, gave them an opportunity to do a role play of the scenarios assigned to them and briefed them on potential criteria for evaluating the quality of services. The scenarios assigned to the mystery clients included an unmarried young woman, aged 17, who felt pressured by her boyfriend to engage in pre-marital sex and was seeking oral contraceptives; a married young woman, aged 20, seeking information on protective actions to be taken in a marital relationship characterised by her husband's extra-marital partnership and perpetration of marital violence; an unmarried young man, aged 19, who was in a relationship with a girl and was seeking condoms; and a married young man, aged 22, who had had sex with sex workers and wanted to undergo an HIV test. The mystery clients were informed about the AFHC that they should visit, and asked to observe everything that the health care provider did or said and not to mention any affiliation with the study during their visit. They were also instructed to refuse to undergo any physical examination. To keep the experience of mystery clients as close as possible to that of genuine clients, no mystery client was sent to more than one clinic in a district. Mystery clients made visits in pairs-one was assigned to serve as the client and the other to serve as an additional observer-to minimise recall bias (Boyce and Neale, 2006), and were paid a monetary compensation of Rs. 1,000 per interview (approximately $\$ 20$ ) to cover their transportation and any other expenses incurred. A total of 24 mystery client visitsone visit each by a male and a female pair per clinic-were targeted and successfully conducted.

Debriefing of mystery clients was done by the study team supervisors immediately after the AFHC visit at a place convenient to the mystery clients. A semi-structured questionnaire, prepared and translated into the local language, was used for debriefing. Each mystery client and observer was debriefed separately. They were probed about their experience in availing of services at the AFHC (registration process, waiting time to see the health care provider etc.), the information given by the health care provider (content, comprehensiveness etc.) and the provider's behaviour toward the client (provider objectivity, level of comfort in discussing sexual and reproductive health matters with the client etc.). We note that the narratives of the client and the observer did not differ in any of the mystery client visits; rather, their narratives supplemented each other's insights.

Exit interviews with clients accessing services at AFHCs: Exit interviews were conducted with adolescents and youth who had availed of services at the selected AFHCs to assess the characteristics of clients visiting these clinics, the health problems/concerns for which young people sought services from these clinics and their experiences at these clinics. Respondents for the exit interviews included adolescents and youth aged 15-24 who sought services 
from the AFHCs on the days when the research investigators from the study team-one female and one male-were stationed at these clinics. The research investigators were posted at each AFHC for a maximum of four to five clinic days. The sample size for the exit interviews was fixed at ten per clinic and therefore, a total of 120 exit interviews were planned. However, we note that the study team was able to conduct just five exit interviews-four in Jharkhand and one in Maharashtra-because hardly any young people visited the AFHCs for services on the days when the exit interviews were conducted.

Female and male investigators administered a short, semi-structured questionnaire prepared in the local language to female and male clients, respectively. The interview was conducted in the clinic premises that offered privacy for the interview. The questionnaire contained questions regarding the respondent's socioeconomic background, health problems/concerns experienced, treatment-seeking patterns for the problem experienced, perceptions about and experiences at the AFHC, the quality of services received and so on.

Survey of adolescents and youth in the community settings: With a view to better understand the awareness of AFHCs among adolescents and youth and the barriers that they face in accessing services from these clinics, a community-based survey was conducted among adolescents and youth aged 15-24, residing in selected villages surrounding the 12 AFHCs identified for the study. As mentioned above, four villages surrounding each AFHC, and therefore, a total of 48 villages, were selected for the survey. The sample size for interviews was fixed at 40 adolescents and youth per village-10 each of unmarried adolescents and young women, married adolescents and young women, unmarried adolescents and young men and married adolescents and young men-and, therefore, 160 adolescents and young men and young women per clinic area, and 640 adolescents and young men and young women per state. This sample size was inflated to 192 for each clinic area, 768 per state and 2,304 in all, assuming a 20 percent non-response rate for individual interviews.

A rapid household listing exercise was conducted in the study villages to identify married and unmarried young men and young women aged 15-24. The listing team visited all the households in selected villages containing less than 300 households, and all households in selected segments (selected by probability proportional to size) of approximately 300 households in larger villages. Information was collected on the age, sex and marital status of all 15-24 year-old usual residents of the household from an adult member of the household and four sampling frames were prepared, one each for married males, unmarried males, married females and unmarried females who were eligible for enrolment in the study. These sampling frames were used to randomly select the required number of respondents from each category of adolescents and youth. Within each household, no more than one male and one female respondent were interviewed, resulting in a maximum of two interviews from any one household.

In each of the three states, the sample was weighted at the village level for males and females separately. The sample weight for each state (the state weight) was calculated based on the differential non-response rates as well as design weights for each village. For the combined sample (three states together), the overall sample weights were calculated as the product of the design weight for each state and the state weight. Finally, the weights were normalised at the state as well as overall levels so that the total number of weighted cases equalled the total number of unweighted cases.

A detailed questionnaire was administered to eligible respondents in their local language. The questionnaire contained questions regarding the respondent's socioeconomic background; selected sexual and reproductive health problems and mental health concerns experienced in the last three months; treatment-seeking patterns; reasons for not seeking treatment for those who had not sought treatment; awareness and perceptions of AFHCs; difficulties faced in seeking treatment from these clinics, if any; interactions with frontline health care providers, namely, ANMs and community health workers, namely, ASHAs and Anganwadi Workers (AWWs); perceptions about the key health problems and concerns faced by adolescents and youth, in general; the type of health services that adolescents and youth require, their preferences regarding the cadre of health care providers and the facilities that should provide these services and so on.

Out of the expected sample of 2,304 adolescents and youth in the three states (768 per state), a total of 2,137 were contacted for the interview (96\% in Jharkhand; 93\% in Rajasthan; 90\% in Maharashtra); inability to contact the remaining largely reflected the paucity of married young men in the age group of 15-24. Of those contacted, 99 percent (a total of 2,131 adolescents and youth) were interviewed in the three states taken together; one percent either refused to participate in the survey or did not complete the interview. State-specific response rates were 99 percent in Jharkhand and Rajasthan, and 100 percent in Maharashtra. 
In-depth interviews with ASHAs: In-depth interviews were conducted with ASHAs to better understand their perspectives about their interactions with adolescents and youth and the constraints that they face in reaching out to these groups. ASHAs were recruited from the survey villages; one ASHA was selected opportunistically from each village. A total of 48 ASHAs-16 per state (4 per AFHC area)-were targeted for the in-depth interviews. As seen from Table 1.2, a total of 46 ASHAs were interviewed in-depth from the three states. The discussion focused on the participant's experience as an ASHA; training received, particularly, in providing services to adolescents and youth; perceptions about the training received; interactions with adolescents and youth and constraints, if any, in reaching out to them; perceptions about the sexual and reproductive health concerns of adolescents and youth and their service needs; and suggestions for enhancing the ASHA's role and skills in meeting the health service needs of adolescents and youth.

In-depth interviews with ANMs, Counsellors and MOs: In-depth interviews were conducted with ANMs and MOs in the selected AFHCs to better understand their role in the AFHCs and the constraints that they face in providing services to adolescents and youth. In each AFHC, one or two ANMs and one MO were expected to take part in the in-depth discussion. If any of the AFHCs had more than one ANM or MO and they were available for interview during the week in which the investigation was conducted, one of them was selected purposively. Thus, whereas a total of eight ANMs and four MOs per state were targeted, in effect, a total of 20 ANMs and 11 MOs were interviewed indepth from the three states taken together. We note that, in Maharashtra, three Counsellors were also interviewed in-depth as they managed the AFHC as well. The in-depth discussion focused on the participant's experience as an ANM, Counsellor or MO; training received, particularly, in providing services to adolescents and youth; perceptions about the training received, services available and provided to adolescents and youth visiting the AFHCs; perceptions about the utilisation of these services by adolescents and youth, and the constraints that they may face in accessing these services, as well as about the sexual and reproductive health concerns of adolescents and youth and their health service needs; views about the constraints that ANMs, Counsellors and MOs face in providing services to adolescents and youth, in general, and through AFHCs in particular, and suggestions for enhancing the capability of ANMs, Counsellors and MOs to provide the required services to adolescents and youth.

We note that all the interviews were conducted in the local language-Marathi in Maharashtra, and Hindi in Jharkhand and Rajasthan. The survey questionnaires and in-depth interview guides were translated into local language, back-translated, and field-tested among a small group of adolescents and youth and health care providers to see whether any questions needed to be modified.

Interviewers were recruited locally and a week-long training workshop was organised to acquaint them with the questionnaires and in-depth interview guides. Data received from the field were regularly checked to assess quality, and feedback was provided to the investigators. The survey data were analysed using SPSS/ STATA 12.0. The indepth interviews were tape-recorded with the consent of the participants, transcribed in the local language and translated into English. The transcripts were coded thematically.

\section{Characteristics of study participants}

Selected background characteristics of the adolescents and youth who participated in the community-based survey are summarised in Table 1.3. Age profiles suggest that more than one-half of the respondents, regardless of sex, were concentrated in the 15-19 age group (54\% and 58\% among young men and young women, respectively). Differences by marital status show that a larger proportion of unmarried than married young men and women fell into the age group of $15-19$ (64\% versus $24 \%$ among young men and $83 \%$ versus $42 \%$ among young women). Ninety percent or more of respondents, regardless of sex and marital status, were Hindus. Caste-wise distribution was generally similar among young men and women, with about half (48-49\%) falling into other backward castes, one-quarter (25-26\%) into scheduled castes, one-sixth (16-17\%) into scheduled tribes and one-tenth into general castes. A larger proportion of married than unmarried young men and women belonged to scheduled castes and tribes (54\% versus 38\% among young men and $46 \%$ versus 33\% among young women). Conversely, a smaller proportion of the married belonged to other backward castes (43\% versus $50 \%$ among young men and $46 \%$ versus $53 \%$ among young women) and general castes (4\% versus $13 \%$ among young men and $8 \%$ versus $14 \%$ among young women).

Levels of educational attainment, also presented in Table 1.3, were low, particularly among young women: two percent of young men and 14 percent of young women had no formal education and just 23 percent and 20 
Table 1.2: Description of study components

\begin{tabular}{|c|c|c|c|}
\hline Study components & Respondents & Sample size targeted & Sample size reached \\
\hline Mystery client interviews & $\begin{array}{l}\text { 18-24 year-old young men } \\
\text { and young women residing in } \\
\text { villages located away from the } \\
\text { selected AFHCs and willing to } \\
\text { act as mystery clients }\end{array}$ & $\begin{array}{l}24 \\
\text { ( } 1 \text { male and } 1 \text { female per } \\
\text { AFHC; } 8 \text { per state) }\end{array}$ & $\begin{array}{l}24 \\
\text { ( } 8 \text { each-4 male and } 4 \\
\text { female-in Jharkhand, } \\
\text { Maharashtra and Rajasthan) }\end{array}$ \\
\hline Exit interviews & $\begin{array}{l}\text { 15-24 year-old young men } \\
\text { and young women seeking } \\
\text { services from the selected } \\
\text { AFHCs }\end{array}$ & $\begin{array}{l}120 \\
\text { (10 per AFHC; } 40 \text { per state) }\end{array}$ & $\begin{array}{l}5 \\
\text { ( } 4 \text { in Jharkhand and } 1 \text { in } \\
\text { Maharashtra) }\end{array}$ \\
\hline $\begin{array}{l}\text { Survey of adolescents and } \\
\text { youth in the community }\end{array}$ & $\begin{array}{l}\text { Adolescents aged } 15-19 \text { and } \\
\text { youth aged } 20-24 \text { residing in } \\
\text { selected villages surrounding } \\
\text { the selected AFHCs }\end{array}$ & $\begin{array}{l}2,304 \\
\text { (192 per AFHC; } 768 \text { per state) }\end{array}$ & $\begin{array}{l}2,131 \\
\text { (736 in Jharkhand; } \\
682 \text { in Maharashtra; } 713 \text { in } \\
\text { Rajasthan) }\end{array}$ \\
\hline $\begin{array}{l}\text { In-depth interviews with } \\
\text { ASHAs }\end{array}$ & $\begin{array}{l}\text { ASHAs residing in villages } \\
\text { surrounding the selected } \\
\text { AFHCs }\end{array}$ & $\begin{array}{l}48 \\
\text { (4 per AFHC; } 16 \text { per state) }\end{array}$ & $\begin{array}{l}46 \\
\text { (15 in Jharkhand; } 15 \\
\text { in Maharashtra; } 16 \text { in } \\
\text { Rajasthan) }\end{array}$ \\
\hline In-depth interviews with ANMs & $\begin{array}{l}\text { ANMs serving the selected } \\
\text { AFHCs }^{1}\end{array}$ & $\begin{array}{l}24 \\
(1-2 \text { per AFHC; } 8 \text { maximum } \\
\text { per state) }\end{array}$ & $\begin{array}{l}20 \\
\text { ( } 8 \text { each in Jharkhand and } \\
\text { Rajasthan; } 4 \text { in Maharashtra) }\end{array}$ \\
\hline $\begin{array}{l}\text { In-depth interviews with } \\
\text { Counsellors }{ }^{*}\end{array}$ & $\begin{array}{l}\text { Counsellors serving the } \\
\text { selected AFHCs }\end{array}$ & None & $\begin{array}{l}3 \\
\text { (all in Maharashtra) }\end{array}$ \\
\hline In-depth interviews with MOs & $\begin{array}{l}\text { MOs serving the selected } \\
\text { AFHCs }^{1}\end{array}$ & 12 (1 per AFHC; 4 per state) & $\begin{array}{l}11 \text { (4 each in Jharkhand } \\
\text { and Rajasthan; } 3 \text { MOs in } \\
\text { Maharashtra) }\end{array}$ \\
\hline
\end{tabular}

Note: ${ }^{1}$ In Rajasthan, services for adolescents and youth were provided in the general OPD of the CHC; ${ }^{\star}$ In Maharashtra, the AFHCs were managed by Counsellors.

percent, respectively, had completed 12 or more years of schooling. On average, both young men and women had completed nine years of schooling, respectively. Moreover, a little less than one-half of young men (46\%) and onethird of young women (33\%) were attending school at the time of the survey. Differences in educational attainment by marital status were notable. Unmarried respondents, irrespective of sex, were better educated than their married counterparts (median years of schooling of ten versus seven). Gender differences were evident with regard to work status, with more young men than young women reporting they had engaged in paid work in the one year preceding the interview (61\% versus $28 \%$ ). In contrast, young men were somewhat less likely than young women to report that they had engaged in unpaid work in the past year (49\% versus $54 \%$ ). While differences by marital status in engagement in paid or unpaid work were modest among young women, they were notable among young men. Married young men were more likely than those who were unmarried to have engaged in paid and unpaid work in the past year. Household economic status indicates that the majority of respondents, regardless of sex, were from economically disadvantaged households (mean score of 17-18 on a wealth index scale that ranged from 0 to 53 ), with married respondents being more likely than the unmarried to come from such households.

State-level differences in selected background characteristics of adolescents and youth who participated in the community-based survey are presented in Table 1.4. Findings indicate that age and religious profiles were similar to those described above for the combined sample in all three states, with each state showing larger proportions aged 15-19 than 20-24, except among young men in Jharkhand, among whom one-half fell into the age groups 15-19 and 20-24, respectively. Caste-wise distributions were more or less similar to those described above for 
Table 1.3: Selected background characteristics of adolescents and youth who participated in the survey by sex and marital status

\begin{tabular}{|c|c|c|c|c|c|c|}
\hline $\begin{array}{l}\text { Background } \\
\text { characteristics }\end{array}$ & $\begin{array}{c}\mathrm{YM} \\
(\mathrm{N}=998)\end{array}$ & $\begin{array}{c}Y W \\
(N=1,133)\end{array}$ & $\begin{array}{c}\text { MYM } \\
(\mathrm{N}=449)\end{array}$ & $\begin{array}{c}\text { MYW } \\
(N=565)\end{array}$ & $\begin{array}{c}\text { UYM } \\
(N=549)\end{array}$ & $\begin{array}{l}\text { UYW } \\
(\mathrm{N}=568)\end{array}$ \\
\hline \multicolumn{7}{|l|}{ Age (years) } \\
\hline $15-19$ & 53.6 & 58.1 & 23.7 & 42.4 & 64.1 & 82.7 \\
\hline $20-24$ & 46.4 & 41.9 & 76.3 & 57.6 & 35.9 & 17.3 \\
\hline Mean & 19.2 & 19.1 & 21.0 & 20.1 & 18.6 & 17.5 \\
\hline \multicolumn{7}{|l|}{ Religion } \\
\hline Hindu & 94.4 & 92.6 & 92.9 & 92.3 & 95.0 & 93.1 \\
\hline Muslim & 3.7 & 4.2 & 6.0 & 4.8 & 2.9 & 3.4 \\
\hline Other ${ }^{1}$ & 1.8 & 3.1 & 1.1 & 2.9 & 2.1 & 3.5 \\
\hline \multicolumn{7}{|l|}{ Caste } \\
\hline SC & 25.8 & 24.6 & 33.1 & 27.9 & 23.2 & 19.6 \\
\hline ST & 16.1 & 16.6 & 20.6 & 18.4 & 14.5 & 13.6 \\
\hline OBC & 47.9 & 48.6 & 42.6 & 45.8 & 49.8 & 52.9 \\
\hline General $^{2}$ & 10.2 & 10.2 & 3.6 & 7.9 & 12.5 & 13.9 \\
\hline \multicolumn{7}{|l|}{ Years of schooling } \\
\hline None $^{3}$ & 2.4 & 13.5 & 8.1 & 19.7 & 0.3 & 3.8 \\
\hline $1-7$ & 23.8 & 24.8 & 42.1 & 33.0 & 17.4 & 11.4 \\
\hline $8-10$ & 51.3 & 42.4 & 34.3 & 32.2 & 57.3 & 58.4 \\
\hline 12 and above & 22.5 & 19.5 & 15.5 & 15.1 & 25.0 & 26.4 \\
\hline $\begin{array}{l}\text { Median yea]rs of schooling } \\
\text { completed }\end{array}$ & 9.0 & 9.0 & 7.0 & 7.0 & 10.0 & 10.0 \\
\hline Currently studying & 46.0 & 32.7 & 18.4 & 13.6 & 56.3 & 69.2 \\
\hline $\begin{array}{l}\text { Engaged in any paid work } \\
\text { in last } 12 \text { months }\end{array}$ & 60.9 & 28.1 & 80.7 & 29.8 & 54.0 & 25.5 \\
\hline $\begin{array}{l}\text { Engaged in any unpaid } \\
\text { work in last } 12 \text { months }\end{array}$ & 48.9 & 54.0 & 57.5 & 56.1 & 45.9 & 50.6 \\
\hline $\begin{array}{l}\text { Mean score, household } \\
\text { wealth index (range 0-53) }\end{array}$ & 18.0 & 17.3 & 14.9 & 15.9 & 19.0 & 19.7 \\
\hline
\end{tabular}

YM: Young Men; YW: Young Women; MYM: Married Young Men; MYW: Married Young Women; UYM: Unmarried Young Men; UYW: Unmarried Young Women.

Note: OBC: Other Backward Caste. SC: Scheduled Caste. ST: Scheduled Tribe. ${ }^{1}$ Includes Christian, Buddhist, Jain, Sikh and no specified religion. ${ }^{2}$ Includes all those not belonging to SC, ST or OBC. ${ }^{3}$ Includes non-literate and literate respondents with no formal schooling.

the overall sample in Rajasthan and Maharashtra; however, the pattern differed in Jharkhand where the largest proportion of young men belonged to other backward castes (57\%), followed by scheduled castes (33\%), scheduled tribes (7\%) and general castes (4\%); the corresponding percentages among young women were 64,26 , five and five, respectively. We note that these differences may be attributed to differences in the caste distribution of the married and the unmarried in the study villages. State-wise differences in educational attainment were notable, with respondents, particularly young women from Maharashtra, being more educated than their counterparts in Jharkhand and Rajasthan. Household economic status data show that irrespective of sex, respondents in Maharashtra were slightly better off than their counterparts in Jharkhand and Rajasthan. 
Table 1.4: Selected background characteristics of adolescents and youth who participated in the survey by state of residence

\begin{tabular}{|c|c|c|c|c|c|c|}
\hline \multirow[t]{2}{*}{ Background characteristics } & \multicolumn{2}{|c|}{$\begin{array}{l}\text { Jharkhand } \\
(N=736)\end{array}$} & \multicolumn{2}{|c|}{$\begin{array}{l}\text { Maharashtra } \\
\qquad(\mathrm{N}=682)\end{array}$} & \multicolumn{2}{|c|}{$\begin{array}{l}\text { Rajasthan } \\
(\mathrm{N}=713)\end{array}$} \\
\hline & $\begin{array}{c}\mathrm{YM} \\
(\mathrm{N}=362)\end{array}$ & $\begin{array}{c}Y W \\
(N=374)\end{array}$ & $\begin{array}{c}\mathrm{YM} \\
(\mathrm{N}=\mathbf{2 8 8})\end{array}$ & $\begin{array}{c}\mathrm{YW} \\
(\mathrm{N}=394)\end{array}$ & $\begin{array}{c}\mathrm{YM} \\
(\mathrm{N}=\mathbf{3 4 8})\end{array}$ & $\begin{array}{c}\mathrm{YW} \\
(\mathrm{N}=365)\end{array}$ \\
\hline \multicolumn{7}{|l|}{ Age (years) } \\
\hline $15-19$ & 50 & 61.5 & 53.1 & 53.5 & 57.4 & 59.6 \\
\hline $20-24$ & 50 & 38.5 & 46.9 & 46.5 & 42.6 & 40.4 \\
\hline Mean & 19.2 & 18.7 & 19.4 & 19.4 & 19 & 19 \\
\hline \multicolumn{7}{|l|}{ Religion } \\
\hline Hindu & 93.9 & 89.2 & 93.8 & 91.9 & 95.6 & 96.6 \\
\hline Muslim & 6.0 & 8.0 & 1.8 & 1.5 & 3.7 & 3.3 \\
\hline Other ${ }^{1}$ & 0.1 & 2.8 & 4.4 & 6.6 & 0.7 & 0.0 \\
\hline \multicolumn{7}{|l|}{ Caste } \\
\hline SC & 32.8 & 26.2 & 18.7 & 20.3 & 26.8 & 27.5 \\
\hline ST & 6.5 & 4.9 & 21.8 & 23.9 & 19 & 20.3 \\
\hline OBC & 56.7 & 64.2 & 42.7 & 43.9 & 45.4 & 38.5 \\
\hline General $^{2}$ & 4.1 & 4.7 & 16.9 & 11.9 & 8.8 & 13.7 \\
\hline \multicolumn{7}{|l|}{ Years of schooling } \\
\hline None $^{3}$ & 3.4 & 13.9 & 1.2 & 3.8 & 2.6 & 22.8 \\
\hline $1-7$ & 29.4 & 23.5 & 16.9 & 13.5 & 26.0 & 36.7 \\
\hline $8-10$ & 45.0 & 45.4 & 58.4 & 54.0 & 49.6 & 28.0 \\
\hline 12 and above & 22.2 & 17.2 & 23.4 & 28.7 & 21.8 & 12.6 \\
\hline $\begin{array}{l}\text { Median years of schooling } \\
\text { completed }\end{array}$ & 9 & 9 & 9 & 10 & 9 & 8 \\
\hline Currently studying & 49.4 & 35.1 & 40.0 & 35.4 & 49.3 & 27.6 \\
\hline Engaged in any paid work in last & & & & & & \\
\hline 12 months & 58.8 & 14.8 & 67.8 & 46.5 & 55.6 & 22.3 \\
\hline $\begin{array}{l}\text { Engaged in any unpaid work in } \\
\text { last } 12 \text { months }\end{array}$ & 48.6 & 39.7 & 32.2 & 50.0 & 66.6 & 71.4 \\
\hline $\begin{array}{l}\text { Mean score, household wealth } \\
\text { index (range 0-53) }\end{array}$ & 15.5 & 15.1 & 20.9 & 20.7 & 17.2 & 16.2 \\
\hline
\end{tabular}

YM: Young Men; YW: Young Women.

Note: OBC: Other Backward Caste. SC: Scheduled Caste. ST: Scheduled Tribe. ${ }^{1}$ Includes Christian, Buddhist, Jain, Sikh and no specified religion. ${ }^{2}$ Includes all those not belonging to SC, ST or OBC. ${ }^{3}$ Includes non-literate and literate respondents with no formal schooling. 


\section{Structure of the report}

This report is divided into five chapters, including this introductory chapter. Chapter 2 presents findings on recent experiences of selected sexual and reproductive health problems and mental health concerns, if any, among adolescents and youth, and treatment-seeking patterns among those who experienced a health problem or concern as well as their interactions with frontline health workers, namely, ANMs and community-level workers, namely, ASHAs and AWWs. Chapter 3 describes the perspectives of the young people about AFHCs and their experiences at these clinics. Chapter 4 presents findings on the preferences of adolescents and youth about the health care providers from whom and facilities from which they would like to obtain selected health services and the reasons for their preferences. Chapter 5 summarises the main findings of this study and highlights lessons for improving the delivery of health services to adolescents and youth. 


\section{Chapter 2}

\section{Health problems and concerns experienced by adolescents and youth and treatment-seeking}

This chapter presents findings on the recent experiences of health problems and concerns, if any, among adolescents and youth participating in the survey, and treatment-seeking patterns among those who experienced a health problem or a concern. It also describes findings related to the interactions of these adolescents and youth with frontline health workers, namely, ANMs and community-level workers, namely, ASHAs and AWWs. The findings draw on the survey data collected from adolescents and youth aged 15-24 in the community settings described in Chapter 1.

\section{Recent experiences of health problems and concerns}

The study probed the adolescent and youth participants about their recent experiences of selected health problems and concerns, namely, sexual and reproductive health problems and mental health concerns in the one year preceding the survey. Sexual and reproductive health problems included menstrual problems (females)/anxiety about nocturnal emission (males), problems in the private parts (that is, genital ulcers, itching in the genital area or swelling in the groin), burning sensation while passing urine and abnormal genital discharge. The mental health concerns about which they were questioned included feeling depressed or worthless, or losing sleep or confidence. Findings are summarised in Table 2.1.

Table 2.1 shows that a substantial proportion of the respondents had experienced sexual and reproductive health problems in the year preceding the interview: 54 percent of young men and 43 percent of young women reported having experienced at least one of the sexual and reproductive health problems probed in the study. Anxiety about nocturnal emission was the most frequently experienced problem reported by young men (37\%), while menstrual problems (23\%) were the most commonly experienced problems among young women. Gender differences were evident in respondents' reports of other sexual and reproductive health problems. For example, young men were more likely than young women to report such symptoms as problems in their private parts (17\% versus $8 \%$ ) and a burning sensation while passing urine (20\% versus $15 \%)$, while they were less likely to report abnormal genital discharge (5\% versus 19\%). Differences by marital status in respondents' experiences of sexual and reproductive health problems show that the married were more likely than the unmarried to report at least one sexual and reproductive health problem; young women, in particular, so reported (56\% versus $41 \%)$. Unmarried young men were more likely than the married to report anxiety about nocturnal emission ( $40 \%$ versus $27 \%$ ); differences were modest with regard to experiences of symptoms suggestive of genital infection (that is, problems in private parts, burning sensation during urination and abnormal genital discharge). Among young women, unmarried young women were more likely than the married to report menstrual problems (29\% versus $20 \%$ ); however, they were less likely to report symptoms suggestive of genital infection (15\% versus $22 \%$ ).

Similarly, a substantial proportion of surveyed adolescents and youth reported feeling depressed or worthless or losing sleep or confidence in the year preceding the interview (18\% and $25 \%$ of young men and women, respectively). Findings, moreover, show that while no differences by marital status were apparent among young men, the married were more likely than the unmarried to report mental health concerns among young women ( $28 \%$ versus $21 \%$ ). 
Table 2.1: Percentage of adolescents and youth reporting recent experiences of selected sexual and reproductive health problems and mental health concerns by sex and marital status

\begin{tabular}{|c|c|c|c|c|c|c|}
\hline Health problems/concerns experienced & YM & YW & MYM & MYW & UYM & UYW \\
\hline \multicolumn{7}{|l|}{ Sexual and reproductive health problems } \\
\hline $\begin{array}{l}\text { Anxiety about nocturnal emission [males]/ menstrual } \\
\text { problems [females] }\end{array}$ & 36.9 & 23.3 & 26.9 & 19.6 & 40.4 & 29.1 \\
\hline $\begin{array}{l}\text { Problems in private parts (genital ulcers, itching in the } \\
\text { genital area or swelling in the groin) }\end{array}$ & 17.2 & 7.5 & 15.1 & 9.4 & 18.0 & 4.4 \\
\hline Burning sensation while passing urine & 20.2 & 15.4 & 24.6 & 21.0 & 18.6 & 6.7 \\
\hline Abnormal genital discharge & 4.6 & 19.2 & 5.9 & 22.0 & 4.1 & 14.9 \\
\hline At least one of the above problems & 54.2 & 43.4 & 48.9 & 56.0 & 44.7 & 41.4 \\
\hline \multicolumn{7}{|l|}{ Mental health concerns } \\
\hline Feeling depressed/worthless, or losing confidence/sleep & 17.5 & 25.2 & 17.0 & 27.9 & 17.7 & 20.9 \\
\hline Number of respondents & 998 & 1,133 & 449 & 565 & 549 & 568 \\
\hline
\end{tabular}

YM: Young Men; YW: Young Women; MYM: Married Young Men; MYW: Married Young Women; UYM: Unmarried Young Men; UYW: Unmarried Young Women.

Table 2.2 indicates that state-wise patterns differed between young men and women and between their experiences of the selected sexual and reproductive health problems and mental health concerns. Young men in Jharkhand were more likely to have experienced most of the selected sexual and reproductive health problems than were their counterparts in Rajasthan and Maharashtra. For example, 65 percent of young men in Jharkhand reported at least one sexual and reproductive health problem compared to 48-51 percent of their counterparts in Rajasthan and Maharashtra. However, no such consistent patterns were evident among young women. With regard to recent experiences of mental health concerns, while state-wise differences were not observed among young men, a larger proportion of young women in Jharkhand than in the other two states reported that they had experienced mental health concerns in the year preceding the interview (32\% versus $20-24 \%$ ).

Table 2.2: Percentage of adolescents and youth reporting recent experiences of selected sexual and reproductive health problems and mental health concerns by state of residence

\begin{tabular}{|c|c|c|c|c|c|c|}
\hline \multirow[t]{2}{*}{ Health problems/concerns experienced } & \multicolumn{2}{|c|}{ Jharkhand } & \multicolumn{2}{|c|}{ Maharashtra } & \multicolumn{2}{|c|}{ Rajasthan } \\
\hline & YM & YW & YM & YW & YM & YW \\
\hline \multicolumn{7}{|l|}{ Sexual and reproductive health problems } \\
\hline $\begin{array}{l}\text { Anxiety about nocturnal emission [males] } \\
\text { problems [females] }\end{array}$ & 41.1 & 22.1 & 32.0 & 34.0 & 38.2 & 13.8 \\
\hline $\begin{array}{l}\text { Problems in private parts (genital ulcers, it } \\
\text { the genital area or swelling in the groin) }\end{array}$ & 23.0 & 7.3 & 16.0 & 6.1 & 13.3 & 9.0 \\
\hline Burning sensation while passing urine & 27.1 & 16.3 & 17.0 & 6.6 & 17.3 & 23.4 \\
\hline Abnormal genital discharge & 6.0 & 17.4 & 1.8 & 13.7 & 6.1 & 26.5 \\
\hline At least one of the above problems & 65.0 & 42.8 & 47.8 & 44.2 & 51.0 & 43.3 \\
\hline \multicolumn{7}{|l|}{ Mental health concerns } \\
\hline $\begin{array}{l}\text { Feeling depressed/worthless/or losing cor } \\
\text { sleep }\end{array}$ & 16.6 & 31.9 & 18.2 & 19.8 & 17.7 & 24.1 \\
\hline Number of respondents & 362 & 374 & 288 & 394 & 348 & 365 \\
\hline
\end{tabular}

YM: Young Men; YW: Young Women. 


\section{Advice and/or treatment-seeking}

Adolescents and youth who reported sexual and reproductive health problems and mental health concerns in the year preceding the interview were probed about whether they had sought advice and/or treatment for the complaint and the source of such care. Table 2.3 presents these findings.

With regard to sexual and reproductive health problems, Table 2.3 shows that just 10 percent of young men who reported anxiety about nocturnal emission and 51 percent of young men who reported symptoms suggestive of genital infection had sought advice and/or treatment, respectively. Among young women, 65 percent of those who reported menstrual problems and 48 percent of those who reported symptoms suggestive of genital infection had sought treatment. Differences by marital status were evident with respect to seeking advice and/or treatment for such problems among young women but not among young men. For example, married young women were more likely than the unmarried to have sought treatment for menstrual problems ( $73 \%$ versus $56 \%$ ) and symptoms suggestive of genital infection (53\% versus 35\%); this finding perhaps reflects the greater social acceptability enjoyed by married than unmarried young women about seeking health services for sexual and reproductive health problems or the perceptions that health care providers discourage unmarried young women from seeking services or dismiss their problems as unimportant. With regard to mental health concerns, the findings presented in Table 2.3 show that just 31-33 percent of respondents who reported such concerns had sought advice and/or treatment. Differences by sex and marital status of the respondent were narrow.

Table 2.4 suggests that state-level differences in seeking advice and/or treatment were modest, except that more young men in Jharkhand than in Rajasthan and Maharashtra reported having sought advice for concerns about nocturnal emission (17\% versus 7-8\%) and more young women in Maharashtra than in the other two states had sought care for mental health concerns (41\% versus $27-28 \%$ ).

Table 2.3: Percentage of adolescents and youth who experienced selected sexual and reproductive health problems and mental health concerns by reported advice and/or treatment-seeking

\begin{tabular}{|c|c|c|c|c|c|c|}
\hline Advice and/or treatment-seeking & YM & YW & MYM & MYW & UYM & UYW \\
\hline $\begin{array}{l}\text { Sought advice for anxiety about nocturnal en } \\
\text { [males]/menstrual problems [females] }\end{array}$ & 10.4 & 64.7 & 9.6 & 72.7 & 10.6 & 56.2 \\
\hline $\begin{array}{l}\text { Number reporting anxiety about nocturnal } \\
\text { [males]/menstrual problems [females] }\end{array}$ & 346 & 272 & 120 & 117 & 226 & 155 \\
\hline $\begin{array}{l}\text { Sought treatment for symptoms suggestive c } \\
\text { infection }\end{array}$ & 50.5 & 48.0 & 52.9 & 52.9 & 49.6 & 35.4 \\
\hline $\begin{array}{l}\text { Number reporting symptoms suggestive of } \\
\text { infection }\end{array}$ & 351 & 330 & 169 & 200 & 182 & 130 \\
\hline $\begin{array}{l}\text { Sought advice and/or treatment for mental } \\
\text { concerns }\end{array}$ & 33.4 & 31.0 & 33.1 & 31.9 & 33.4 & 29.2 \\
\hline Number reporting mental health concerns & 171 & 282 & 75 & 158 & 96 & 124 \\
\hline
\end{tabular}

YM: Young Men; YW: Young Women; MYM: Married Young Men; MYW: Married Young Women; UYM: Unmarried Young Men; UYW: Unmarried Young Women. 
Table 2.4: Percentage of adolescents and youth who experienced selected sexual and reproductive health problems and mental health concerns by reported advice and/or treatment-seeking, according to state of residence

\begin{tabular}{|c|c|c|c|c|c|c|}
\hline \multirow[t]{2}{*}{ Advice and/or treatment-seeking } & \multicolumn{2}{|c|}{ Jharkhand } & \multicolumn{2}{|c|}{ Maharashtra } & \multicolumn{2}{|c|}{ Rajasthan } \\
\hline & YM & YW & YM & YW & YM & YW \\
\hline $\begin{array}{l}\text { Sought advice for anxiety about nocturnal emission [males]/ } \\
\text { menstrual problems [females] }\end{array}$ & 16.5 & 65.0 & 7.7 & 65.7 & 6.9 & 61.6 \\
\hline \multicolumn{7}{|l|}{ Number reporting anxiety about nocturnal emission } \\
\hline [males]/menstrual problems [females] & 135 & 85 & 84 & 134 & 127 & 53 \\
\hline Sought treatment for symptoms suggestive of genital infection & 49.2 & 50.6 & 46.7 & 47.0 & 56.1 & 46.7 \\
\hline Number reporting symptoms suggestive of genital infection & 163 & 117 & 84 & 81 & 104 & 132 \\
\hline Sought advice and/or treatment for mental health concerns & 35.8 & 27.6 & (34.3) & 41.4 & 30.3 & 27.0 \\
\hline Number reporting mental health concerns & 62 & 116 & 47 & 78 & 62 & 88 \\
\hline
\end{tabular}

YM: Young Men; YW: Young Women.

Note: ( ) Based on 25-49 unweighted cases.

Table 2.5 presents the percentage of surveyed adolescents and youth who had sought advice and/or treatment for selected sexual and reproductive health problems and mental health concerns according to the type of service provider they consulted and their marital status. Panel A of the table shows that young men and women, who had sought advice and/or treatment for such problems had mainly consulted MOs in government facilities or doctors in private facilities, respectively. Other individuals from whom the young people had sought advice and/or treatment included informal providers, and friends and family members. Specifically, the most frequently sought providers for sexual health problems differed between young men and women. Young men reported that they had largely consulted friends and family members about anxiety related to nocturnal emission and informal providers for symptoms suggestive of genital infection. In contrast, young women reported that they had mostly consulted doctors in private facilities for both menstrual problems and symptoms suggestive of genital infection. The findings further indicate that respondents who had sought advice and/or treatment for mental health concerns had consulted doctors in a private facility (41\% of young men and $43 \%$ of young women) or MOs in a government facility (39\% and $14 \%$, respectively) as well as informal providers (18\% and $11 \%$, respectively). Young women, in addition, reported that they had discussed their concerns with family members and friends (37\%); few young men (2\%) so reported. Hardly any young person who had experienced a problem reported seeking advice or treatment from frontline health workers, including ANMs and LHVs (no more than 5\%).

Table 2.5 also indicates modest differences by marital status in the type of provider from whom the respondents sought advice and/or treatment, with a few exceptions. Among young men (Panel B), the married were more likely than the unmarried to have sought services from MOs in government facilities for symptoms suggestive of genital infection (39\% versus $26 \%$ ), and less likely than the unmarried to have sought advice and/or treatment from doctors in private facilities for mental health concerns (30\% versus $45 \%$ ). Among young women (Panel C), the married were more likely than the unmarried to report that they had sought advice and/or treatment from private facilities for mental health concerns ( $57 \%$ versus $14 \%$ ) and menstrual problems (65\% versus $48 \%$ ), and from government facilities for symptoms suggestive of genital infection (26\% versus $10 \%$ ). In contrast, unmarried young women were more likely than the married to report that they had sought advice from friends and family members for mental health concerns (62\% versus $25 \%$ ), menstrual problems (22\% versus $8 \%$ ) and symptoms suggestive of genital infection (31\% versus 14\%).

State-wise data on advice and/or treatment-seeking by surveyed adolescents and youth according to the type of service provider consulted are presented in Table 2.6. The findings suggest that respondents in different settings sought advice and/or treatment from different sources, overall. For example, adolescents and youth in Rajasthan (Panel C) were, by and large, more likely than those in Jharkhand and Maharashtra (Panels A and B, respectively) to 
Table 2.5: Percentage of adolescents and youth who sought advice and/or treatment for selected sexual and reproductive health problems and mental health concerns by type of provider, according to marital status

\begin{tabular}{|c|c|c|c|c|c|c|c|c|c|c|c|c|}
\hline \multirow[t]{2}{*}{$\begin{array}{l}\text { Health problems/concerns } \\
\text { experienced }\end{array}$} & \multicolumn{2}{|c|}{ ASHA } & \multicolumn{2}{|c|}{ LHV/ANM } & \multicolumn{2}{|c|}{$\begin{array}{c}\text { Mo, } \\
\text { Government } \\
\text { facility }\end{array}$} & \multicolumn{2}{|c|}{$\begin{array}{c}\text { Mo, } \\
\text { Private } \\
\text { facility }\end{array}$} & \multicolumn{2}{|c|}{$\begin{array}{l}\text { Informal } \\
\text { providers }^{\text {a }}\end{array}$} & \multicolumn{2}{|c|}{$\begin{array}{c}\text { Friends/ } \\
\text { Family } \\
\text { members }^{b}\end{array}$} \\
\hline & \multicolumn{8}{|c|}{ A. Combined } & & & & \\
\hline $\begin{array}{l}\text { Anxiety about nocturnal } \\
\text { emission [males] / } \\
\text { menstrual problems } \\
\text { [females] }\end{array}$ & $(1.2)$ & YW & $(1.2)$ & YW & $(25.2)$ & 15.9 & $(25.0)$ & 58.0 & (19.9) & 15.7 & $(40.2)$ & $\mathbf{Y W}$ \\
\hline \multicolumn{13}{|l|}{ Number who sought } \\
\hline $\begin{array}{l}\text { Symptoms suggestive of } \\
\text { genital infection }\end{array}$ & 0.0 & 0.0 & 1.8 & 3.3 & 29.7 & 22.7 & 22.3 & 44.3 & 48.1 & 25.9 & 10.6 & 17.7 \\
\hline \multicolumn{12}{|l|}{ Number who sought } & 154 \\
\hline Mental health concerns & 0.8 & 0.0 & 0.0 & 0.7 & 39.1 & 14.4 & 41.1 & 43.3 & 17.5 & 10.9 & 1.6 & 36.5 \\
\hline $\begin{array}{l}\text { Number who sought } \\
\text { treatment }\end{array}$ & 57 & 88 & 57 & 88 & 57 & 88 & 57 & 88 & 57 & 88 & 57 & 88 \\
\hline \multicolumn{13}{|c|}{ B. Young men } \\
\hline $\begin{array}{l}\text { Anxiety about nocturnal } \\
\text { emission }\end{array}$ & MYM & UYM & MYM & UYM & MYM & UYM & $\begin{array}{r}\text { MYM } \\
\text { * }\end{array}$ & UYM & MYM & UYM & $\begin{array}{r}\text { MYM } \\
*\end{array}$ & $\begin{array}{r}\text { UYM } \\
\text { * }\end{array}$ \\
\hline $\begin{array}{l}\text { Number who sought } \\
\text { treatment }\end{array}$ & 12 & 24 & 12 & 24 & 12 & 24 & 12 & 24 & 12 & 24 & 12 & 24 \\
\hline $\begin{array}{l}\text { Symptoms suggestive of } \\
\text { genital infection }\end{array}$ & 0.0 & 0.0 & 1.5 & 2.0 & 39.3 & 25.6 & 22.6 & 22.1 & 43.7 & 49.9 & 8.2 & 11.5 \\
\hline $\begin{array}{l}\text { Number who sought } \\
\text { treatment }\end{array}$ & 87 & 91 & 87 & 91 & 87 & 91 & 87 & 91 & 87 & 91 & 87 & 91 \\
\hline Mental health concerns & (3.1) & $(0.0)$ & $(0.0)$ & $(0.0)$ & $(46.4)$ & $(36.7)$ & (29.9) & $(44.8)$ & $(14.5)$ & (18.5) & $(6.2)$ & $(0.0)$ \\
\hline $\begin{array}{l}\text { Number who sought } \\
\text { treatment }\end{array}$ & 25 & 32 & 25 & 32 & 25 & 32 & 25 & 32 & 25 & 32 & 25 & 32 \\
\hline \multicolumn{13}{|c|}{ C. Young women } \\
\hline & MYW & UYW & MYW & UYW & MYW & UYW & MYW & UYW & MYW & UYW & MYW & UYW \\
\hline Menstrual problems & 1.0 & 8.1 & 5.5 & 4.4 & 17.9 & 13.2 & 65.1 & 48.4 & 14.2 & 17.7 & 8.4 & 22.0 \\
\hline $\begin{array}{l}\text { Number who sought } \\
\text { treatment }\end{array}$ & 86 & 87 & 86 & 87 & 86 & 87 & 86 & 87 & 86 & 87 & 86 & 87 \\
\hline $\begin{array}{l}\text { Symptoms suggestive of } \\
\text { genital infection }\end{array}$ & 0.0 & $(0.0)$ & 3.7 & $(1.8)$ & 25.9 & $(10.0)$ & 45.1 & $(41.2)$ & 26.8 & $(22.4)$ & 14.4 & $(30.7)$ \\
\hline $\begin{array}{l}\text { Number who sought } \\
\text { treatment }\end{array}$ & 107 & 47 & 107 & 47 & 107 & 47 & 107 & 47 & 107 & 47 & 107 & 47 \\
\hline Mental health concerns & 0.0 & $(0.0)$ & 0.0 & $(2.3)$ & 15.1 & (12.6) & 56.5 & (13.5) & 8.5 & $(16.2)$ & 25.4 & $(61.7)$ \\
\hline $\begin{array}{l}\text { Number who sought } \\
\text { treatment }\end{array}$ & 52 & 36 & 52 & 36 & 52 & 36 & 52 & 36 & 52 & 36 & 52 & 36 \\
\hline
\end{tabular}

YM: Young Men; YW: Young Women; MYM: Married Young Men; MYW: Married Young Women; UYM: Unmarried Young Men; UYW: Unmarried Young Women.

Note: ( ) Based on 25-49 unweighted cases. *Percentage not shown, based on fewer than 25 unweighted cases. alncludes chemists, vaid/traditional healers and unregistered/rural medical practitioners; ${ }^{b}$ Includes family members, friends, neighbours. 
Table 2.6: Percentage of adolescents and youth who sought advice and/or treatment for selected sexual and reproductive health problems and mental health concerns by type of provider, according to state of residence

\begin{tabular}{|c|c|c|c|c|c|c|c|c|c|c|c|c|}
\hline \multirow[t]{2}{*}{$\begin{array}{l}\text { Health problems/concerns } \\
\text { experienced }\end{array}$} & \multicolumn{2}{|c|}{ ASHA } & \multicolumn{2}{|c|}{ LHV/ANM } & \multicolumn{2}{|c|}{$\begin{array}{c}\text { MO, } \\
\text { Government } \\
\text { facility }\end{array}$} & \multicolumn{2}{|c|}{$\begin{array}{c}\text { MO, } \\
\text { Private facility }\end{array}$} & \multicolumn{2}{|c|}{$\begin{array}{l}\text { Informal } \\
\text { providers }^{\text {a }}\end{array}$} & \multicolumn{2}{|c|}{$\begin{array}{c}\text { Friends/ } \\
\text { Family } \\
\text { members }^{\text {b }}\end{array}$} \\
\hline & YM & YW & YM & YW & YM & YW & YM & YW & YM & YW & YM & YW \\
\hline \multicolumn{13}{|c|}{ A. Jharkhand } \\
\hline $\begin{array}{l}\text { Anxiety about nocturnal } \\
\text { emission [males] / } \\
\text { menstrual problems } \\
\text { [females] }\end{array}$ & $*$ & 0.0 & * & 4.2 & * & 11.1 & * & 36.7 & * & 31.6 & * & 29.4 \\
\hline $\begin{array}{l}\text { Number who sought } \\
\text { treatment }\end{array}$ & 21 & 55 & 21 & 55 & 21 & 55 & 21 & 55 & 21 & 55 & 21 & 55 \\
\hline $\begin{array}{l}\text { Symptoms suggestive of } \\
\text { genital infection }\end{array}$ & 0.0 & 0.0 & 0.0 & 0.0 & 26.6 & 13.8 & 11.9 & 30.4 & 56.8 & 40.2 & 17.4 & 28.2 \\
\hline $\begin{array}{l}\text { Number who sought } \\
\text { treatment }\end{array}$ & 79 & 59 & 79 & 59 & 79 & 59 & 79 & 59 & 79 & 59 & 79 & 59 \\
\hline Mental health concerns & * & $(0.0)$ & * & 0.0 & * & 12.1 & * & 36.7 & * & 15.9 & * & 45.1 \\
\hline $\begin{array}{l}\text { Number who sought } \\
\text { treatment }\end{array}$ & 21 & 33 & 21 & 33 & 21 & 33 & 21 & 33 & 21 & 33 & 21 & 33 \\
\hline \multicolumn{13}{|c|}{ B. Maharashtra } \\
\hline $\begin{array}{l}\text { Anxiety about nocturnal } \\
\text { emission [males] / } \\
\text { menstrual problems } \\
\text { [females] }\end{array}$ & * & 7.9 & * & 5.7 & * & 11.4 & * & 73.9 & * & 4.5 & * & 4.5 \\
\hline $\begin{array}{l}\text { Number who sought } \\
\text { treatment }\end{array}$ & 6 & 88 & 6 & 88 & 6 & 88 & 6 & 88 & 6 & 88 & 6 & 88 \\
\hline $\begin{array}{l}\text { Symptoms suggestive of } \\
\text { genital infection }\end{array}$ & $(0.0)$ & $(0.0)$ & $(0.0)$ & $(5.3)$ & $(26.0)$ & $(13.2)$ & $(49.8)$ & $(73.7)$ & $(28.1)$ & $(7.9)$ & $(6.7)$ & $(5.3)$ \\
\hline $\begin{array}{l}\text { Number who sought } \\
\text { treatment }\end{array}$ & 40 & 38 & 40 & 38 & 40 & 38 & 40 & 38 & 40 & 38 & 40 & 38 \\
\hline Mental health concerns & * & 0.0 & * & 0.0 & * & $(28.1)$ & * & $(65.7)$ & * & $(9.3)$ & * & (3.1) \\
\hline $\begin{array}{l}\text { Number who sought } \\
\text { treatment }\end{array}$ & 17 & 32 & 17 & 32 & 17 & 32 & 17 & 32 & 17 & 32 & 17 & 32 \\
\hline
\end{tabular}




\begin{tabular}{|c|c|c|c|c|c|c|c|c|c|c|c|c|}
\hline \multirow[t]{2}{*}{$\begin{array}{l}\text { Health problems/concerns } \\
\text { experienced }\end{array}$} & \multicolumn{2}{|c|}{ ASHA } & \multicolumn{2}{|c|}{ LHV/ANM } & \multicolumn{2}{|c|}{$\begin{array}{c}\text { MO, } \\
\text { Government } \\
\text { facility }\end{array}$} & \multicolumn{2}{|c|}{$\begin{array}{c}\text { MO, } \\
\text { Private facility }\end{array}$} & \multicolumn{2}{|c|}{$\begin{array}{c}\text { Informal } \\
\text { providers }^{a}\end{array}$} & \multicolumn{2}{|c|}{$\begin{array}{c}\text { Friends/ } \\
\text { Family } \\
\text { members }\end{array}$} \\
\hline & YM & YW & YM & YW & YM & YW & YM & YW & YM & YW & YM & YW \\
\hline \multicolumn{13}{|c|}{ C. Rajasthan } \\
\hline $\begin{array}{l}\text { Anxiety about nocturnal } \\
\text { emission [males] / } \\
\text { menstrual problems } \\
\text { [females] }\end{array}$ & * & $(0.0)$ & $*$ & $(4.6)$ & * & (35.4) & * & $(50.3)$ & * & (19.8) & * & $(15.2)$ \\
\hline $\begin{array}{l}\text { Number who sought } \\
\text { treatment }\end{array}$ & 9 & 30 & 9 & 30 & 9 & 30 & 9 & 30 & 9 & 30 & 9 & 30 \\
\hline $\begin{array}{l}\text { Symptoms suggestive of } \\
\text { genital infection }\end{array}$ & 0.0 & 0.0 & 5.5 & 5.0 & 36.3 & 34.9 & 12.3 & 40.7 & 54.0 & 23.4 & 5.6 & 15.5 \\
\hline $\begin{array}{l}\text { Number who sought } \\
\text { treatment }\end{array}$ & 59 & 57 & 59 & 57 & 59 & 57 & 59 & 57 & 59 & 57 & 59 & 57 \\
\hline Mental health concerns & * & * & * & * & * & * & * & * & * & * & * & * \\
\hline $\begin{array}{l}\text { Number who sought } \\
\text { treatment }\end{array}$ & 19 & 23 & 19 & 23 & 19 & 23 & 19 & 23 & 19 & 23 & 19 & 23 \\
\hline
\end{tabular}

YM: Young Men; YW: Young Women.

Note: ( ) Based on 25-49 unweighted cases. *Percentage not shown, based on fewer than 25 unweighted cases. ${ }^{a}$ Includes chemists, vaid/traditional healers and unregistered/rural medical practitioners; ${ }^{b}$ Includes family members, friends, neighbours.

report that they had sought advice and/or treatment from MOs in government facilities, regardless of the nature of health problems or concerns experienced. In contrast, adolescents and youth in Maharashtra (Panel B) were more likely than those in the other two states (Panels $\mathrm{A}$ and $\mathrm{C}$ ) to report that they had sought the services of doctors in private facilities, irrespective of the health problem or concern. Finally, young people in Jharkhand (Panel A) were more likely than those in the other two states (Panels B and C) to have relied on informal providers.

\section{Reasons for not seeking advice and/or treatment for the health problems and concerns experienced}

Adolescents and youth who did not seek advice and/or treatment for their sexual and reproductive health problems and mental health concerns were probed about the reasons for not doing so. The findings, summarised in Table 2.7, Panels A, B and C, suggest that the major reason for lack of care-seeking was the perception that the health problem/concern was not serious enough to seek advice and/or treatment, a reason mentioned by $82-90$ percent of young men and 64-88 percent of young women, regardless of the nature of the health problem/concern experienced. Embarrassment in seeking treatment was additionally cited as a reason for not seeking advice and/ or treatment. Lack of money, lack of family support and concerns about poor quality of care were mentioned by few respondents. Gender differences in reasons for not seeking advice and/or treatment were narrow for most health problems/concerns. Even so, young women were somewhat more likely than young men to report economic constraints, and less likely to report that the problem was not serious. They were also more likely to report embarrassment as a reason for not seeking treatment for symptoms suggestive of genital infection (Panel B), while young men were somewhat more likely to give this reason for not seeking care for anxiety about nocturnal emission and mental health concerns (Panels $A$ and $C$, respectively).

Differences in reasons for not seeking advice and/or treatment by marital status did not show a consistent pattern among young men and young women (Table 2.7). Married young men were more likely than the unmarried to report perceptions that their anxiety about nocturnal emission and symptoms suggestive of genital infection were not serious enough to seek advice and/or treatment (Panels A and B, respectively) but less likely to do so in case of their mental health concerns (Panel C); they were also less likely to report embarrassment as a reason for not seeking treatment for symptoms suggestive of genital infection (Panel B). Among young women, the married were more likely 
Table 2.7: Percentage of adolescents and youth who did not seek advice and/or treatment for selected sexual and reproductive health problems and mental health concerns by reasons for not seeking care, according to sex and marital status

\begin{tabular}{|c|c|c|c|c|c|c|}
\hline Reasons for not seeking advice and/or treatment & YM & YW & MYM & MYW & UYM & UYW \\
\hline \multicolumn{7}{|c|}{ A. Anxiety about nocturnal emission [males] /menstrual problems [females] } \\
\hline Did not consider it serious & 82.3 & 75.1 & 76.6 & 82.8 & $(71.4)$ & 77.6 \\
\hline Did not have money & 1.6 & 7.6 & 4.3 & 0.9 & $(13.2)$ & 3.9 \\
\hline Lack of family or social support & 0.0 & 1.3 & 0.0 & 3.3 & $(0.0)$ & 0.0 \\
\hline Lack of facility/poor quality service & 0.0 & 1.1 & 0.0 & 2.7 & $(0.0)$ & 0.0 \\
\hline Felt shy/embarrassed & 37.3 & 22.9 & 30.7 & 38.9 & $(15.4)$ & 27.8 \\
\hline Other & 1.6 & 2.1 & 4.0 & 1.1 & $(0.0)$ & 3.4 \\
\hline Number who did not seek treatment & 310 & 99 & 108 & 202 & 31 & 68 \\
\hline \multicolumn{7}{|c|}{ B. Symptoms suggestive of genital infection } \\
\hline Did not consider it serious & 85.9 & 63.9 & 91.9 & 65.1 & 83.8 & 61.2 \\
\hline Did not have money & 3.4 & 8.5 & 4.0 & 11.8 & 3.2 & 1.1 \\
\hline Lack of family or social support & 0.2 & 3.4 & 0.9 & 3.5 & 0.0 & 3.1 \\
\hline Lack of facility/poor quality service & 1.1 & 0.0 & 1.7 & 0.0 & 0.8 & 0.0 \\
\hline Felt shy/embarrassed & 23.3 & 36.9 & 12.4 & 32.2 & 27.2 & 47.5 \\
\hline Other & - & - & - & - & - & - \\
\hline Number who did not seek treatment & 206 & 202 & 97 & 114 & 109 & 88 \\
\hline \multicolumn{7}{|c|}{ C. Mental health concerns } \\
\hline Did not consider it serious & 90.4 & 87.6 & 86.1 & 84.6 & 91.8 & 93.6 \\
\hline Did not have money & 6.3 & 11.6 & 4.6 & 15.3 & 6.8 & 4.3 \\
\hline Lack of family or social support & 0.7 & 1.6 & 2.6 & 2.8 & 0.0 & 0.0 \\
\hline Lack of facility/poor quality service & 0.0 & 0.0 & 0.0 & 0.0 & 00 & 0.0 \\
\hline Felt shy embarrassed & 8.6 & 3.6 & 9.5 & 3.8 & 8.3 & 3.1 \\
\hline Other & 0.0 & 0.9 & 0.0 & 0.8 & 0.0 & 1.1 \\
\hline Number who did not seek treatment & 114 & 194 & 50 & 106 & 64 & 88 \\
\hline
\end{tabular}

YM: Young Men; YW: Young Women; MYM: Married Young Men; MYW: Married Young Women; UYM: Unmarried Young Men; UYW: Unmarried Young Women.

Note: ( ) Based on 25-49 unweighted cases.

than the unmarried to report economic constraints for their lack of care-seeking for symptoms suggestive of genital infection and mental health concerns (Panels B and C, respectively). They were also less likely than their unmarried counterparts to report embarrassment for not seeking treatment for symptoms suggestive of genital infection.

State-wise data on reasons given by surveyed adolescents and youth who had not sought advice or treatment for their health complaint are presented in Table 2.8. Findings show that young women in Jharkhand and Rajasthan were somewhat more likely than those in Maharashtra to report economic constraints for not seeking treatment for the selected health complaints indicated in Panels A, B and C. In contrast, young men in Maharashtra, for the most part, were more likely than their counterparts in Jharkhand and Rajasthan to report embarrassment as a constraint for seeking services.

\section{Interactions with ANMs and community-level health workers}

The study also explored the interactions of the surveyed adolescents and youth with ANMs and community-level workers such as ASHAs and AWWs in the year preceding the interview. The findings, presented in Table 2.9, show 
Table 2.8: Percentage of adolescents and youth who did not seek advice and/or treatment for selected sexual and reproductive health problems and mental health concerns by reasons for not seeking care, according to state of residence

\begin{tabular}{|c|c|c|c|c|c|c|}
\hline \multirow{2}{*}{$\begin{array}{l}\text { Reasons for not seeking advice and/or } \\
\text { treatment }\end{array}$} & \multicolumn{2}{|c|}{ Jharkhand } & \multicolumn{2}{|c|}{ Maharashtra } & \multicolumn{2}{|c|}{ Rajasthan } \\
\hline & YM & YW & YM & YW & YM & $\mathbf{Y W}$ \\
\hline \multicolumn{7}{|c|}{ A. Anxiety about nocturnal emission [males] /menstrual problems [females] } \\
\hline Did not consider it serious & 87.4 & $(74.1)$ & 91.7 & $(95.6)$ & 69.8 & * \\
\hline Did not have money & 1.6 & $(16.4)$ & 0.0 & $(2.2)$ & 2.8 & * \\
\hline Lack of family or social support & 0.0 & $(4.3)$ & 0.0 & $(0.0)$ & 0.0 & * \\
\hline Lack of facility/poor quality service & 0.0 & $(0.0)$ & 0.0 & $(2.2)$ & 0.0 & * \\
\hline Felt shy/embarrassed & 22.4 & $(12.1)$ & 48.0 & (10.9) & 41.2 & * \\
\hline Others & 1.6 & $(0.0)$ & 2.0 & $(4.3)$ & 1.3 & * \\
\hline Number who did not seek treatment & 114 & 30 & 78 & 46 & 118 & 23 \\
\hline \multicolumn{7}{|c|}{ B. Symptoms suggestive of genital infection } \\
\hline Did not consider it serious & 90.0 & 63.0 & 86.2 & (84.1) & 79.1 & 55.9 \\
\hline Did not have money & 1.6 & 9.5 & 0.0 & $(2.3)$ & 10.5 & 10.4 \\
\hline Lack of family or social support & 0.5 & 3.7 & 0.0 & $(2.3)$ & 0.0 & 3.6 \\
\hline Lack of facility/poor quality service & 2.5 & 0.0 & 0.0 & $(0.0)$ & 0.0 & 0.0 \\
\hline Felt shy/embarrassed & 16.8 & 35.3 & 35.6 & $(25.0)$ & 22.4 & 43.2 \\
\hline Others & - & - & - & - & - & - \\
\hline Number who did not seek treatment & 102 & 70 & 51 & 44 & 53 & 88 \\
\hline \multicolumn{7}{|c|}{ C. Mental health concerns } \\
\hline Did not consider it serious & $(87.0)$ & 85.0 & $(100.0)$ & $(93.5)$ & $(83.4)$ & 87.0 \\
\hline Did not have money & $(11.7)$ & 14.1 & $(0.0)$ & $(6.5)$ & $(8.4)$ & 11.9 \\
\hline Lack of family or social support & $(0.0)$ & 4.3 & $(0.0)$ & $(0.0)$ & $(1.8)$ & 0.0 \\
\hline Lack of facility/poor quality service & $(0.0)$ & 0.0 & $(0.0)$ & $(0.0)$ & $(0.0)$ & 0.0 \\
\hline Felt shy/embarrassed & $(1.4)$ & 3.7 & $(11.6)$ & $(2.2)$ & $(11.2)$ & 4.3 \\
\hline Others & $(0.0)$ & 0.9 & $(0.0)$ & $(2.2)$ & $(0.0)$ & 0.0 \\
\hline Number who did not seek treatment & 41 & 83 & 30 & 46 & 43 & 65 \\
\hline
\end{tabular}

YM: Young Men; YW: Young Women.

Note: ( ) Based on 25-49 unweighted cases. *Percentage not shown, based on fewer than 25 unweighted cases.

gender differences and differences by marital status in these interactions. Young women were more likely than young men to report interaction with ANMs (36\% versus 9\% among 15-19 year-olds and 52\% versus 11\% among $20-24$ year-olds), and the married were more likely than the unmarried to report so ( $14 \%$ versus $8 \%$ among young men; $57 \%$ versus $20 \%$ among young women). Among young men, additionally, differences by educational attainment were evident; interaction with ANMs increased with years of schooling completed, from two percent among those with no schooling to 13 percent among those who had 12 or more years of schooling. Besides, among young women, differences by age, educational status, caste and economic status were notable. Specifically, those aged 15-19 were less likely than those aged 20-24 to report interactions with ANMs (36\% versus 52\%). Unlike in the case of young men, interaction with ANMs decreased with years of schooling completed among young women, from $56 \%$ among those with no schooling to 30 percent among those who had completed 12 or more years of schooling. Further, caste-wise data show that young women belonging to scheduled castes and tribes were more likely than those belonging to general castes to report interactions with ANMs ( $47-48 \%$ and $33 \%$, respectively). Finally, interaction with ANMs decreased with household wealth among young women, from 51 percent among those in the poorest quintile to 22 percent among those in the richest quintile. State-wise differences were modest. 
Table 2.9: Percentage of adolescents and youth reporting interaction with ANMs in the year preceding the interview by selected background characteristics

\begin{tabular}{|c|c|c|c|c|}
\hline Background characteristics & YM & $\mathbf{N}$ & YW & $\mathbf{N}$ \\
\hline \multicolumn{5}{|l|}{ Age (years) } \\
\hline $15-19$ & 8.8 & 454 & 35.7 & 703 \\
\hline $20-24$ & 10.8 & 544 & 52.0 & 430 \\
\hline \multicolumn{5}{|l|}{ Marital status } \\
\hline Unmarried & 8.4 & 549 & 19.7 & 568 \\
\hline Married & 13.6 & 448 & 57.1 & 564 \\
\hline \multicolumn{5}{|l|}{ Religion } \\
\hline Hindu & 9.6 & 937 & 42.9 & 1049 \\
\hline Muslim & 12.6 & 45 & 40.2 & 48 \\
\hline Other $^{1}$ & 11.4 & 16 & 34.3 & 36 \\
\hline \multicolumn{5}{|l|}{ Caste } \\
\hline $\mathrm{SC}$ & 12.4 & 282 & 47.4 & 263 \\
\hline ST & 11.0 & 170 & 48.2 & 185 \\
\hline $\mathrm{OBC}$ & 7.8 & 461 & 40.2 & 558 \\
\hline General $^{2}$ & 10.4 & 85 & 32.8 & 127 \\
\hline \multicolumn{5}{|l|}{ Educational level (years) } \\
\hline None $^{3}$ & 1.9 & 41 & 56.1 & 126 \\
\hline $1-7$ & 8.6 & 281 & 52.0 & 240 \\
\hline $8-11$ & 9.2 & 399 & 38.7 & 449 \\
\hline 12 and above & 13.1 & 277 & 29.6 & 318 \\
\hline \multicolumn{5}{|l|}{ Wealth quintile } \\
\hline First & 8.0 & 231 & 50.9 & 252 \\
\hline Second & 9.9 & 241 & 47.4 & 247 \\
\hline Third & 9.9 & 193 & 48.3 & 187 \\
\hline Fourth & 10.7 & 183 & 40.3 & 231 \\
\hline Fifth & 10.2 & 150 & 22.2 & 216 \\
\hline \multicolumn{5}{|l|}{ State of residence } \\
\hline Jharkhand & 7.7 & 362 & 40.7 & 374 \\
\hline Maharashtra & 11.4 & 288 & 39.9 & 394 \\
\hline Rajasthan & 9.9 & 348 & 46.7 & 365 \\
\hline Total & 9.8 & 998 & 42.5 & 1,133 \\
\hline
\end{tabular}

YM: Young Men; YW: Young Women; N: Number.

Note: OBC: Other Backward Caste. SC: Scheduled Caste. ST: Scheduled Tribe. ${ }^{1}$ Includes Christian, Buddhist, Jain, Sikh and no specified religion. ${ }^{2}$ Includes all those not belonging to SC, ST or OBC. ${ }^{3}$ Includes non-literate and literate respondents with no formal schooling. 
Young men and young women who reported that they had interacted with ANMs in the last one year were further asked about the place where they had met the ANM, the number of times they had met her, the topics that were discussed and the quality of interaction. The findings are summarised in Table 2.10. Among those who reported that they had interacted with an ANM, most had done so only at the Anganwadi Centre (AWC) or the health facility (82\% each of young men and young women); some 10 percent of young men and four percent of young women reported that such meetings had occurred only during home visits, and eight percent and 14 percent of young men and young women, respectively, reported both the health facility and their home as the meeting place. Marital status differences were negligible.

The frequency of interaction with ANMs was higher among young women than among young men; 57 percent of young women compared to 23 percent of young men reported three or more interactions (Table 2.10). While there was no difference in the frequency of interaction between married and unmarried young men, among young women, the married were more likely than the unmarried to report three or more interactions (64\% versus $25 \%$ ).

Table 2.10: Percentage of adolescents and youth who interacted with ANMs by the nature of their interaction, according to sex and marital status

\begin{tabular}{|c|c|c|c|c|c|c|}
\hline Nature of interaction & YM & YW & MYM & MYW & UYM & UYW \\
\hline \multicolumn{7}{|l|}{ Place of interaction with ANMs } \\
\hline Respondent's home only & 10.0 & 3.8 & 8.1 & 2.3 & (11.1) & 11.1 \\
\hline Anganwadi Centre/health facility & 82.2 & 81.8 & 89.7 & 82.5 & $(77.8)$ & 78.1 \\
\hline $\begin{array}{l}\text { Both at respondent's home and anganwadi centre/ } \\
\text { health facility }\end{array}$ & 7.8 & 14.4 & 2.2 & 15.2 & (11.1) & 10.8 \\
\hline \multicolumn{7}{|l|}{ Number of times interacted with ANMs } \\
\hline $1-2$ times & 77.5 & 42.6 & 74.2 & 35.8 & $(79.4)$ & 75.4 \\
\hline 3 or more times & 22.5 & 57.4 & 25.8 & 64.2 & $(20.6)$ & 24.6 \\
\hline \multicolumn{7}{|l|}{ Topics discussed } \\
\hline General hygiene & 6.3 & 2.2 & 2.7 & 1.2 & $(8.3)$ & 6.7 \\
\hline Menstrual hygiene/problems & NA & 7.5 & NA & 3.1 & NA & 29.4 \\
\hline Family planning & 0.8 & 6.6 & 2.2 & 7.7 & $(0.0)$ & 0.9 \\
\hline Pregnancy-related care & 19.3 & 48.9 & 47.9 & 57.0 & NA & 9.3 \\
\hline Newborn-related care & 9.5 & 44.8 & 23.0 & 53.7 & NA & 1.2 \\
\hline RTIS/STIS/HIV & 1.3 & 1.9 & 3.6 & 2.2 & $(0.0)$ & 0.8 \\
\hline Sexual matters & 0.0 & 1.1 & 0.0 & 0.0 & $(0.0)$ & 6.3 \\
\hline Common illnesses & 68.9 & 31.0 & 32.3 & 22.9 & $(90.3)$ & 70.8 \\
\hline Nutrition & 0.0 & 2.2 & 0.0 & 1.9 & $(0.0)$ & 4.1 \\
\hline Other (TB, appendicitis etc) & 0.0 & 0.4 & 0.0 & 0.3 & $(0.0)$ & 0.9 \\
\hline \multicolumn{7}{|l|}{ Quality of interaction } \\
\hline ANMs paid attention to the respondent & 88.5 & 96.4 & 91.2 & 96.5 & (86.9) & 95.7 \\
\hline $\begin{array}{l}\text { Respondent was not worried that ANMs will reveal } \\
\text { the content of their interaction to others }\end{array}$ & 90.1 & 96.3 & 94.3 & 96.9 & $(87.6)$ & 93.7 \\
\hline ANMs did not shout at or make fun of the respondent & 89.0 & 96.6 & 92.9 & 96.3 & $(86.8)$ & 98.3 \\
\hline Number of respondents ${ }^{1}$ & 101 & 419 & 59 & 319 & 42 & 100 \\
\hline
\end{tabular}

YM: Young Men; YW: Young Women; MYM: Married Young Men; MYW: Married Young Women; UYM: Unmarried Young Men; UYW: Unmarried Young Women.

Note: ( ) Based on 25-49 unweighted cases. NA: Not asked. ${ }^{1}$ Excludes 16 unweighted cases for which information was missing. 
Table 2.10 further indicates that the topics that young people discussed with ANMs varied by sex. Young men most frequently discussed common illnesses (69\%), followed by pregnancy-related care (19\%) and newborn related care (10\%). Young women also mentioned the same topics, but the percentages discussing the topics differed-31 percent, 49 percent and 45 percent, respectively. Such topics as general hygiene, menstrual hygiene or menstrual problems, family planning, RTIS/STIS/HIV and sexual matters were discussed by fewer than 10 percent of young men and young women, overall. Differences by marital status could not be discerned among young men (few unmarried young men reported interactions with ANMs); but among young women, the unmarried were far more likely than the married to report having discussed such issues as common illnesses (71\% vs. $23 \%$ ) and menstrual hygiene or menstrual problems (29\% versus 3\%); in contrast, the married were far more likely than the unmarried to have discussed pregnancy and newborn-related care ( $57 \%$ versus $9 \%$ and $54 \%$ versus $1 \%$, respectively).

Table 2.10 also shows that the assessment made by the adolescent and youth participants about the quality of their interactions with ANMs was generally positive. For example, 89-90 percent of young men and 96-97 percent of young women reported that ANMs paid attention to them, that they were not worried that the ANMs would reveal the content of their interactions to others and that the ANMs did not shout at or make fun of them.

State-wise data on the nature of interactions between the young people and ANMs are described in Table 2.11. Given the small number of respondents, particularly young men who reported an interaction with ANMs in the year preceding the interview in each of the states, we describe the findings pertaining only to young women's interactions

Table 2.11: Percentage of young women who interacted with ANMs by the nature of their interaction, according to state of residence

\begin{tabular}{|c|c|c|c|}
\hline Nature of interaction & Jharkhand & Maharashtra & Rajasthan \\
\hline \multicolumn{4}{|l|}{ Place of interaction with ANMs } \\
\hline Respondent's home only & 1.8 & 9.9 & 0.3 \\
\hline Anganwadi Centre/health facility & 93.3 & 60.3 & 90.2 \\
\hline Both at respondent's home and anganwadi centre/health facility & 4.9 & 29.8 & 9.5 \\
\hline \multicolumn{4}{|l|}{ Number of times interacted with ANMs } \\
\hline $1-2$ times & 45.2 & 47.6 & 36.1 \\
\hline 3 or more times & 54.8 & 52.4 & 63.9 \\
\hline \multicolumn{4}{|l|}{ Topics discussed } \\
\hline General hygiene & 1.0 & 6.0 & 0.0 \\
\hline Menstrual hygiene/problems & 6.4 & 14.5 & 2.6 \\
\hline Family planning & 10.4 & 8.6 & 1.7 \\
\hline Pregnancy-related care & 39.6 & 41.8 & 62.5 \\
\hline Newborn-related care & 54.5 & 29.2 & 49.7 \\
\hline RTIs/STIs/HIV & 1.6 & 0.0 & 3.8 \\
\hline Sexual matters & 1.5 & 0.7 & 1.0 \\
\hline Common illnesses & 24.1 & 37.7 & 31.2 \\
\hline Nutrition & 3.8 & 2.0 & 1.2 \\
\hline Other (TB, appendicitis) & 1.3 & 0.0 & 0.0 \\
\hline \multicolumn{4}{|l|}{ Quality of interaction } \\
\hline ANMs paid attention to the respondent & 97.4 & 96.0 & 95.8 \\
\hline $\begin{array}{l}\text { Respondent was not worried that ANMs will reveal the content of } \\
\text { their interaction to others }\end{array}$ & 94.4 & 98.0 & 96.6 \\
\hline ANMs did not shout at or make fun of the respondent & 95.3 & 97.3 & 97.1 \\
\hline Number of respondents & 132 & 151 & 136 \\
\hline
\end{tabular}


with ANMs in this section. Findings show that young women in Maharashtra were more likely than those in Jharkhand and Rajasthan to report that they had met the ANMs during home visits (40\% versus $7-10 \%$ ), and young women in Rajasthan were more likely than those in the other two states to report three or more interactions with ANMs (64\% versus $52-55 \%)$. The topics of interaction were, by and large, similar across the three states, with a few notable differences. For example, young women in Maharashtra were more likely than their counterparts in the other two states to report that the ANMs had discussed menstrual hygiene (15\% versus 3-6\%) and common illnesses (38\% versus $24-31 \%$ ) with them. Young women in Maharashtra and Jharkhand were more likely than those in Rajasthan to report family planning as their topic of discussion with ANMs (9-10\% versus $2 \%$ ) but less likely to have discussed pregnancy-related care (40-42\% versus 63\%). Also, young women in Jharkhand and Rajasthan were more likely than those in Maharashtra to mention newborn care as a topic of interaction (50-55\% versus 29\%). With regard to quality, over 90 percent of the respondents in all three states reported satisfaction with their interactions with ANMs.

Findings related to the interactions of the surveyed adolescents and youth with community health workers (CHWs) such as ASHAs and AWWs in the one year preceding the interview are presented in Table 2.12. As with their interactions with ANMs, young men were less likely than young women to have interacted with $\mathrm{CHWs}(7 \%$ versus 38\%). Differences by marital status show that married respondents were more likely than the unmarried to report such interactions (13\% versus $5 \%$ among young men; $48 \%$ versus $22 \%$ among young women). Other socio-demographic differences were negligible among young men. Among young women, however, differences by educational attainment, religion, caste and household wealth index were also notable. Less educated young women were more likely than others to have interacted with CHWs: 41-44 percent of young women with no schooling or 1-7 years of schooling compared to 28 percent of those with 12 or more years of schooling reported such interactions. Religion-wise differences show that young Hindu and Muslim women were less likely than those belonging to other religions to report interactions with $\mathrm{CHWs} \mathrm{(35-37 \%} \mathrm{versus} \mathrm{50 \% ).} \mathrm{Likewise,} \mathrm{young} \mathrm{women} \mathrm{belonging} \mathrm{to} \mathrm{other}$ backward castes and general castes were less likely than those belonging to scheduled castes and tribes to so report (33-36\% versus 43-46\%). Finally, young women belonging to the richest quintile were less likely than others to report such interactions (26\% versus 39-42\%). State-wise differences show that young women in Jharkhand were least likely and those in Maharashtra were most likely to report interactions with CHWs (29\% and 50\%, respectively).

Respondents who reported that they had interacted with CHWs were further asked about the place where they had met the CHW, the number of times they had met her, the topics that were discussed and the quality of interaction. The findings, summarised in Table 2.13, indicate that young men were more likely than young women to report that they had met the CHW only at the AWC or health facility (61\% and $48 \%$ ) or only during home visits ( $26 \%$ and $12 \%$ ). In contrast, considerably more young women than young men reported that they had met the CHW both at the AWC/health facility and during home visits (40\% versus $14 \%$ ). Differences by marital status were evident. Far more married than unmarried young women reported interaction both in the home and in the AWC /health facility (46\% versus $22 \%$ ).

As in the case of ANMs, young women were more likely than young men to report frequent interaction with CHWs; 67 percent of young women compared to 28 percent of young men reported three or more interactions. While married young men were slightly more likely than their unmarried counterparts to report frequent interaction (32\% versus $26 \%$ ), married young women were far more likely than unmarried young women to so report (72\% versus $50 \%$ ).

Table 2.13 further shows that the topics of discussion with CHWs that were most frequently cited by young men were newborn-related care (58\%) followed by common illnesses (42\%), pregnancy-related care (28\%) and general hygiene (10\%). The most frequently discussed topics listed by young women were newborn-related care (84\%), followed by pregnancy-related care (46\%), common illnesses (23\%), nutrition (13\%) and menstrual hygiene/ problems (10\%). Marital status differences were evident. Among young men, for example, topics discussed with the married focused on pregnancy and newborn care (55\% and $86 \%$, respectively), topics not probed for unmarried young men. In contrast, far more unmarried than married young men reported discussing common illnesses (71\% versus $6 \%$ ) and general hygiene (16\% versus $3 \%$ ). Among young women, while the leading topic of discussion with CHWs for both the married and the unmarried was newborn care $(90 \%$ and $67 \%$, respectively), the married were far more likely than the unmarried to have discussed pregnancy-related care (54\% versus $20 \%$ ), while the unmarried were far more likely to have discussed common illnesses (51\% versus $14 \%)$, menstrual problems/ hygiene (34\% versus $2 \%$ ), and general hygiene (10\% versus $1 \%)$. Notably, discussions on family planning were reported by just nine percent of married young women. 
Table 2.12: Percentage of adolescents and youth reporting interactions with Community Health Workers by selected background characteristics

\begin{tabular}{|c|c|c|c|c|}
\hline Background characteristics & YM & $\mathbf{N}$ & YW & $\mathbf{N}$ \\
\hline \multicolumn{5}{|l|}{ Age (years) } \\
\hline $15-19$ & 4.4 & 454 & 31.2 & 703 \\
\hline $20-24$ & 10.9 & 544 & 46.7 & 430 \\
\hline \multicolumn{5}{|l|}{ Marital status } \\
\hline Unmarried & 5.4 & 549 & 22.3 & 568 \\
\hline Married & 13.0 & 448 & 47.5 & 564 \\
\hline \multicolumn{5}{|l|}{ Religion } \\
\hline Hindu & 7.1 & 937 & 37.4 & 1,049 \\
\hline Muslim & 12.9 & 45 & 35.0 & 48 \\
\hline Others ${ }^{1}$ & 11.6 & 16 & 50.0 & 36 \\
\hline \multicolumn{5}{|l|}{ Caste } \\
\hline SC & 9.8 & 282 & 42.7 & 263 \\
\hline ST & 6.2 & 170 & 46.1 & 185 \\
\hline OBC & 6.9 & 461 & 32.6 & 558 \\
\hline General $^{2}$ & 5.7 & 85 & 35.8 & 127 \\
\hline \multicolumn{5}{|l|}{ Educational level (years) } \\
\hline None $^{3}$ & 5.7 & 41 & 40.9 & 126 \\
\hline $1-7$ & 8.2 & 281 & 43.8 & 240 \\
\hline $8-11$ & 6.4 & 399 & 37.4 & 449 \\
\hline 12 and above & 9.0 & 277 & 28.2 & 318 \\
\hline \multicolumn{5}{|l|}{ Wealth quintile } \\
\hline First & 10.0 & 231 & 40.6 & 252 \\
\hline Second & 7.2 & 241 & 39.0 & 247 \\
\hline Third & 5.1 & 193 & 41.9 & 187 \\
\hline Fourth & 7.6 & 183 & 39.7 & 231 \\
\hline Fifth & 7.0 & 150 & 25.7 & 216 \\
\hline \multicolumn{5}{|l|}{ State of residence } \\
\hline Jharkhand & 11.2 & 362 & 28.8 & 374 \\
\hline Maharashtra & 7.7 & 288 & 49.5 & 394 \\
\hline Rajasthan & 3.6 & 348 & 34.2 & 365 \\
\hline Total & 7.4 & 998 & 37.7 & 1,133 \\
\hline
\end{tabular}

YM: Young Men; YW: Young Women; N: Number.

Note: OBC: Other Backward Caste. SC: Scheduled Caste. ST: Scheduled Tribe. ${ }^{1}$ Includes Christian, Buddhist, Jain, Sikh and no specified religion. ${ }^{2}$ Includes all those not belonging to SC, ST or OBC. ${ }^{3}$ Includes non-literate and literate respondents with no formal schooling. 
Table 2.13: Percentage of adolescents and youth who interacted with Community Health Workers by the nature of their interaction

\begin{tabular}{|c|c|c|c|c|c|c|}
\hline Nature of interaction & YM & YW & MYM & MYW & UYM & UYW \\
\hline \multicolumn{7}{|c|}{ Place of interaction with community health workers (CHWs) } \\
\hline Respondent's home only & 25.5 & 12.2 & 17.2 & 11.8 & $(32.5)$ & 13.4 \\
\hline Anganwadi Centre/health facility & 60.6 & 47.5 & 70.4 & 42.3 & $(52.3)$ & 64.8 \\
\hline $\begin{array}{l}\text { Both at respondent's home and anganwadi centre/he } \\
\text { facility }\end{array}$ & 13.9 & 40.3 & 12.4 & 45.9 & $(15.2)$ & 21.8 \\
\hline \multicolumn{7}{|l|}{ Number of times interacted with CHWs } \\
\hline $1-2$ times & 71.6 & 33.3 & 68.3 & 28.3 & $(74.4)$ & 49.8 \\
\hline 3 or more times & 28.4 & 66.7 & 31.7 & 71.7 & $(25.6)$ & 50.2 \\
\hline \multicolumn{7}{|l|}{ Topics discussed } \\
\hline General hygiene & 10.2 & 3.0 & 2.9 & 0.9 & $(16.3)$ & 10.2 \\
\hline Menstrual hygiene/problems & NA & 9.6 & NA & 2.2 & NA & 34.0 \\
\hline Family planning & 5.6 & 7.3 & 3.7 & 9.2 & (7.1) & 0.7 \\
\hline Pregnancy-related care & 27.7 & 46.0 & 55.1 & 53.9 & NA & 19.7 \\
\hline Newborn-related care & 58.0 & 84.2 & 86.0 & 89.5 & NA & 66.6 \\
\hline RTIS/STIS/HIV & 0.6 & 0.3 & 1.3 & 0.0 & $(0.0)$ & 1.5 \\
\hline Sexual matters & 3.2 & 0.7 & 3.6 & 0.3 & $(2.9)$ & 2.1 \\
\hline Common illnesses & 41.6 & 22.5 & 6.4 & 14.0 & $(71.4)$ & 50.5 \\
\hline Nutrition & 0.0 & 13.3 & 0.0 & 14.0 & $(0.0)$ & 10.8 \\
\hline Other (government schemes, education of children) & 4.5 & 0.7 & 6.3 & 0.0 & (3.1) & 3.0 \\
\hline \multicolumn{7}{|l|}{ Quality of interaction } \\
\hline $\mathrm{CHWs}$ paid attention to the respondent & 94.2 & 98.5 & 96.0 & 91.1 & $(92.6)$ & 96.4 \\
\hline $\begin{array}{l}\text { Respondent was not worried that CHWs will reveal the } \\
\text { of their interaction to others }\end{array}$ & 91.4 & 97.9 & 91.4 & 98.4 & $(89.5)$ & 96.3 \\
\hline $\mathrm{CHWs}$ did not shout at or make fun of the respondent & 95.7 & 98.6 & 94.7 & 98.4 & $(96.7)$ & 99.3 \\
\hline Number of respondents & 93 & 390 & 65 & 276 & 28 & 114 \\
\hline
\end{tabular}

YM: Young Men; YW: Young Women; MYM: Married Young Men; MYW: Married Young Women; UYM: Unmarried Young Men; UYW: Unmarried Young Women.

Note: ( ) Based on 25-49 unweighted cases. NA: Not asked.

The assessment of the young men and women about the quality of their interactions with CHWs was generally positive (Table 2.13). For example, 91-96 percent of young men and 98-99 percent of young women reported that the $\mathrm{CHWs}$ paid attention to them, that they were not worried that the CHWs would reveal the content of their interactions to others and that the CHWs did not shout at or make fun of them. Marital status differences were, moreover, modest.

Table 2.14 presents findings on the interactions of the surveyed adolescents and youth with CHWs by state of residence. Given the small number of young men who reported such interactions, we describe the nature of only young women's interactions with CHWs. The patterns described earlier for the combined sample in terms of the place of interaction were observed across all three states, with large proportions reporting that they had interacted only in the AWC or health facility (41-53\%) or in both the home and the AWC or health facility (33-47\%). With regard to the frequency of interaction, young women in Rajasthan were most likely and those in Maharashtra were least likely to report three or more interactions ( $76 \%$ and $59 \%$, respectively). Across all three states, the most frequently 
Table 2.14: Percentage of young women who interacted with Community Health Workers by the nature of their interaction, according to state of residence

\begin{tabular}{|c|c|c|c|}
\hline Nature of interaction & $\begin{array}{l}\text { Jharkhand } \\
\text { Yw }\end{array}$ & $\begin{array}{l}\text { Maharashtra } \\
\text { Yw }\end{array}$ & $\begin{array}{l}\text { Rajasthan } \\
\text { Yw }\end{array}$ \\
\hline \multicolumn{4}{|l|}{ Place of interaction with community health workers (CHWs) } \\
\hline Respondent's home only & 7.9 & 14.4 & 12.3 \\
\hline AWC/health facility & 46.2 & 52.8 & 40.9 \\
\hline Both at respondent's home and anganwadi centre/health facility & 45.9 & 32.8 & 46.8 \\
\hline \multicolumn{4}{|l|}{ Number of times interacted with $\mathrm{CHWs}$} \\
\hline 1-2 times & 31.0 & 41.0 & 23.8 \\
\hline 3 or more times & 69.0 & 59.0 & 76.2 \\
\hline \multicolumn{4}{|l|}{ Topics discussed } \\
\hline General hygiene & 0.7 & 5.1 & 1.9 \\
\hline Menstrual hygiene/problems & 6.5 & 13.3 & 6.6 \\
\hline Family planning & 14.5 & 6.7 & 2.3 \\
\hline Pregnancy-related care & 46.6 & 34.9 & 61.7 \\
\hline Newborn-related care & 88.4 & 80.0 & 87.0 \\
\hline RTIS/STIS/HIV & 1.4 & 0.0 & 0.0 \\
\hline Sexual matters & 1.4 & 0.5 & 0.5 \\
\hline Common illnesses & 17.6 & 34.8 & 8.3 \\
\hline Nutrition & 12.2 & 7.2 & 22.9 \\
\hline Other (government schemes, education of children) & 0.0 & 1.5 & 0.0 \\
\hline \multicolumn{4}{|l|}{ Quality of interaction } \\
\hline CHWs paid attention to the respondent & 99.3 & 97.9 & 98.6 \\
\hline $\begin{array}{l}\text { Respondent was not worried that CHWs will reveal the content of } \\
\text { their interaction to others }\end{array}$ & 98.2 & 96.4 & 100.0 \\
\hline CHWs did not shout at or make fun of the respondent & 97.0 & 98.5 & 100.0 \\
\hline Number of respondents & 93 & 195 & 102 \\
\hline
\end{tabular}

YW: Young Women.

mentioned topic of discussion with CHWs was newborn-related care (80-88\%). Other topics, discussed with onefifth or more young women, varied by state: pregnancy-related care in Jharkhand (47\%), pregnancy-related care and nutrition in Rajasthan (62\% and 23\%, respectively), and pregnancy-related care and common illnesses in Maharashtra (35\% each). Notably again, the CHWs discussed family planning with relatively few young women, ranging from two percent in Rajasthan to seven percent in Maharashtra and 15 percent in Jharkhand. Almost all young women gave a positive assessment of their interactions with $\mathrm{CHWs}$ in all three states.

\section{Summary}

Although adolescence and young adulthood represent a generally healthy period of life, sexual and reproductive health concerns, ranging from worries about nocturnal emission among adolescent boys or menstruation among adolescent girls to symptoms suggestive of genital infection, and mental health concerns including feeling depressed or worthless, or losing sleep or confidence, affected notable proportions of adolescents and youth in the study settings. Indeed, over one-half of young men and over two-fifths of young women reported having experienced at least one sexual and reproductive health problem and/or mental health concern in the year preceding the interview, 
and the married were more likely than the unmarried to so report. Similarly, about one-fifth of young men and a quarter of young women reported feeling depressed or worthless or losing sleep or confidence in the year preceding the interview.

Seeking care for sexual and reproductive health problems and mental health concerns remains limited among adolescents and youth in these settings. Although care-seeking varied by the type of health problem and mental health concern, no more than one-half of young men and no more than two-thirds of young women who experienced a sexual and reproductive health problem had sought advice and/or treatment and even fewer-one-third-had done so for mental health concerns. The major reason for not seeking advice and/or treatment was the perception that the health issue was not serious enough to do so, followed by embarrassment in seeking treatment, lack of money, lack of family support and concerns about poor quality of care.

Adolescents and youth who sought treatment and/or advice for health concerns largely consulted doctors in government or private facilities. State-wise data suggest that young people in different settings sought advice and/ or treatment from different sources, overall. Adolescents and youth in Rajasthan were, by and large, more likely than those in Jharkhand and Maharashtra to report that they consulted doctors (Medical Officers) in government facilities, regardless of the nature of the health problem experienced. In contrast, adolescents and youth in Maharashtra were more likely than those in the other two states to report that they sought the services of doctors in private facilities, irrespective of the health problem for which they sought care, while those in Jharkhand were more likely than those in the other two states to have relied on informal providers.

The interaction of adolescents and youth with frontline health care providers such as ANMs as well as those based at the community level, such as ASHAs and AWWs, remain limited. Notably, such interactions were more limited among young men than young women, and among the unmarried than the married. While a little over two-fifths of young women had interacted with an ANM in the one year preceding the interview, just one in ten young men had done so. Likewise, while slightly less than two-fifths of young women had interacted with ASHAs/AWWs, just seven percent of young men had done so. Findings also suggest that young women from scheduled castes and tribes interacted with health workers in the public system more than those belonging to other castes, and that better educated young women, and those from wealthier households interacted with health workers in the public system less often than other young women. Findings, moreover, suggest that the most commonly discussed topics were newborn care followed by common illnesses, and pregnancy-related care (more commonly discussed with young women than young men). Discussion on changes during adolescence (except menstruation among girls and nocturnal emission among boys) and relationships or issues related to mental health that have been expressed as important concerns by young people are missing. 


\section{Chapter 3}

\section{Awareness about and experiences at Adolescent Friendly Health Clinics}

In this chapter, we present findings on the perspectives of adolescents and youth about AFHCs and their experiences of accessing services at these clinics. The findings draw on data from the community-based survey of adolescents and youth as well as from exit interviews with AFHC clients and mystery client visits conducted at the AFHCs.

\section{Awareness of AFHCs}

Participants in the community-based survey were probed about whether they had heard about AFHCs. In probing their awareness, the research investigators were instructed to use the local term, if any, to describe the AFHC and to describe it in detail while posing this question, for example, "a clinic at the PHC/CHC/DH (District Hospital) where adolescents and youth are provided services separately" and so on.

Table 3.1 gives the percentage of young people who were aware of and had sought services from AFHCs by selected characteristics. The findings show that their awareness of AFHCs was rather dismal; just five percent of young men and eight percent of young women in the study villages were aware of AFHCs, even though their villages were located within 5-10 kilometres from the AFHCs. Differences by marital status were modest. Awareness of AFHCs in the individual states ranged from 1-2 percent in Rajasthan to 4-7 percent in Jharkhand and 7-16 percent in Maharashtra.

Table 3.1: Percentage of adolescents and youth who were aware of and had sought services from AFHCs by selected characteristics

\begin{tabular}{lcccc}
\hline Characteristics & \multicolumn{2}{c}{ Heard about AFHCs } & \multicolumn{2}{c}{ Sought services from AFHCs } \\
\cline { 2 - 5 } & $\begin{array}{c}\text { YM } \\
(\mathbf{N = 9 9 8 )}\end{array}$ & $\begin{array}{c}\text { YW } \\
(\mathbf{N}=\mathbf{1 , 1 3 3 )}\end{array}$ & $\begin{array}{c}\text { YM } \\
(\mathbf{N}=\mathbf{9 9 8})\end{array}$ & $\begin{array}{c}\text { YW } \\
(\mathbf{N}=\mathbf{1 , 1 3 3 )}\end{array}$ \\
\hline Overall & $\mathbf{4 . 5}$ & $\mathbf{7 . 8}$ & $\mathbf{0 . 0}$ & $\mathbf{0 . 8}$ \\
Marital status & & & & \\
Unmarried & 5.3 & 10.6 & 0.0 & 0.6 \\
Married & 2.4 & 6.0 & 0.2 & 0.9 \\
State of residence & & & & \\
Jharkhand & & & 0.1 & 0.7 \\
Maharashtra & 4.3 & 6.7 & 0.0 & 1.5 \\
Rajasthan & 7.3 & 15.5 & 0.0 & 0.0 \\
\hline
\end{tabular}

YM: Young Men; YW: Young Women.

\section{Experiences at the AFHCs}

Table 3.1 also indicates that less than one percent of young men and young women who participated in the community-based survey had ever sought services from the AFHCs. In the subsections below, we describe their experiences, drawing on case studies from 15 young persons who had visited these clinics for services (ten identified through the community-based survey and five identified through the exit interviews at the AFHCs) and 24 mystery client visits. Given that only a small number of young people had sought services from the AFHCs, we present insights for the combined sample and not separately for the three states. 


\section{Observations of AFHC clients}

Of the 15 young clients who sought services from the AFHCs, eight were from Jharkhand and seven were from Maharashtra. Most of them were female-13 females and two males. Among young women clients, the majority were married (eight compared to five unmarried clients). The clients were equally divided between the two age groups-15-19 year-olds and 20-24 year-olds. For most clients (nine of the 13), the AFHC was located in their own or a nearby village, while the remaining six clients reported that it was located far from their village.

The health services sought by the AFHC clients included common illnesses and sexual and reproductive health problems. Eight clients reported that they had visited the AFHC for treatment of common illnesses, while ten reported doing so for sexual and reproductive health problems. ${ }^{1}$ The latter included those seeking services for menstrual problems (six clients), pregnancy-related care (two clients), and anxiety about nocturnal emission, contraceptive supplies and an HIV test (one client each).

Most of the AFHC clients had consulted a MO, and also a nurse or a Counsellor (13 clients) while the remaining two had met only a nurse. While six of them had met the service provider without any delay or within ten minutes of reaching the AFHC, nine others had waited for 15-30 minutes to one hour for a consultation. Further, two-fifths of the young clients were referred to the AFHC (10 clients); just five had come on their own.

The assessment made by the AFHC clients about their interaction with health care providers was generally positive. For example, all but one client reported that the health care provider had paid attention to them when they described their problem; none was worried that the provider would tell others about the health problem for which she/he had sought services; and all but two clients reported that the provider did not shout at them or make fun of them. Of the 13 clients who consulted a MO, almost all (12 clients) reported that the MO had treated them very well; only one reported that he had been treated "somewhat well". Most clients also said that other AFHC staff had treated them well (six of the ten clients who met other staff).

Despite these positive assessments, concerns about privacy, time spent in consultation and information received from the health care providers had come up in the experiences described by the AFHC clients. For example, seven of the 15 clients reported that they felt that their conversation with the MO or other staff could have been overheard by others. Similarly, four of the nine clients who underwent a physical examination felt that others could have seen them being examined by the MO. The time that the MO spent in consultation with the young clients ranged from as little as one minute to ten minutes per client, and the time that other staff, including the Staff Nurse, ANM or the Counsellor, spent with the client ranged from five minutes to as much as one hour. While most clients reported that the MO or other staff had explained the prescription given or advised them about the precautions to be followed, the narratives of the five exit interview clients who were interviewed at the AFHCs suggest that the information provided was not comprehensive and was, at times, moralistic. The following excerpts (information on state of residence not provided so as to ensure anonymity of these five clients) illustrate this:

The doctor spent five minutes in consultation which I felt was too short; I also met the counsellor who spent 60 minutes with me which I felt was too long. I wasn't very comfortable with either the doctor or the counsellor. Both told me that my menstrual problem is not something to be worried about. [Exit interview, married girl, aged 18, seeking treatment for a menstrual problem]

The doctor did not explain anything to me, but the nurse did. She told me that I have a menstrual problem because I got married at a young age. She told me that I should use contraceptives. [Exit interview, married girl, aged 17, seeking treatment for a menstrual problem and a common illness]

The doctor did not tell me anything, but the counsellor advised me. He told me that I should pay attention to my studies, play and eat good food on time. He said that I should not look at vulgar things. [Exit interview, unmarried boy, aged 18, seeking advice for anxiety about nocturnal emission]

With regard to payments, supplies and infrastructure at the AFHC, the perceptions of the young clients were, by and large, positive. The majority-13 of the 15 clients-reported that they had not made any payments at the AFHC; two clients said that they had paid a registration fee but had not paid for services. One-half of the clients reported that they had received all the prescribed medicines from the AFHC (eight clients), three reported that they had received

\footnotetext{
${ }^{1}$ We note that the number of clients adds up to more than 15 because of multiple responses.
} 
some of the prescriptions and only one said that $\mathrm{s} /$ he had not received any of the prescribed medicines (the remaining three were not prescribed any medicines). None of the exit interview clients who were interviewed at the AFHC reported receiving any informational materials (those who were interviewed in the community were not asked this question). All the clients had found the facility to be clean: 10 clients reported that it was very clean and five, that it was "somewhat clean".

Despite the mixed assessment given by the AFHC clients, all of them said that they would recommend the AFHC to their friends and would visit it again if the need arose.

\section{Observations of mystery clients}

A total of 24 mystery client visits were made to better understand facility-based interactions between young people and the MOs and ANMs. Mystery clients were given four scenarios to act out-an unmarried young woman, aged 17, who felt pressured by her boyfriend to engage in pre-marital sex and was seeking oral contraceptives; a married young woman, aged 20, who was concerned about her husband's extra-marital relationship and perpetration of marital violence, and was seeking information on how she could protect herself; an unmarried young man, aged 19, who was in a relationship with a girl and was seeking condoms; and a married young man, aged 22, who had had sex with sex workers, and wanted to undergo an HIV test.

We note that of the 24 visits made by the mystery clients, in 14 cases, the mystery client had received the service at the AFHC itself (six in Jharkhand and eight in Maharashtra); in the remaining 10 visits the service had been provided in the general OPD of the facility (two in Jharkhand and eight in Rajasthan). Even among those who had obtained services from the AFHC, in six visits, clients (all from Jharkhand) had to visit the general OPD first and then the AFHC.

Of the ten visits in which the mystery clients received the service in the general OPD, in two instances, the clients, both from Jharkhand, reported that the designated AFHC was closed on the day of their visit and they had been attended to by the physician in the general OPD. In the remaining eight visits, the mystery clients, all from Rajasthan, reported that there was no designated facility or fixed timings for providing services specifically to adolescents and youth in the $\mathrm{CHC}$ that they visited, although these $\mathrm{CHCs}$ were shown as housing AFHCs in the records of the state health department, and provided services for adolescents and youth in the general OPD.

\section{Experiences related to registration at the AFHC}

In all 24 visits, the mystery clients had to go through some formality before they met the health care provider. These formalities comprised free registration in eight and paid registration in 16 instances. In addition, in two visits, mystery clients were made to explain the reason for their visit to other clinic staff. Differences in registration formalities did not vary by the sex or the scripted marital status of the mystery client but differed by state of residence. While all the mystery clients in Jharkhand reported that registration was free at the AFHC they visited, all those in Rajasthan and Maharashtra reported that they had paid a registration fee. The mystery clients' experience at the registration desk was captured by a single question regarding whether the staff at the registration desk had greeted them cordially; findings show that in three-fourths of all visits (18 of 24), the mystery clients were greeted in a friendly way. Again, differences by state were evident-while clients were greeted cordially in 15 of 16 visits in Jharkhand and Rajasthan, only in one-half ( 4 of 8 ) of their visits were clients in Maharashtra so greeted.

\section{Type of health care provider consulted at the AFHC and waiting time for consultation}

In three-fifths of all visits made by the mystery clients, it was the MO of the AFHC who was consulted (14 of 24 visits). In seven instances, however, the mystery clients were not seen by a MO, but rather, by a nurse, an ANM, a laboratory technician or other staff, and in three others, the mystery client met both the MO and other staff members. The type of provider consulted by the mystery clients did not differ by the sex of the client, the scenario they enacted or their state of residence. While in four-fifths of the visits made by male clients, a male health care provider was consulted (10 of 12 visits), in only about one-half of all visits made by female clients was a female provider consulted (five of 12 visits). Almost all the mystery clients in Jharkhand and Rajasthan reported that they had consulted a male health care provider during their visits (six and seven, respectively, out of eight visits), while in Maharashtra, the clients were about as likely to consult a male as a female provider in the course of their visits. 
In two-thirds of all visits, the mystery clients had consulted the health care provider without any delay or within ten minutes of reaching the facility (16 of 24 visits), while in four instances, the client had to wait for anywhere between 15-30 and 45-60 minutes to do so. Differences in waiting time to consult the health care provider did not differ by the sex or the scripted marital status of the client. However, state-wise differences were evident-fewer mystery clients in Jharkhand (three of the eight visits made) than in the other two states reported that they had consulted the provider without any delay or within 10 minutes of reaching the facility compared to five of the eight visits made by mystery clients in Rajasthan and all of the eight visits made by those in Maharashtra.

\section{Services provided to mystery clients}

Table 3.2 indicates that the services provided to the mystery clients varied. Although all the scenarios warranted the provision of information about contraceptive methods and condoms, information about different contraceptive methods was provided in fewer than two-thirds of all client visits (six by male clients and nine by female clients). Even fewer were provided contraceptives: in just two-fifths of all visits were clients supplied a contraceptive (six by male and four by female clients). The narratives of the mystery clients suggest that in most cases, health care providers who did not provide contraceptives did not offer any explanation for doing so; in the few instances where they did offer some explanation, they attributed it to stock-outs, absence of staff who handled contraceptive supplies and preference to give the method (condoms) to males. In 15 visits, moreover, the clients were advised to undergo STI/ HIV tests (10 by male clients and five by female clients). Further, two male mystery clients reported that they were referred to a higher facility while a female client was advised to bring her husband to the facility as shown by the following narratives:

The doctor told me about different contraceptive methods and gave me condoms. He enquired whether I had experienced any burning sensation while passing urine, and said that it did not look like I had AIDS, but I should undergo an HIV test. He also told me that in the initial stage, AIDS can be cured and he would give me some medicine if the test turned out to be positive. He referred me to Sadar Hospital for an HIV test. He told me that condoms can prevent pregnancy; that I should always use condoms during sex and that sex with sex workers is not safe. [Mystery client enacting a married young man, aged 22, who had had sex with sex workers and wanted to undergo an HIV test; AFHC A, Jharkhand]

The doctor told me about condoms, IUDs and emergency pills and advised me to undergo STI/HIV tests. He also gave me condoms and advised me to talk to my husband. [Mystery client enacting a married young woman, aged 20, seeking advice on protective actions to be taken against her husband's extra-marital relationship and marital violence; OPD providing adolescent health services, Rajasthan]

He (The doctor) told me: 'Don't be upset; everything will be fine. Go for an HIV test; we will see what to do later.' He referred me to the Community Health Centre for HIV testing. [Mystery client enacting a married young man, aged 22, who had had sex with sex workers and wanted to undergo an HIV test; OPD providing adolescent health services, Rajasthan]

Table 3.2: Services provided to mystery clients visiting AFHCs

\begin{tabular}{lcc}
\hline Responses of clients & YM & YW \\
\hline Gave information about different contraceptive methods & 6 & 9 \\
Advised to undergo STI/HIV tests & 10 & 5 \\
Supplied contraceptives & 6 & 4 \\
Referred to a higher facility & - & - \\
Advised the female client to bring her husband to the facility & 3 & 1 \\
Did not supply contraceptives & - & 4 \\
Gave some brochure, but did not explain anything & 7 & 9 \\
Other responses & 7 \\
\hline
\end{tabular}

YM: Young Men; YW: Young Women. 
At the same time, negative feedback was received from a few mystery clients. For example, in some visits, clients reported that they were not given any contraceptives (visits made by three male clients and four female clients), and that they were given a brochure but the provider did not explain anything to them (visits made by two female clients).

\section{Quality of services received}

A number of questions were asked to assess whether the service provided at the AFHC was appropriate to the needs of adolescents and youth, particularly their need for privacy and confidentiality. Specifically, the mystery clients were probed about: (1) the availability of the service for which they had visited the AFHC; (2) the extent to which the delivery of services adhered to the right of youth to privacy, and confidential and non-judgemental services; and (3) the nature of client-provider interpersonal relations.

The responses of the mystery clients present a mixed picture of the quality of services they received at the AFHCs.

The mystery clients reported that in spite of meeting a health care provider during all their visits to the AFHC, in one-quarter of these visits, they had not received the service for which they had visited the AFHC. An equal number of male and female mystery clients so reported. Differences by the scenario for which the client had visited the AFHC were narrow. State-wise differences show that while just one mystery client each in Jharkhand and Rajasthan reported a visit in which the required service was not provided by the AFHC, mystery clients in Maharashtra reported so for one-half of all their visits to the AFHC. Mystery clients who did not receive the service for which they visited the AFHC offered the following reasons:

The doctor advised me to use condoms but he told me that he wouldn't be able to give them to me that day because the store was locked and the designated staff member was on leave. He told me to get an HIV test done and then he would give me the condoms. [Mystery client enacting an unmarried young man, aged 19, in relationship with a girl and seeking condoms; AFHC C, Jharkhand]

It (the clinic) was too crowded; the doctor was very busy and he asked me to come back after $2 \mathrm{pm}$. [Mystery client enacting a married young woman, aged 20 , seeking advice about protective actions to be taken against her husband's extra-marital relationship and marital violence; AFHC D, Jharkhand]

There were several people and the doctor wasn't really attending to the patients. [Mystery client enacting a married young woman, aged 20 , seeking advice about protective actions to be taken against her husband's extra-marital relationship and marital violence; AFHC A, Maharashtra]

The doctor was busy; he just told me about the HIV test. [Mystery client enacting an unmarried young woman, aged 17, pressured by her boyfriend for pre-marital sex and seeking oral contraceptives; AFHC B, Maharashtra]

The doctor did not give me the information that I sought. [Mystery client enacting a married young man, aged 22, who had had sex with sex workers and wanted to undergo an HIV test; AFHC B, Maharashtra]

In order to assess the extent to which the delivery of services offered at the AFHC adhered to the right of young people to privacy, and confidential and non-judgemental services, the mystery clients were probed about: (1) whether other clients were present during the consultation; (2) whether their conversation with the health care provider could have been overheard by others; (3) whether the health care provider had insisted on parental or spousal consent; and (4) whether there were circumstances that could make youth uncomfortable. In one-quarter of all visits, clients reported that other clients were present during their consultation with the provider (seven of the 24 visits; two by male and five by female clients). These clients represented all three states-one from Jharkhand, two from Rajasthan and four from Maharashtra. Likewise, in one-quarter of all visits, clients, mostly from Maharashtra (four visits), reported that others could have overheard their interaction with the provider (six of the 24 visits-two by males and four by females). In all but two mystery client visits-one each by a married and unmarried young woman-the provider did not ask for parental or spousal consent for providing the service.

When probed specifically about whether there were any circumstances in the AFHC that could make young people uncomfortable, the mystery clients answered in the affirmative for about one-half of the visits they had made (11 of the 24 clients-five male and six female clients). These visits represented all the three states and the scenario the mystery clients enacted incorporated all the four scenarios designed for mystery client visits. The circumstances that 
the mystery clients perceived would make young people uncomfortable included the lack of privacy, lack of female health care providers and the discomfort of the health care provider, as the narratives below suggest:

There was only male staff there (at the AFHC). I felt shy to describe my personal problem; other things were fine. [Mystery client enacting an unmarried young woman, aged 17, pressured by her boyfriend for pre-marital sex and seeking oral contraceptives; AHFC A, Jharkhand]

There was no privacy; I felt shy to narrate my problem in front of others. The doctor was surrounded by male and female patients; it was very difficult to describe my problem. [Mystery client enacting a married young woman, aged 20, seeking advice about protective actions to be taken against her husband's extra-marital relationship and marital violence; AFHC D, Jharkhand]

There was no privacy. The doctor wasn't comfortable explaining things to me. I also hesitated to narrate my problem. [Mystery client enacting a married young woman, aged 20, seeking advice about protective actions to be taken against her husband's extra-marital relationship and marital violence; AFHC C, Rajasthan]

There was no privacy; there was no separate room for the AFHC. [Mystery client enacting a married young man, aged 22, who had had sex with sex workers and wanted to undergo an HIV test; OPD providing adolescent health services, Rajasthan]

The AFHC was held in the OPD itself; there was no privacy and no informational materials were provided. [Mystery client enacting an unmarried girl, aged 17, pressured by her boyfriend for pre-marital sex and seeking oral contraceptives; OPD providing adolescent health services, Rajasthan]

The doctor asked (me about my problem) in front of others; therefore, I felt very uncomfortable. [Mystery client enacting an unmarried girl, aged 17, pressured by her boyfriend for pre-marital sex and seeking oral contraceptives; AFHC B, Maharashtra]

There was no separate room for the AFHC. [Mystery client enacting a married young man, aged 22, who had had sex with sex workers and wanted to undergo an HIV test; AFHC C, Maharashtra]

In order to assess the nature of client-provider interpersonal relations, the mystery clients were probed about: (1) whether the provider had greeted them when they entered the consultation room; (2) how much time the provider had spent with them; (3) whether the $\mathrm{MO}$ and other staff had behaved in a friendly and respectful manner and offered information and services in a non-judgmental way; (4) whether the provider had paid attention when they narrated their problem; (5) whether the provider had responded to any questions that they asked apart from narrating their problem; (6) whether the provider had given them information about any precautions to be taken, including how the contraceptive method should be used; and (7) whether they had been reassured about visiting the facility again if needed.

Almost all mystery clients, regardless of their sex, the scenario enacted and their state of residence, reported that the health care provider had greeted them cordially when they entered the consultation room (21 of the 24 visits). The time that the provider had spent in consultation ranged from less than 10 minutes (two visits made by male clients and three by female clients) to 10-15 minutes (seven visits made by male clients and five by female clients) to 20-45 minutes (three visits made by male clients and four by female clients). The consultation time did not differ by the sex or scripted marital status of the client. More mystery clients in Maharashtra than in the other two states reported that the provider had given them less than 10 minutes of consultation time (three visits versus one each in Jharkhand and Rajasthan).

In many visits (nine of the 17 in which the client had met a MO), the providers who supplied information and contraceptives were reported as being unfriendly and judgmental at times. This was particularly evident in the case of scenarios relating to unmarried clients (six of the nine visits). These incidents were reported from all three states. As the narratives below show, some providers advised young clients that sex before marriage is wrong; others insisted that they would supply condoms to a female client only if she brought her husband along with her. The following narratives illustrate this:

The doctor advised me to ask my husband to see her. She told me to use condoms to avoid infection but did not give me any condoms; she told me that she would give me condoms if I brought my husband along with me. She gave me some medicines to use in case of infection. She also told me that if I do not want any 35 more children, I could use an IUD, but I should come with my husband. [Mystery client enacting a married 
young woman, aged 20, seeking information about protective actions to be taken against her husband's extra-marital relationship and marital violence; AFHC B, Jharkhand]

The doctor told me that I should not engage in sex before marriage... He told me that he cannot insert an IUD for me as I am unmarried; that I could use an injection that can prevent pregnancy for three months; or I could use condoms or the OCP (oral contraceptive pill). He advised me to take a packet of condoms for my boyfriend. [Mystery client enacting an unmarried girl, aged 17, pressured by her boyfriend for pre-marital sex and seeking oral contraceptives; AFHC C, Jharkhand]

He (The doctor) told me that it is wrong to engage in sex before marriage. He said that I could take the emergency contraceptive pill (ECP) after sex, but it is dangerous, that is, it can cause more bleeding and difficulty in conceiving (in future). He said that he cannot give me oral pills because of their side effects, and it is better that my boyfriend uses condoms because my life will be ruined if my partner refuses to marry me (if I become pregnant). He said that the condom is good (safe) to use and not the OCP. [Mystery client enacting an unmarried young woman, aged 17, pressured by her boyfriend for pre-marital sex and seeking oral contraceptives; OPD providing adolescent health services, Rajasthan]

He (The doctor) said to me: 'This (pre-marital sex) is not a good thing; you get married or have relations with just one girl. You should always use a condom; you should not have sex with sex workers.' [Mystery client enacting an unmarried young man, aged 19, in relationship with a girl and seeking condoms; OPD providing adolescent health services, Rajasthan]

She (The doctor) gave me a brochure but did not explain anything. She told me that if my husband beats me again, I should leave him and get married again or report him to the police. She also told me about male condoms but later told me to use female condoms and prescribed a blood test. She also advised me to come again after 2-3 days as female condoms were not available at that time but that she would get me some after 2-3 days. [Mystery client enacting a married young woman, aged 20, seeking advice on protective actions to be taken against her husband's extra-marital relationship and marital violence; OPD providing adolescent health services, Rajasthan]

The doctor advised me to undergo STI/HIV tests. He did not give me any condoms. He told me that engaging in sex with sex workers is wrong and that the police can register a case against me for doing so. He told me that I should stop doing it. [Mystery client enacting an unmarried young man, aged 19, in relationship with a girl and seeking condoms; OPD providing adolescent health services, Rajasthan]

The doctor explained various contraceptive methods and gave me some brochures, but did not explain anything. In fact, the doctor made me feel silly. [Mystery client enacting a married young woman, aged 20, seeking advice on seeking advice on protective actions to be taken against her husband's extra-marital relationship and marital violence; AFHC A, Maharashtra]

The doctor told me about different contraceptive methods and gave me condoms. He advised me not to engage in sex with sex workers and to always use condoms. He also told me that I should not do such things (visit sex workers) at this (young) age. [Mystery client enacting an unmarried young man, aged 19, in relationship with a girl and seeking condoms; AFHC B, Jharkhand]

With regard to the behaviour of AFHC staff other than the MO, out of 10 visits, clients in four visits reported that the other staff had treated them well; clients in the remaining six visits, however, said that they had not been well treated by the other staff. Mystery clients who were dissatisfied with the treatment that they received from AHFC staff other than the MO were mostly from Jharkhand and Maharashtra (three each); the following excerpts describe their experiences:

He (The lab technician who attended to the client) did not give me condoms but told me that engaging in sex with extra-marital partners is wrong. He told me to pay Rs. 1,000 for an HIV test and other blood tests. [Mystery client enacting a married young man, aged 22, who had had sex with sex workers and wanted to undergo an HIV test; AFHC D, Jharkhand]

The ANM advised me about different contraceptive methods and gave me a strip of oral pills. She also told me to come with my boyfriend so that she could advise him that sex before marriage is wrong. [Mystery 
client enacting an unmarried girl, aged 17, pressured by her boyfriend for pre-marital sex and seeking oral contraceptives; AFHC A, Jharkhand]

In two-thirds of the visits made by mystery clients (17 of the 24 visits), they reported that the health care provider had paid full attention when they were narrating their problem while clients in the remaining seven visits said that they had received "some attention" when they were describing their problem. Differences by sex of the client, the scenario enacted and state of residence were modest.

Findings further show that in one-half of the visits, the mystery clients (12 of the 24 visits) did ask questions about how to use the specific contraceptive method prescribed and its side effects, infection symptoms, side effects of prescribed medicines, the cost of the HIV test and facilities where the HIV test can be obtained. Except in one instance, all clients reported that the provider had answered their questions.

In two-thirds of all visits (15 of the 24 visits), clients also said that the health care provider had informed them about the precautions to be taken and how the contraceptive method should be used. All of them reported that the provider had explained this to them in a way that they easily understood. However, the narratives are mixed and suggest that some providers appeared to have given comprehensive contraceptive information while others appeared to be reluctant to impart such information to young people. For example:

The doctor enquired about my periods and advised me to take one tablet daily at night as shown on the cover of the packet. The doctor told me to have lunch on time. The doctor also told me that I may visit again after the pills are over. [Mystery client enacting an unmarried girl, aged 17, pressured by her boyfriend for pre-marital sex and seeking oral contraceptives; AFHC A, Jharkhand]

$\mathrm{He}$ (The doctor) told me that I should not engage in sex with sex workers; that I should always use a condom with sex workers. He gave me a condom demonstration and told me that condoms can prevent infection. [Mystery client enacting a married young man, aged 22, who had had sex with sex workers and wanted to undergo an HIV test; AFHC A, Jharkhand]

The doctor gave me a condom demonstration and told me that one should wash one's hands with soap after condom use. [Mystery client enacting an unmarried young man, aged 19, in relationship with a girl and seeking condoms; AFHC B, Jharkhand]

The doctor told me that she would explain about the male condom to my husband. The doctor also told me that the IUD can be inserted in the uterus if I do not want a child now and that it can be removed when I want a child. [Mystery client enacting a married young woman, aged 20, seeking information on protective actions against her husband's extra-marital relationship and marital violence; AFHC B, Jharkhand]

The doctor told me that he cannot prescribe an IUD for me since I am unmarried, and that he also cannot explain to me how the condom is used, but would explain it to my boyfriend. He said that I should start taking the oral contraceptive pill on the day my next menstrual period ends. [Mystery client enacting an unmarried young woman, aged 17, pressured by her boyfriend for pre-marital sex and seeking oral pills; AFHC C, Jharkhand]

The doctor told me not to have sexual relations with sex workers, to use condoms always and to go for an HIV test immediately. [Mystery client enacting a married young man, aged 22, who had had sex with sex workers and wanted to undergo an HIV test; AFHC D, Jharkhand]

The doctor told me that the condom is a safe method. He said that the ECP (emergency contraceptive pill) has to be taken within 72 hours of sexual intercourse, but it is better not to use it because of its side effects. The doctor said that the OCP has a lot of side effects too He said that he cannot give me the ECP, that it should be purchased from the market, and recommended the condom as a good (safe) method. [Mystery client enacting an unmarried young woman, aged 17, pressured by her boyfriend for pre-marital sex and seeking oral pills; OPD providing adolescent health services, Rajasthan]

The doctor advised me not to have sex with sex workers and to go for an HIV test. The doctor also told me that he would not be able to treat me at the AFHC if I tested positive for HIV, and I would have to go to Bhilwara. [Mystery client enacting a married young man, aged 22, who had had sex with sex workers and wanted to undergo an HIV test; OPD providing adolescent health services, Rajasthan] 
He (The doctor) told me that my husband should use condoms; that I could use the ECP or Copper-T if I do not want a child now. [Mystery client enacting a married young woman, aged 20, seeking information on protective actions against her husband's extra-marital relationship and marital violence; OPD providing adolescent health services, Rajasthan]

The doctor gave me a condom demonstration and counselled me that having sex with sex workers is not good. [Mystery client enacting a married young man, aged 22, who had had sex with sex workers and wanting to undergo an HIV test; OPD providing adolescent health services, Rajasthan]

The doctor told me that Mala-D and Mala-N are not safe and will harm the body. She explained the use of the condom, and recommended the I-pill [emergency contraceptive pill]; she said that this pill can be used within 48 hours of sexual intercourse. [Mystery client enacting an unmarried young woman, aged 17, pressured by her boyfriend for pre-marital sex and seeking oral contraceptives; OPD providing adolescent health services, Rajasthan]

In three-quarters of all visits made, the clients were reassured that they were welcome to visit again if needed (18 of 24 visits-ten by male clients and eight by female clients). Such reassurance was given at mystery client visits in all three states-eight in Jharkhand and five each in Rajasthan and Maharashtra.

Despite these mixed perceptions, the mystery clients' overall experiences at the AFHC that they had visited were quite positive. Indeed, they reported that in three-quarters of the facilities that they had visited (16 of the 24 clients), adolescents and youth could get good services, but emphasised the need for ensuring privacy and providing more information to young people who seek services, as narrated below:

Yes, they (young people) can get good information. [Mystery client enacting an unmarried young woman, aged 17, pressured by her boyfriend for pre-marital sex and seeking oral contraceptives; AFHC C, Maharashtra]

Yes, they (young people) will get good services but they (AFHC staff) should ensure privacy. The doctor and the ANM should be sensitised to the need for ensuring privacy. [Mystery client enacting a married young woman, aged 20 seeking information on protective actions against her husband's extra-marital relationship and marital violence; OPD providing adolescent health services, Rajasthan]

Yes, they (young people) can get good services but the doctor should give more information. Services are available but they (providers) need to give correct information about the problem that the young person is experiencing. [Mystery client enacting an unmarried young man, aged 19, in relationship with a girl and seeking condoms; OPD providing adolescent health services, Rajasthan]

On the other hand, mystery clients who visited eight AFHCs felt that adolescents and youth may not get good services at these clinics, and voiced concerns about the lack of privacy, supplies and facilities, and provider indifference with regard to counselling youth, as narrated below:

The doctor provided good services but the other staff was not sensitive; the ANM gave me a packet of condoms in front of others. I did not like it. [Mystery client enacting an unmarried young woman, aged 17, pressured by her boyfriend for pre-marital sex and seeking oral contraceptives; OPD providing adolescent health services, Rajasthan]

Medicines were not available; the doctor should have given me some alternative medicine if the prescribed medicine was not available. Moreover, they (doctors) should try to understand the problem before prescribing any medicine. Also, they do not provide any counselling to young people. [Mystery client enacting an unmarried young woman, aged 17, pressured by her boyfriend for pre-marital sex and seeking oral contraceptives; OPD providing adolescent health services, Rajasthan]

No, the doctors don't pay attention there (AFHC). [Mystery client enacting an unmarried young man, aged 19 , in relationship with a girl and seeking condoms; AFHC A, Maharashtra]

No, there should be privacy. Young people should get the required services when they visit the facility and should not be asked to come later; there should be good infrastructure. [Mystery client enacting a married young woman, aged 20, seeking advice on protective actions against her husband's extra-marital relationship and marital violence; AFHC D, Jharkhand] 
Testing facilities should be made available, privacy should be maintained, and they (AFHCs) should provide counselling services. [Mystery client enacting a married young man, aged 22, who had had sex with sex workers and wanted to undergo an HIV test; OPD providing adolescent health services, Rajasthan]

No, they (adolescents and youth) will not get good services from this (AFHC) doctor. [Mystery client enacting a married young woman, aged 20, seeking information about protective actions against her husband's extra-marital relationship and marital violence; AFHC A, Maharashtra]

\section{Summary}

Awareness of AFHCs was abysmally low among adolescents and youth in the study settings. Just five percent of young men and eight percent of young women in the study villages were aware of AFHCs, even though the study villages were located within 5-10 kilometres from the AFHCs. Not surprisingly, less than one percent of young men and women had ever sought services from the AFHCs. Moreover, the services provided to young clients, as assessed by using mystery clients, varied. Although all the mystery client scenarios warranted the provision of information about contraceptive methods and condoms, information about different contraceptive methods was provided in less than two-thirds of all client visits and contraceptives were provided in even fewer. A few mystery clients reported that they were referred to a higher facility.

The quality of services received by clients at the AFHCs, as assessed by genuine and mystery clients, was mixed. Most clients met with a health care provider without any delay; most reported that the health care provider paid attention to them when they described their complaint; none was worried that the provider would tell others about the health problem for which she/he had sought AFHC services; and most reported that the provider did not shout at them or make fun of them. At the same time, concerns about lack of auditory and visual privacy (that is, the presence of other clients during consultation, having to explain the reason for visiting the AFHC to other clinic staff besides the health care provider who attended to the client and so on), limited consultation time and limited information received from the providers were raised in the descriptions of youth experiences at the AFHCs. Information provided to the clients was not comprehensive and was, at times, moralistic and judgmental. 


\section{Chapter 4 \\ Preferences of adolescents and youth about health care providers and facilities}

This chapter presents findings on the preferences of adolescents and youth about the health care providers from whom and facilities from which they would like to obtain selected health services and the reasons for their preferences. The findings draw on the data collected from adolescents and youth who participated in the communitybased survey.

\section{Health care providers and facilities preferred by adolescents and youth for selected health services}

The study explored the preferences of the surveyed adolescents and youth regarding the type of health care providers and health facilities that they would like to visit for selected health services. The health services included treatment for minor illnesses, contraceptive counselling, contraceptive supplies and treatment of symptoms of genital infection. We probed unmarried respondents additionally about their preferred provider(s) and facilities for counselling needs with regard to physical changes during adolescence, and female respondents additionally about their preferred provider(s) and facilities for pregnancy-related care and abortion. We caution that there is a fair chance that the preferences of the respondents may have been influenced by the types of health care providers and facilities that were available in their village or in nearby villages at the time of the survey. As mentioned in the section on 'Study Setting', all the villages were located 5-10 kms from the AHFCs-16 study villages were situated around AFHCs located in a sub-district hospital/rural hospital and 32 study villages were situated around AHFCs located in a $\mathrm{CHC}$.

Table 4.1 summarises the preferences of the surveyed adolescents and youth about the type of health care providers that they chose to approach for the selected health services. Several findings are notable. As Panel A of the Table indicates, first, MOs topped the list of preferred providers for most services, regardless of the sex of the respondent. Between 48 percent and 92 percent of young men and between 52 percent and 88 percent of young women preferred to approach a MO for most services. Two exceptions were observed. Young men were more likely to cite a pharmacist, rural medical practitioner or traditional healer as a preferred provider from whom to seek contraceptive supplies than a MO (54\% versus $48 \%$ ). Also, an identical percentage of young women reported a preference for ANMs and MOs for contraceptive counselling (52\%). Second, wide gender differences were evident with regard to approaching other types of providers. Young men were less likely than young women to approach communitylevel health workers including ASHAs and AWWs, regardless of the type of health service that we probed (2-9\% of young men versus $2-38 \%$ of young women). A similar pattern was evident with regard to approaching ANMs; $4-17$ percent of young men reported that they would approach an ANM for a health service compared to 20-58 percent of young women who reported so. Third, the preferred health care provider differed by the type of service about which we probed. For example, although a sizeable proportion of young women reported that they would approach a community-level health worker for services, they were likely to approach them for such services as contraceptive counselling (38\%), pregnancy-related care (37\%) and contraceptive supplies (23\%). Likewise, the few young men who would approach an ANM were more likely to do so for contraceptive counselling (16\%) and contraceptive supplies (17\%) than for treatment of symptoms of genital infection (4\%). Young women who preferred to approach an ANM were far more likely to do so for contraceptive counselling (52\%), contraceptive supplies (53\%) and pregnancy-related care $(58 \%)$ than for such services as treatment for minor illnesses (20\%) treatment of symptoms of genital infection (26\%) and abortion (24\%). Fourth, a sizeable proportion of the respondents reported that they preferred to approach a pharmacist, rural medical practitioner or traditional healer for a range of health services. For example, between 12 and 54 percent of young men reported that they preferred these providers for various services-contraceptive counselling (12\%), treatment of symptoms of genital infection (15\%), treatment of minor illnesses (29\%) and contraceptive supplies (54\%). Likewise, 13 percent and 36 percent of young women preferred to approach these providers for contraceptive supplies and treatment of minor illnesses, respectively. Finally, a substantial proportion of the respondents (17-25 percent) reported that they preferred to consult friends or family 
members rather than a health care provider for a range of services; for example, $17-25 \%$ preferred not to consult a health care provider for contraceptive counselling.

Table 4.1, which also presents the preferences of the young men and young women who participated in our survey by marital status, further shows that the preferred providers for the selected health services, for the most part, did not differ between married and unmarried respondents. Even so, a few differences were observed. For example, as Panel C suggests, married young women were more likely than the unmarried to report that they would approach an ANM for pregnancy-related care (63\% versus $51 \%$ ) or consult only family members and friends for contraceptive counselling (31\% versus 17\%). Among young men, as seen in Panel B of the table, the married were more likely than the unmarried to prefer such health care providers as pharmacists, rural medical practitioners or traditional healers for the treatment of common illnesses (37\% versus $27 \%$ ).

State-wise analysis shows that the patterns with regard to preferred health care providers, described earlier for the combined sample of adolescents and youth were, by and large, observed across all three states (Table 4.2, Panels A, B and C). The analysis also shows that adolescents and youth in Rajasthan (Panel C) were most likely and those in Maharashtra (Panel B) were least likely to report that they would approach an ANM for the selected health services. Further, a larger proportion of adolescents and youth in Maharashtra (Panel B) than those in Jharkhand and Rajasthan (Panels A and C, respectively) preferred to consult a MO for most services. Finally, young people in Maharashtra were also less likely than those in the other two states to report that they chose to consult a pharmacist, rural medical practitioner or traditional healer, or friends and family members for various health services.

Table 4.1: Percentage of adolescents and youth by preferred health care provider for selected health services, according to sex and marital status

\begin{tabular}{|c|c|c|c|c|c|c|c|c|c|c|}
\hline Type of health services & \multicolumn{2}{|c|}{ CHW } & \multicolumn{2}{|c|}{ ANM } & \multicolumn{2}{|c|}{ MO } & \multicolumn{2}{|c|}{$\begin{array}{c}\text { Other } \\
\text { providers }^{\mathrm{a}}\end{array}$} & \multicolumn{2}{|c|}{$\begin{array}{c}\text { Friends/family } \\
\text { members }^{\text {b }}\end{array}$} \\
\hline \multicolumn{11}{|c|}{ A. Combined } \\
\hline & YM & YW & YM & YW & YM & YW & YM & YW & YM & YW \\
\hline Treatment for minor illnesses & 7.8 & 8.5 & 12.1 & 20.3 & 80.6 & 80.1 & 29.1 & 35.5 & 1.0 & 2.5 \\
\hline $\begin{array}{l}\text { Counseling on physical } \\
\text { changes during adolescence }\end{array}$ & NS & NS & NS & NS & NS & NS & NS & NS & NS & NS \\
\hline Contraceptive counseling & 9.4 & 38.1 & 15.5 & 52.1 & 74.5 & 52.2 & 12.0 & 2.1 & 16.7 & 25.2 \\
\hline Contraceptive supplies & 8.4 & 23.0 & 17.0 & 52.6 & 47.9 & 70.4 & 54.1 & 13.1 & 5.5 & 6.3 \\
\hline $\begin{array}{l}\text { Treatment of symptoms of } \\
\text { genital infection }\end{array}$ & 2.1 & 4.8 & 3.8 & 26.2 & 91.7 & 87.9 & 14.9 & 4.9 & 2.8 & 4.4 \\
\hline Pregnancy-related care & - & 36.7 & - & 58.2 & - & 69.6 & - & 0.9 & - & 5.6 \\
\hline Abortion & - & 2.4 & - & 23.7 & - & 85.9 & - & 1.7 & - & 3.3 \\
\hline Number of respondents & 998 & 1,138 & 998 & 1,138 & 998 & 1,138 & 998 & 1,138 & 998 & 1,138 \\
\hline \multicolumn{11}{|c|}{ B. Young men } \\
\hline & MYM & UYM & MYM & UYM & MYM & UYM & MYM & UYM & MYM & UYM \\
\hline Treatment for minor illnesses & 5.6 & 8.5 & 14.0 & 11.4 & 78.6 & 81.3 & 36.6 & 26.7 & 1.0 & 1.0 \\
\hline $\begin{array}{l}\text { Counseling on physical } \\
\text { changes during adolescence }\end{array}$ & NA & 3.8 & NA & 4.2 & NA & 72.6 & NA & 5.4 & NA & 14.4 \\
\hline Contraceptive counseling & 12.5 & 8.2 & 18.6 & 14.4 & 74.2 & 74.5 & 13.9 & 11.3 & 13.5 & 17.8 \\
\hline Contraceptive supplies & 9.5 & 8.1 & 19.2 & 16.2 & 46.3 & 48.5 & 54.8 & 53.8 & 4.2 & 6.0 \\
\hline $\begin{array}{l}\text { Treatment of symptoms of } \\
\text { genital infection }\end{array}$ & 2.1 & 2.1 & 5.4 & 3.2 & 92.2 & 91.6 & 16.6 & 14.2 & 1.1 & 3.3 \\
\hline Pregnancy-related care & - & - & - & - & - & - & - & - & - & - \\
\hline Abortion & - & - & - & - & - & - & - & - & - & - \\
\hline Number of respondents & 449 & 549 & 449 & 549 & 449 & 549 & 449 & 549 & 449 & 549 \\
\hline
\end{tabular}




\begin{tabular}{|c|c|c|c|c|c|c|c|c|c|c|}
\hline \multirow[t]{3}{*}{ Type of health services } & \multicolumn{2}{|c|}{ CHW } & \multicolumn{2}{|c|}{ ANM } & \multicolumn{2}{|c|}{ MO } & \multicolumn{2}{|c|}{$\begin{array}{c}\text { Other } \\
\text { providers }^{a}\end{array}$} & \multicolumn{2}{|c|}{$\begin{array}{c}\text { Friends/family } \\
\text { members }^{\text {b }}\end{array}$} \\
\hline & \multicolumn{6}{|c|}{ C. Young women } & \multirow[b]{2}{*}{ MYW } & \multirow[b]{2}{*}{ UYW } & \multirow[b]{2}{*}{ MYW } & \multirow[b]{2}{*}{ UYW } \\
\hline & MYW & UYW & MYW & UYW & MYW & UYW & & & & \\
\hline Treatment for minor illnesses & 7.7 & 9.7 & 19.9 & 20.9 & 78.7 & 82.2 & 36.9 & 33.2 & 2.3 & 2.9 \\
\hline $\begin{array}{l}\text { Counseling on physical } \\
\text { changes during adolescence }\end{array}$ & NA & 22.6 & NA & 31.3 & NA & 62.8 & NA & 2.6 & NA & 19.1 \\
\hline Contraceptive counseling & 39.4 & 36.2 & 53.2 & 50.5 & 49.8 & 56.1 & 2.7 & 1.1 & 30.8 & 16.5 \\
\hline Contraceptive supplies & 23.1 & 23.0 & 54.6 & 49.5 & 70.7 & 69.9 & 14.3 & 11.2 & 7.0 & 5.3 \\
\hline $\begin{array}{l}\text { Treatment of symptoms of } \\
\text { genital infection }\end{array}$ & 4.2 & 5.8 & 25.2 & 27.8 & 87.9 & 88.0 & 6.3 & 2.8 & 4.3 & 4.7 \\
\hline Pregnancy-related care & 39.2 & 32.7 & 62.7 & 51.1 & 66.7 & 74.2 & 0.9 & 0.8 & 5.0 & 6.7 \\
\hline Abortion & 2.7 & 1.9 & 23.2 & 24.3 & 85.1 & 87.2 & 1.9 & 1.4 & 3.9 & 2.4 \\
\hline Number of respondents & 565 & 568 & 565 & 568 & 565 & 568 & 565 & 568 & 565 & 568 \\
\hline
\end{tabular}

YM: Young Men; YW: Young Women; MYM: Married Young Men; MYW: Married Young Women; UYM: Unmarried Young Men; UYW: Unmarried Young Women.

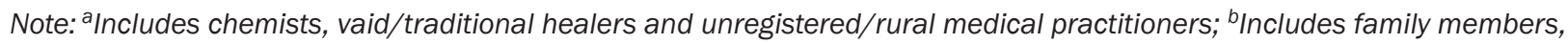
friends, neighbours; NS: Not shown since the question was posed only to the unnmarried; NA: Not asked.

Table 4.2: Percentage of adolescents and youth by preferred health care provider for selected health services, according to state of residence

\begin{tabular}{|c|c|c|c|c|c|c|c|c|c|c|}
\hline \multirow[t]{2}{*}{ Type of health services } & \multicolumn{2}{|c|}{ CHW } & \multicolumn{2}{|c|}{ ANM } & \multicolumn{2}{|c|}{ MO } & \multicolumn{2}{|c|}{$\begin{array}{c}\text { Other } \\
\text { providers }^{\mathrm{a}}\end{array}$} & \multicolumn{2}{|c|}{$\begin{array}{c}\text { Friends/family } \\
\text { members }^{b}\end{array}$} \\
\hline & YM & YW & YM & YW & YM & YW & YM & YW & YM & YW \\
\hline \multicolumn{11}{|c|}{ A. Jharkhand } \\
\hline Treatment for minor illnesses & 10.4 & 5.3 & 9.4 & 14.3 & 74.3 & 74.9 & 51.4 & 52.2 & 0.9 & 6.6 \\
\hline Contraceptive counseling & 16.4 & 43.4 & 16.8 & 52.7 & 65.3 & 45.1 & 22.3 & 4.9 & 19.8 & 31.3 \\
\hline Contraceptive supplies & 16.4 & 25.9 & 21.2 & 52.5 & 44.7 & 73.1 & 51.2 & 22.3 & 6.8 & 10.8 \\
\hline $\begin{array}{l}\text { Treatment of symptoms of } \\
\text { genital infection }\end{array}$ & 4.7 & 4.7 & 3.6 & 21.3 & 85.3 & 89.3 & 27.6 & 6.3 & 2.3 & 8.9 \\
\hline Pregnancy-related care & NA & 42.6 & NA & 62.3 & NA & 65.7 & NA & 1.9 & NA & 8.4 \\
\hline Abortion & NA & 6.7 & NA & 23.2 & NA & 83.5 & NA & 5.1 & NA & 7.5 \\
\hline Number of respondents & 362 & 374 & 362 & 374 & 362 & 374 & 362 & 374 & 362 & 374 \\
\hline \multicolumn{11}{|c|}{ B. Maharashtra } \\
\hline Treatment for minor illnesses & 8.0 & 17.8 & 4.8 & 21.6 & 94.0 & 91.1 & 1.7 & 3.6 & 0.0 & 0.3 \\
\hline Contraceptive counseling & 4.8 & 31.0 & 5.4 & 31.7 & 88.5 & 69.6 & 0.6 & 0.0 & 9.6 & 3.6 \\
\hline Contraceptive supplies & 5.4 & 25.6 & 9.6 & 28.7 & 53.0 & 68.0 & 54.1 & 6.1 & 6.8 & 2.3 \\
\hline $\begin{array}{l}\text { Treatment of symptoms of } \\
\text { genital infection }\end{array}$ & 0.9 & 8.9 & 1.8 & 23.4 & 95.6 & 86.3 & 0.5 & 0.3 & 3.4 & 1.0 \\
\hline Pregnancy-related care & NA & 24.6 & NA & 26.2 & NA & 84.8 & NA & 0.0 & NA & 0.0 \\
\hline Abortion & NA & 0.5 & NA & 17.0 & NA & 89.0 & NA & 0.3 & NA & 0.0 \\
\hline Number of respondents & 288 & 394 & 288 & 394 & 288 & 394 & 288 & 394 & 288 & 394 \\
\hline
\end{tabular}




\begin{tabular}{|c|c|c|c|c|c|c|c|c|c|c|}
\hline \multirow[t]{2}{*}{ Type of health services } & \multicolumn{2}{|c|}{ CHW } & \multicolumn{2}{|c|}{ ANM } & \multicolumn{2}{|c|}{ MO } & \multicolumn{2}{|c|}{$\begin{array}{c}\text { Other } \\
\text { providers }^{\mathrm{a}}\end{array}$} & \multicolumn{2}{|c|}{$\begin{array}{c}\text { Friends/family } \\
\text { members }\end{array}$} \\
\hline & YM & YW & YM & YW & YM & YW & YM & YW & YM & YW \\
\hline \multicolumn{11}{|c|}{ C. Rajasthan } \\
\hline Treatment for minor illnesses & 5.1 & 2.3 & 22.1 & 24.6 & 73.1 & 73.9 & 37.6 & 51.6 & 2.1 & 0.9 \\
\hline Contraceptive counseling & 7.9 & 40.3 & 24.6 & 72.0 & 68.1 & 41.6 & 14.4 & 1.4 & 21.2 & 41.2 \\
\hline Contraceptive supplies & 4.4 & 17.8 & 21.0 & 76.6 & 45.7 & 70.2 & 56.7 & 11.4 & 3.0 & 6.2 \\
\hline $\begin{array}{l}\text { Treatment of symptoms of } \\
\text { genital infection }\end{array}$ & 1.0 & 0.9 & 6.1 & 33.7 & 93.6 & 88.2 & 18.3 & 8.3 & 2.5 & 3.7 \\
\hline Pregnancy-related care & NA & 43.1 & NA & 86.3 & NA & 58.1 & NA & 0.7 & NA & 9.0 \\
\hline Abortion & NA & 0.3 & NA & 30.7 & NA & 85.0 & NA & 0.0 & NA & 2.6 \\
\hline Number of respondents & 348 & 365 & 348 & 365 & 348 & 365 & 348 & 365 & 348 & 365 \\
\hline
\end{tabular}

YM: Young Men; YW: Young Women.

Note: IIncludes chemists, vaid/traditional healers and unregistered/rural medical practitioners; ${ }^{b}$ Includes family members, friends, neighbours; NA: Not asked.

The type of health facilities that the surveyed adolescents and youth preferred to visit for selected health services are summarised in Table 4.3. As seen from Panel A of the table, the $\mathrm{CHC}$ was their most preferred facility for seeking all of the health services probed in the study. Among young men, reported preference for seeking services from the $\mathrm{CHC}$ ranged from 37 percent for contraceptive supplies to 58 percent for treatment of symptoms of genital infection. Among young women, on the other hand, reported preference ranged from 42 percent for seeking contraceptive counselling to 52-55 percent for seeking contraceptive supplies, treatment of symptoms of genital infection, pregnancy-related care and abortion. Lower level facilities such as sub-centres and PHCs were mentioned by only a small proportion of the study participants, particularly young men; just 2-12 percent of young men and 4-20 percent of young women so reported. Even so, it is notable that one-sixth of young women preferred to visit a subcentre for contraceptive supplies and about one-fifth for contraceptive counselling and pregnancy-related care. Interestingly, a sizeable proportion of young women (but not young men) reported that they preferred to visit an AWC for a range of health services: contraceptive supplies (24\%), contraceptive counselling (36\%) and pregnancy-related care (40\%). We note that this finding may reflect the fact that antenatal clinics are held in AWCs in villages in which sub-centres have not been established. Moreover, only a minority of adolescents and youth preferred to visit a DH for any of the services probed in the study-2-9 percent of young men and 3-11 percent of young women. At the same time, large proportions of young people reported that they preferred to visit private facilities: between 17 and 52 percent of young men and between 28 and 63 percent of young women so reported. Finally, findings suggest that a substantial minority of young men and young women preferred not to visit any facility for such services as contraceptive counselling and contraceptive supplies (7\% and 5\% of young men; $21 \%$ and $6 \%$ of young women, respectively) but rather, obtain these on their own (perhaps from a pharmacist, friend or family member).

Table 4.3 further suggests that gender differences in the type of health facilities preferred by the adolescents and youth were modest; even so, it is clear that young women had more options available within the village, or preferred to use facilities closer to home than did young men. For example, young women were more likely than young men to report that they preferred to visit a sub-centre or an AWC for contraceptive counselling and supplies, and a private facility for contraceptive supplies and treatment of minor illnesses.

The facility preferred by married and unmarried respondents did not differ for the most part (Table 4.3, Panels $B$ and $C$ ). Even so, Panel B suggests that married young men were more likely than the unmarried to report that they preferred to visit a $\mathrm{CHC}$, regardless of the service (41-68\% versus 36-54\%). Among young women (Panel C), the unmarried were more likely than the married to report a preference for private facilities for such services as pregnancy-related care and abortion (39\% versus $30 \%$, and $52 \%$ versus $43 \%$, respectively). Also, married young women were more likely than the unmarried to report that they would not visit a health facility for such services as contraceptive counselling ( $26 \%$ versus $14 \%$ ), suggesting perhaps that they relied on their husband for both seeking information and procuring contraceptive supplies. 
A state-wise analysis of the type of health facilities preferred by the surveyed adolescents and youth indicates that the patterns described earlier for the combined sample were, by and large, observed across all three states (Table 4.4, Panels A, B and C). Even so, some differences were notable across the states. First, as with the combined sample, most young men and women preferred to visit a $\mathrm{CHC}$ for the selected health services in Jharkhand (Panel A: $55-72 \%$ of young men and $52-72 \%$ of young women) and Rajasthan (Panel C: $42-79 \%$ of young men and $47-70 \%$ of young women). However in Maharashtra (Panel B), private facilities topped the list of facilities that adolescents and youth favoured for seeking the selected health services; 26-63 percent of young men and 40-67 percent of young women preferred a private facility as compared with 18-29 percent of young men and 23-29 percent of young women who preferred a $\mathrm{CHC}$.

Second, no consistent pattern was observed across the states in terms of the preferences of young people for such facilities as PHCs and sub-centres (Table 4.4). Again, as depicted earlier for the combined sample, few adolescents and youth-less than 10 percent-preferred to visit these facilities in Jharkhand (Panel A). In contrast, in Rajasthan, significant minorities of adolescents and youth reported that they preferred to visit a sub-centre for selected services (Panel C). For example, 14-18 percent of young men would visit a sub-centre for treatment of minor illnesses and contraceptive counselling and supplies, and 13-35 percent of young women would visit a subcentre for treatment for these services as well as for pregnancy-related care. However, as in Jharkhand, here too, a negligible minority of adolescents and youth-less than 10 percent-reported that they preferred to visit a PHC. The situation in Maharashtra (Panel B) differed from that in Jharkhand and Rajasthan (Panels A and C, respectively). Here, preferences for public sector facilities were evenly distributed across sub-centres, PHCs and CHCs, particularly among young women. For example, 12-19 percent of young women preferred to visit a sub-centre for most services (except for abortion); 13-15 percent, a PHC for all services and 23-29 percent, a CHC for all services (Panel B). Likewise, 21-28 percent of young men in Maharashtra preferred to visit a PHC for all services and 18-29 percent, a CHC for all types of services. However, as in Jharkhand (Panel A) and unlike in Rajasthan (Panel C), only a small minority of young men in Maharashtra (Panel B) reported that they would visit a sub-centre for any of the services.

Third, as with the combined sample of adolescents and youth described earlier, only a minority of surveyed adolescents and youth preferred to visit a $\mathrm{DH}$ for any service (Table 4.4, Panels A, B and C). Even so, significant minorities in Rajasthan preferred to visit a DH for selected services (Panel C). For example, 16 percent of young men would visit a DH for the treatment of symptoms of genital infection and 13-22 percent of young women for such services as contraceptive supplies, pregnancy-related care, abortion and treatment of symptoms of genital infection.

Fourth, similar to the combined sample shown earlier, a sizeable proportion of the adolescents and youth, particularly young women preferred not to visit any health facility, especially for contraceptive counselling and supplies in Jharkhand and Rajasthan (Table 4.4, Panels A and C). In contrast, in Maharashtra (Panel B), very few adolescents and youth so reported, perhaps reflecting the greater accessibility of a range of facilities for all services, including contraceptive counselling and supplies, in Maharashtra than in the other two states. 
Table 4.3: Percentage of adolescents and youth by preferred health facility for selected health services, according to sex and marital status

\begin{tabular}{|c|c|c|c|c|c|c|c|c|c|c|c|c|c|c|}
\hline $\begin{array}{l}\text { Type of health } \\
\text { services }\end{array}$ & \multicolumn{2}{|c|}{ sc } & \multicolumn{2}{|c|}{ PHC } & \multicolumn{2}{|c|}{$\mathrm{CHC}$} & \multicolumn{2}{|c|}{ DH } & \multicolumn{2}{|c|}{ AWC } & \multicolumn{2}{|c|}{$\begin{array}{l}\text { Private } \\
\text { facility }\end{array}$} & \multicolumn{2}{|c|}{ Nowhere } \\
\hline \multicolumn{15}{|c|}{ A. Combined } \\
\hline & YM & YW & YM & YW & YM & YW & YM & YW & YM & YW & YM & YW & YM & YW \\
\hline $\begin{array}{l}\text { Treatment for } \\
\text { minor illnesses }\end{array}$ & 8.8 & 10.9 & 11.5 & 7.2 & 51.0 & 44.1 & 3.0 & 4.3 & 3.6 & 7.6 & 51.9 & 63.3 & 0.7 & 2.2 \\
\hline $\begin{array}{l}\text { Counseling } \\
\text { on physical } \\
\text { changes during }\end{array}$ & & & & & & & & & & & & & & \\
\hline adolescence & NS & NS & NS & NS & NS & NS & NS & NS & NS & NS & NS & NS & NS & NS \\
\hline $\begin{array}{l}\text { Contraceptive } \\
\text { counseling }\end{array}$ & 8.2 & 20.3 & 10.5 & 6.3 & 47.7 & 42.3 & 2.9 & 2.7 & 5.0 & 35.7 & 33.6 & 27.9 & 6.5 & 21.4 \\
\hline Contraceptive & & & & & & & & & & & & & & \\
\hline supplies & 8.9 & 16.8 & 9.3 & 7.5 & 37.4 & 55.1 & 1.6 & 6.8 & 4.3 & 23.7 & 16.5 & 29.7 & 5.4 & 5.9 \\
\hline $\begin{array}{l}\text { Treatment of } \\
\text { symptoms of } \\
\text { genital infection }\end{array}$ & 2.2 & 6.8 & 9.4 & 6.5 & 57.9 & 55.1 & 8.8 & 10.1 & 0.7 & 3.8 & 42.1 & 47.3 & 2.7 & 3.9 \\
\hline Pregnancy-relatec & & & & & & & & & & & & & & \\
\hline care & NA & 18.4 & NA & 7.3 & NA & 53.5 & NA & 7.1 & NA & 39.8 & NA & 33.7 & NA & 5.6 \\
\hline Abortion & NA & 4.2 & NA & 5.3 & NA & 52.0 & NA & 11.1 & NA & 1.8 & NA & 44.9 & NA & 5.4 \\
\hline $\begin{array}{l}\text { Number of } \\
\text { respondents }\end{array}$ & 98 & 1.133 & 98 & 1,133 & 98 & 133 & 998 & 1,133 & 998 & 1,133 & 998 & 1,133 & 998 & 1,133 \\
\hline \multicolumn{15}{|c|}{ B. Young men } \\
\hline & MYM & UYM & MYM & UYM & MYM & UYM & MYM & UYM & MYM & UYM & MYM & UYM & MYM & UYM \\
\hline $\begin{array}{l}\text { Treatment for } \\
\text { minor illnesses }\end{array}$ & 9.9 & 8.4 & 7.2 & 13.0 & 57.2 & 48.9 & 4.3 & 2.6 & 2.0 & 4.1 & 50.5 & 52.4 & 0.5 & 0.8 \\
\hline $\begin{array}{l}\text { Counseling } \\
\text { on physical } \\
\text { changes during }\end{array}$ & & & & & & & & & & & & & & \\
\hline adolescence & NA & 3.3 & NA & 10.2 & NA & 39.1 & NA & 3.1 & NA & 1.9 & NA & 31.9 & NA & 14.8 \\
\hline $\begin{array}{l}\text { Contraceptive } \\
\text { counseling }\end{array}$ & 11.1 & 7.2 & 7.2 & 11.6 & 55.3 & 45.0 & 3.4 & 2.8 & 8.7 & 3.8 & 29.5 & 35.1 & 5.4 & 6.8 \\
\hline $\begin{array}{l}\text { Contraceptive } \\
\text { supplies }\end{array}$ & 11.7 & 7.9 & 6.1 & 10.4 & 41.3 & 36.1 & 1.1 & 1.9 & 6.3 & 3.7 & 16.1 & 16.6 & 4.0 & 5.9 \\
\hline $\begin{array}{l}\text { Treatment of } \\
\text { symptoms of } \\
\text { genital infection }\end{array}$ & 3.1 & 1.9 & 6.8 & 10.3 & 68.2 & 54.3 & 9.4 & 8.5 & 1.0 & 0.6 & 39.7 & 43.0 & 1.3 & 3.2 \\
\hline $\begin{array}{l}\text { Pregnancy-relatec } \\
\text { care }\end{array}$ & NA & NA & NA & NA & NA & NA & NA & NA & NA & NA & NA & NA & NA & NA \\
\hline Abortion & NA & NA & NA & NA & NA & NA & NA & NA & NA & NA & NA & NA & NA & NA \\
\hline $\begin{array}{l}\text { Number of } \\
\text { respondents }\end{array}$ & 449 & 549 & 449 & 549 & 449 & 549 & 449 & 549 & 449 & 549 & 449 & 549 & 449 & 549 \\
\hline
\end{tabular}




\begin{tabular}{|c|c|c|c|c|c|c|c|c|c|c|c|c|c|c|}
\hline $\begin{array}{l}\text { Type of health } \\
\text { services }\end{array}$ & \multicolumn{2}{|c|}{ sc } & \multicolumn{2}{|c|}{ PHC } & \multicolumn{2}{|c|}{$\mathrm{CHC}$} & \multicolumn{2}{|c|}{ DH } & \multicolumn{2}{|c|}{ AWC } & \multicolumn{2}{|c|}{$\begin{array}{l}\text { Private } \\
\text { facility }\end{array}$} & \multicolumn{2}{|c|}{ Nowhere } \\
\hline \multicolumn{15}{|c|}{ c. Young women } \\
\hline & MYW & UYW & MYW & UYW & MYW & UYW & MYW & UYW & MYW & UYW & MYW & UYW & MYW & UYW \\
\hline $\begin{array}{l}\text { Treatment for } \\
\text { minor illnesses }\end{array}$ & 10.8 & 11.2 & 6.9 & 7.8 & 47.0 & 39.6 & 4.4 & 4.1 & 7.0 & 8.5 & 61.0 & 66.9 & 2.2 & 2.2 \\
\hline $\begin{array}{l}\text { Counseling } \\
\text { on physical } \\
\text { changes during }\end{array}$ & & & & & & & & & & & & & & \\
\hline adolescence & NA & 12.3 & NA & 8.1 & NA & 38.6 & NA & 3.9 & NA & 20.3 & NA & 37.9 & NA & 18.8 \\
\hline $\begin{array}{l}\text { Contraceptive } \\
\text { counseling }\end{array}$ & 20.7 & 19.7 & 5.5 & 7.5 & 42.4 & 42.2 & 2.2 & 3.4 & 37.4 & 33.1 & 25.4 & 31.9 & 26.4 & 13.5 \\
\hline $\begin{array}{l}\text { Contraceptive } \\
\text { supplies }\end{array}$ & 17.4 & 15.9 & 7.7 & 7.3 & 56.6 & 52.9 & 8.2 & 4.7 & 25.0 & 21.6 & 28.5 & 31.5 & 6.5 & 5.1 \\
\hline $\begin{array}{l}\text { Treatment of } \\
\text { symptoms of } \\
\text { genital infection }\end{array}$ & 5.3 & 0 & 6 & 5 & 3.3 & 1 & 8 & D & 32 & 8 & 5 & 5 & 8 & 3 \\
\hline Pregnancy-related & & & & & & & & & & & & & & \\
\hline care & 18.8 & 17.7 & 7.3 & 7.2 & 55.3 & 50.8 & 8.1 & 5.5 & 45.1 & 31.6 & 30.4 & 38.9 & 5.2 & 6.3 \\
\hline Abortion & 3.8 & 5.0 & 4.7 & 6.2 & 54.2 & 48.6 & 12.0 & 9.7 & 1.7 & 2.0 & 43.1 & 52.4 & 5.4 & 5.3 \\
\hline $\begin{array}{l}\text { Number of } \\
\text { respondents }\end{array}$ & 565 & 568 & 565 & 568 & 565 & 568 & 565 & 568 & 565 & 568 & 565 & 568 & 565 & 568 \\
\hline
\end{tabular}

YM: Young Men; YW: Young Women; MYM: Married Young Men; MYW: Married Young Women; UYM: Unmarried Young Men; UYW: Unmarried Young Women.

Note: NS: Not shown since the question was posed only to the unmarried; NA: Not asked.

Table 4.4: Percentage of adolescents and youth by preferred health facility for selected health services, according to state of residence

\begin{tabular}{|c|c|c|c|c|c|c|c|c|c|c|c|c|c|c|}
\hline \multirow[t]{2}{*}{$\begin{array}{l}\text { Type of health } \\
\text { services }\end{array}$} & \multicolumn{2}{|c|}{ SC } & \multicolumn{2}{|c|}{ PHC } & \multicolumn{2}{|c|}{$\mathrm{CHC}$} & \multicolumn{2}{|c|}{ DH } & \multicolumn{2}{|c|}{ AWC } & \multicolumn{2}{|c|}{$\begin{array}{l}\text { Private } \\
\text { facility }\end{array}$} & \multicolumn{2}{|c|}{ Nowhere } \\
\hline & YM & YW & YM & YW & YM & YW & YM & YW & YM & YW & YM & YW & YM & YW \\
\hline \multicolumn{15}{|c|}{ A. Jharkhand } \\
\hline $\begin{array}{l}\text { Treatment for } \\
\text { minor illnesses }\end{array}$ & 1.2 & 2.1 & 0.0 & 1.7 & 64.9 & 54.1 & 0.1 & 2.9 & 3.6 & 3.7 & 51.8 & 72.6 & 0.9 & 5.5 \\
\hline $\begin{array}{l}\text { Contraceptive } \\
\text { counseling }\end{array}$ & 4.3 & 6.6 & 0.9 & 1.1 & 62.3 & 56.8 & 0.4 & 2.0 & 8.4 & 40.7 & 32.5 & 26.0 & 8.1 & 25.6 \\
\hline $\begin{array}{l}\text { Contraceptive } \\
\text { supplies }\end{array}$ & 4.1 & 4.1 & 1.2 & 2.7 & 54.9 & 71.1 & 0.0 & 4.4 & 6.5 & 26.3 & 15.9 & 32.7 & 7.1 & 9.0 \\
\hline $\begin{array}{l}\text { Treatment of } \\
\text { symptoms of } \\
\text { genital infection }\end{array}$ & 0.3 & 2.3 & 0.0 & 1.5 & 71.5 & 68.7 & 4.9 & 6.7 & 1.4 & 3.3 & 42.3 & 52.1 & 2.5 & 7.7 \\
\hline $\begin{array}{l}\text { Pregnancy-relatec } \\
\text { care }\end{array}$ & NA & 4.9 & NA & 1.6 & NA & 71.8 & NA & 4.6 & NA & 44.3 & NA & 31.5 & NA & 8.4 \\
\hline Abortion & NA & 4.2 & NA & 5.3 & NA & 52.0 & NA & 11.1 & NA & 1.8 & NA & 48.6 & NA & 5.4 \\
\hline $\begin{array}{l}\text { Number of } \\
\text { respondents }\end{array}$ & 362 & 374 & 362 & 374 & 362 & 374 & 362 & 374 & 362 & 374 & 362 & 374 & 362 & 374 \\
\hline
\end{tabular}




\begin{tabular}{|c|c|c|c|c|c|c|c|c|c|c|c|c|c|c|}
\hline \multirow[t]{2}{*}{$\begin{array}{l}\text { Type of health } \\
\text { services }\end{array}$} & \multicolumn{2}{|c|}{ sc } & \multicolumn{2}{|c|}{ PHC } & \multicolumn{2}{|c|}{$\mathrm{CHC}$} & \multicolumn{2}{|c|}{ DH } & \multicolumn{2}{|c|}{ AWC } & \multicolumn{2}{|c|}{$\begin{array}{l}\text { Private } \\
\text { facility }\end{array}$} & \multicolumn{2}{|c|}{ Nowhere } \\
\hline & YM & YW & YM & YW & YM & YW & YM & YW & YM & YW & YM & $\mathbf{Y W}$ & YM & YW \\
\hline \multicolumn{15}{|c|}{ B. Maharashtra } \\
\hline $\begin{array}{l}\text { Treatment for } \\
\text { minor illnesses }\end{array}$ & 6.3 & 17.3 & 28.1 & 14.5 & 29.0 & 22.6 & 2.8 & 2.3 & 4.2 & 14.2 & 62.6 & 67.0 & 0.0 & 0.3 \\
\hline $\begin{array}{l}\text { Contraceptive } \\
\text { counseling }\end{array}$ & 4.1 & 19.0 & 24.7 & 12.7 & 23.8 & 23.6 & 5.2 & 2.5 & 1.4 & 22.6 & 48.1 & 45.9 & 5.8 & 2.3 \\
\hline Contraceptive & & & & & & & & & & & & & & \\
\hline supplies & 8.3 & 17.0 & 20.8 & 14.0 & 18.3 & 25.4 & 3.4 & 2.0 & 1.8 & 19.8 & 26.1 & 39.6 & 6.4 & 2.3 \\
\hline $\begin{array}{l}\text { Treatment of } \\
\text { symptoms of } \\
\text { genital infection }\end{array}$ & 2.6 & 11.7 & 23.2 & 12.7 & 25.7 & 27.2 & 5.4 & 3.0 & 0.5 & 5.6 & 55.5 & 55.1 & 3.4 & 1.0 \\
\hline $\begin{array}{l}\text { Pregnancy-relatec } \\
\text { care }\end{array}$ & NA & 16.3 & NA & 14.9 & NA & 27.4 & NA & 3.6 & NA & 18.8 & NA & 52.5 & NA & 0.5 \\
\hline Abortion & NA & 7.6 & NA & 12.9 & NA & 28.7 & NA & 4.3 & NA & 0.3 & NA & 59.4 & NA & 1.8 \\
\hline $\begin{array}{l}\text { Number of } \\
\text { respondents }\end{array}$ & 288 & 394 & 288 & 394 & 288 & 394 & 288 & 394 & 288 & 394 & 288 & 394 & 288 & 394 \\
\hline \multicolumn{15}{|c|}{ C. Rajasthan } \\
\hline $\begin{array}{l}\text { Treatment for } \\
\text { minor illnesses }\end{array}$ & 18.4 & 13.0 & 4.7 & 5.2 & 61.5 & 56.1 & 5.9 & 7.6 & 2.8 & 4.7 & 40.0 & 50.8 & 1.3 & 0.9 \\
\hline $\begin{array}{l}\text { Contraceptive } \\
\text { counseling }\end{array}$ & 16.1 & 34.6 & 4.2 & 4.8 & 59.4 & 47.4 & 2.8 & 3.5 & 5.8 & 44.2 & 18.9 & 11.7 & 5.7 & 36.5 \\
\hline $\begin{array}{l}\text { Contraceptive } \\
\text { supplies }\end{array}$ & 13.9 & 28.6 & 4.6 & 5.6 & 41.5 & 69.8 & 1.4 & 13.9 & 5.0 & 25.1 & 6.9 & 16.9 & 3.0 & 6.7 \\
\hline $\begin{array}{l}\text { Treatment of } \\
\text { symptoms of } \\
\text { genital infection }\end{array}$ & 3.5 & 6.1 & 3.5 & 5.1 & 79.1 & 70.3 & 15.8 & 20.4 & 0.2 & 2.5 & 28.1 & 34.9 & 2.2 & 3.4 \\
\hline $\begin{array}{l}\text { Pregnancy-relatec } \\
\text { care }\end{array}$ & NA & 33.2 & NA & 4.9 & NA & 62.3 & NA & 12.9 & NA & 56.6 & NA & 16.9 & NA & 8.0 \\
\hline Abortion & NA & 3.2 & NA & 1.8 & NA & 67.8 & NA & 21.7 & NA & 0.3 & NA & 26.8 & NA & 3.8 \\
\hline $\begin{array}{l}\text { Number of } \\
\text { respondents }\end{array}$ & 348 & 365 & 348 & 365 & 348 & 365 & 348 & 365 & 348 & 365 & 348 & 365 & 348 & 365 \\
\hline
\end{tabular}

YM: Young Men; YW: Young Women.

Note: NA: Not asked.

\section{Reasons for preferring government or private health facilities}

Adolescents and youth who expressed a preference for government or private facilities for most of the selected health services were further probed about the reasons for their preference. We note that as many as two-thirds of young men and women in our sample preferred a government facility for most services, and the remaining preferred a private facility.

Table 4.5 describes the reasons furnished by the respondents for preferring the services of government or private facilities for the health problems probed in this study. Among those who preferred government facilities, the most frequently cited reason was easy access to services, with 92 percent and 89 percent of young men and women, respectively, reporting so. Other frequently mentioned reasons included the quality of the facility (mentioned by $57 \%$ and $62 \%$ of young men and women, respectively), and quality of care (mentioned by $17 \%$ and $12 \%$ of young men and women, respectively). Gender differences were modest. Differences by marital status, however, were notable. The married were considerably more likely than the unmarried to report easy access as a reason for preferring 
government facilities (90\% versus $8-14 \%$ ). In contrast, unmarried young women were more likely than the married to cite the quality of the facility (68\% versus $59 \%$ in the case of young women, but no difference in the case of young men) and quality of care (15\% versus $10 \%$ among young women; $19 \%$ versus $11 \%$ among young men) as their grounds for favouring government facilities.

Table 4.5: Percentage of adolescents and youth by reasons for preferring government or private health facilities, according to sex and marital status

\begin{tabular}{lrrrrrr}
\hline Reasons for preferring & YM & YW & MYM & MYW & UYM & UYW \\
\hline Government Facilities & & & & & & \\
Easy access & 91.5 & 88.5 & 90.3 & 90.2 & 8.0 & 13.6 \\
Quality of facility & 57.1 & 62.3 & 56.8 & 59.0 & 57.2 & 68.1 \\
Quality of care & 16.6 & 12.1 & 11.0 & 10.2 & 18.6 & 15.3 \\
No choice & 1.9 & 7.8 & 2.2 & 9.0 & 1.8 & 5.9 \\
Other & 1.9 & 1.9 & 2.6 & 1.9 & 1.6 & 1.9 \\
Number who preferred & $\mathbf{6 9 5}$ & $\mathbf{7 8 0}$ & $\mathbf{3 1 1}$ & $\mathbf{3 9 2}$ & $\mathbf{3 8 4}$ & $\mathbf{3 8 8}$ \\
Private Facilities & & & & & & \\
Easy access & 31.2 & 24.7 & 31.1 & 20.1 & 31.3 & 30.8 \\
Quality of facility & 90.4 & 95.7 & 90.9 & 95.8 & 90.2 & 95.5 \\
Quality of care & 33.8 & 36.6 & 27.2 & 35.1 & 35.9 & 38.5 \\
No choice & 1.6 & 3.9 & 0.7 & 4.1 & 1.9 & 3.7 \\
Other & 4.8 & 5.3 & 3.4 & 3.6 & 5.2 & 7.4 \\
Number who preferred & $\mathbf{3 0 3}$ & $\mathbf{3 5 3}$ & $\mathbf{1 3 8}$ & $\mathbf{1 7 3}$ & $\mathbf{1 6 5}$ & $\mathbf{1 8 0}$ \\
\hline
\end{tabular}

YM: Young Men; YW: Young Women; MYM: Married Young Men; MYW: Married Young Women; UYM: Unmarried Young Men; UYW: Unmarried Young Women.

Respondents who preferred private facilities cited a host of reasons which differed somewhat from the reasons mentioned by those who preferred government facilities (Table 4.5). The most frequently mentioned reason was the quality of the facility, reported by 90-96 percent of respondents, a reason cited by those who preferred government facilities as well, albeit in smaller numbers (57-62\%). Other reasons cited related to quality of care (34-37\%) and easy access (25-31\%). Gender differences were modest. Differences by marital status show that unmarried young women were more likely than the married to cite easy access (31\% versus $20 \%$ ) and unmarried young men were more likely than the married to mention quality of care (36\% versus $27 \%$ ) as their justification for preferring private facilities.

A state-wise analysis of the reasons given by the surveyed adolescents and youth for their preference for government or private facilities, presented in Table 4.6, indicates that similar reasons were mentioned by respondents in all three states. Even so, young people in Maharashtra were more likely than those in the other two states to mention quality of the facility ( $77-80 \%$ versus $46-57 \%$ in Jharkhand and $52-55 \%$ in Rajasthan) and quality of care (28-32\% versus $10-14 \%$ in Jharkhand and $4-8 \%$ in Rajasthan) as reasons for preferring government facilities. Young women in Rajasthan additionally mentioned that they favoured government facilities as these were the only facilities available in their villages. The analysis further shows that young people in Maharashtra were also more likely than those in the other two states to mention easy access and quality of care as grounds for preferring private health facilities. 
Table 4.6: Percentage of adolescents and youth by reasons for preferring government or private health facilities, according to sex and state of residence

\begin{tabular}{lrrrrrr}
\hline Reasons for preferring & \multicolumn{2}{c}{ Jharkhand } & \multicolumn{2}{c}{ Maharashtra } & \multicolumn{2}{c}{ Rajasthan } \\
\cline { 2 - 6 } & YM & YW & YM & YW & YM & YW \\
\hline Government Facilities & & & & & & \\
Easy access & 95.1 & 91.2 & 86.9 & 88.5 & 92.0 & 86.7 \\
Quality of facility & 45.8 & 57.2 & 77.2 & 79.9 & 51.7 & 55.3 \\
Quality of care & 13.5 & 10.2 & 32.1 & 28.2 & 8.0 & 3.5 \\
No choice & 2.9 & 2.6 & 1.9 & 1.9 & 1.2 & 15.4 \\
Other & 2.2 & 2.6 & 2.1 & 2.9 & 1.4 & 0.7 \\
Number who preferred & $\mathbf{2 5 0}$ & $\mathbf{2 6 0}$ & $\mathbf{1 3 2}$ & $\mathbf{1 8 5}$ & $\mathbf{2 8 9}$ & $\mathbf{3 1 1}$ \\
Private Facilities & & & & & & \\
Easy access & 21.4 & 11.6 & 38.3 & 38.4 & 27.8 & 7.4 \\
Quality of facility & 87.4 & 95.4 & 91.0 & 94.6 & 93.4 & 100.0 \\
Quality of care & $\mathbf{2 8 . 6}$ & $\mathbf{3 2 . 0}$ & 40.1 & 44.3 & 25.3 & 20.7 \\
No choice & 1.3 & 1.7 & 2.4 & 6.5 & 0.0 & 0.0 \\
Other & 5.0 & 1.0 & 3.1 & 9.2 & 8.6 & 1.1 \\
Number who preferred & $\mathbf{1 1 2}$ & $\mathbf{1 1 4}$ & $\mathbf{1 3 2}$ & $\mathbf{1 8 5}$ & $\mathbf{5 9}$ & $\mathbf{5 4}$ \\
\hline
\end{tabular}

YM: Young Men; YW: Young Women.

\section{Summary}

With regard to the preferences of adolescents and youth about health care providers and facilities, findings show that among both young men and women, Medical Officers topped the list of preferred providers for most health services probed in this study. It is not clear from the available data whether this preference was because of young people's lack of awareness that other health care providers were also competent to provide quality services, a bias in favour of physicians or based on real experiences. Wide gender differences were evident with regard to approaching other types of health care providers: young men were less likely than young women to approach frontline and community-level health workers including ANMs, ASHAs and AWWs, regardless of the type of health service. The preferred health care provider differed by the type of service: for example, the few young men who would approach an ANM were more likely to do so for contraceptive counselling and contraceptive supplies than for treatment of symptoms of genital infection, while young women who expressed this preference were more likely to do so for contraceptive counselling, contraceptive supplies and pregnancy-related care than for such services as treatment for minor illnesses, treatment of symptoms of genital infection and abortion-related services. Finally, a substantial proportion of young men and young women reported that they preferred to consult friends or family members rather than a health care provider for a range of services, including for contraceptive counselling.

The facility that adolescents and youth preferred for seeking all of the health services probed in the study was a $\mathrm{CHC}$. Lower-level facilities such as sub-centres and Primary Health Centres were mentioned by only a small proportion of study participants, particularly young men ( $2-12 \%$ of young men and $4-20 \%$ of young women). Even so, it is notable that one-sixth of young women would opt to visit a sub-centre for contraceptive supplies and about one-fifth for contraceptive counselling and pregnancy-related care. Interestingly, a sizeable proportion of young women (not young men) reported that they preferred an Anganwadi Centre for a range of health services: contraceptive supplies, contraceptive counselling and pregnancy-related care. Moreover, only a minority of young people preferred a District Hospital for any of the selected services. 


\section{Chapter 5 Summary and recommendations}

This chapter summarises the main findings of this study and highlights lessons for improving the delivery of health services to adolescents and youth visiting Adolescent Friendly Health Clinics.

\section{Summary}

Although adolescence and young adulthood represent a generally healthy period of life, sexual and reproductive health concerns, ranging from worries about nocturnal emission among adolescent boys or menstruation among adolescent girls to symptoms suggestive of genital infection, and mental health concerns including feeling depressed or worthless, or losing sleep or confidence, affected notable proportions of adolescents and youth in the study settings. Indeed, over one-half of young men and over two-fifths of young women reported having experienced at least one sexual and reproductive health problem and/or mental health concern in the year preceding the interview, and the married were more likely than the unmarried to so report. Similarly, about one-fifth of young men and a quarter of young women reported feeling depressed or worthless or losing sleep or confidence in the year preceding the interview.

Seeking care for sexual and reproductive health problems and mental health concerns remains limited among adolescents and youth in these settings. Although care-seeking varied by the type of health problem and mental health concern, no more than one-half of young men and no more than two-thirds of young women who experienced a sexual and reproductive health problem had sought advice and/or treatment and even fewer-one-third-had done so for mental health concerns. The major reason for not seeking advice and/or treatment was the perception that the health issue was not serious enough to do so, followed by embarrassment in seeking treatment, lack of money, lack of family support and concerns about poor quality of care.

Adolescents and youth who sought treatment and/or advice for health concerns largely consulted doctors in government or private facilities. State-wise data suggest that adolescents and youth in different settings sought advice and/or treatment from different sources, overall. Adolescents and youth in Rajasthan were, by and large, more likely than those in Jharkhand and Maharashtra to report that they consulted doctors (Medical Officers) in government facilities, regardless of the nature of the health problem experienced. In contrast, adolescents and youth in Maharashtra were more likely than those in the other two states to report that they sought the services of doctors in private facilities, irrespective of the health problem for which they sought care, while those in Jharkhand were more likely than those in the other two states to have relied on informal providers.

The interaction of adolescents and youth with frontline health care providers such as ANMs as well as those based at the community level, such as ASHAs and AWWs, remain limited. Notably, such interactions were more limited among young men than young women, and among the unmarried than the married. While a little over two-fifths of young women had interacted with an ANM in the one year preceding the interview, just one in 10 young men had done so. Likewise, while slightly less than two-fifths of young women had interacted with ASHAs/AWWs, just seven percent of young men had done so. Findings also suggest that young women from scheduled castes and tribes interacted with health workers in the public system more than those belonging to other castes, and that better educated young women, and those from wealthier households interacted with health workers in the public system less often than other young women. Findings, moreover, suggest that the most commonly discussed topics were newborn care followed by common illnesses, and pregnancy-related care (more commonly discussed with young women than young men). Discussion on changes during adolescence (except menstruation among girls and nocturnal emission among boys) and relationships or issues related to mental health that have been expressed as important concerns by young people are missing.

Awareness of AFHCs was abysmally low among adolescents and youth in the study settings. Just five percent of young men and eight percent of young women in the study villages were aware of AFHCs, even though the study villages were located within 5-10 kilometres from the AFHCs. Not surprisingly, less than one percent of young men and women had ever sought services from the AFHCs. Moreover, the services provided to young clients, as assessed 
by using mystery clients, varied. Although all the mystery client scenarios warranted the provision of information about contraceptive methods and condoms, information about different contraceptive methods was provided in less than two-thirds of all client visits and contraceptives were provided in even fewer. A few mystery clients reported that they were referred to a higher facility.

The quality of services received by clients at the AFHCs, as assessed by genuine and mystery clients, was mixed. Most clients met with a health care provider without any delay; most reported that the health care provider paid attention to them when they described their complaint; none was worried that the provider would tell others about the health problem for which she/he had sought AFHC services; and most reported that the provider did not shout at them or make fun of them. At the same time, concerns about lack of auditory and visual privacy (that is, the presence of other clients during consultation, having to explain the reason for visiting the AFHC to other clinic staff besides the health care provider who attended to the client and so on), limited consultation time and limited information received from the providers were raised in the descriptions of youth experiences at the AFHCs. Information provided to the clients was not comprehensive and was, at times, moralistic and judgmental.

With regard to the preferences of adolescents and youth about health care providers and facilities, findings show that among both young men and women, Medical Officers topped the list of preferred providers for most health services probed in this study. It is not clear from the available data whether this preference was because of young people's lack of awareness that other health care providers were also competent to provide quality services, a bias in favour of physicians or based on real experiences. Wide gender differences were evident with regard to approaching other types of health care providers: young men were less likely than young women to approach frontline and community-level health workers including ANMs, ASHAs and AWWs, regardless of the type of health service. The preferred health care provider differed by the type of service: for example, the few young men who would approach an ANM were more likely to do so for contraceptive counselling and contraceptive supplies than for treatment of symptoms of genital infection, while young women who expressed this preference were more likely to do so for contraceptive counselling, contraceptive supplies and pregnancy-related care than for such services as treatment for minor illnesses, treatment of symptoms of genital infection and abortion-related services. Finally, a substantial proportion of young men and young women reported that they preferred to consult friends or family members rather than a health care provider for a range of services, including for contraceptive counselling.

The facility that adolescents and youth preferred for seeking all of the health services probed in the study was a CHC. Lower-level facilities such as sub-centres and Primary Health Centres were mentioned by only a small proportion of study participants, particularly young men ( $2-12 \%$ of young men and $4-20 \%$ of young women). Even so, it is notable that one-sixth of young women would opt to visit a sub-centre for contraceptive supplies and about one-fifth for contraceptive counselling and pregnancy-related care. Interestingly, a sizeable proportion of young women (not young men) reported that they preferred an Anganwadi Centre for a range of health services: contraceptive supplies, contraceptive counselling and pregnancy-related care. Moreover, only a minority of young people preferred a District Hospital for any of the selected services.

\section{Recommendations}

\section{Raise awareness of common health problems experienced in adolescence}

Findings that a substantial proportion of adolescents and youth did not seek advice and/or treatment for their health problem and perceived that the health problem they experienced was not serious enough to seek care call for health education programmes to raise awareness of the common health problems and concerns of adolescence. These programmes should provide age-appropriate health information, starting from early adolescence. Moreover, health care providers should be trained in better understanding the kinds of problems adolescents face.

\section{Expand the scope of services provided to adolescents and youth}

Findings that almost one-fifth of young men and one-quarter of young women experienced mental health concerns in the one year preceding the interview underscore the need for expanding the scope of services offered to adolescents and youth to include mental health services. The recently launched RKSK programme does acknowledge the need for addressing the mental health concerns of adolescents and youth. The programme has proposed several interventions, including addressing mental health concerns during Adolescent Health Days organised at the 
community level; making available counselling, referral and management of mental health disorders at the facility level; raising awareness of common mental health concerns and symptoms of mental health problems among adolescents and youth as well as influential adults in their life; incorporating the topic of mental health concerns in the adolescence education programme curriculum and screening for mental health concerns under the Rashtriya Bal Swasthya Karyakram (RBSK). It is important that these strategies are implemented in a timely and effective way.

\section{Expand the health care provider base to serve adolescents and youth}

Findings highlight that although public sector facilities continue to be favoured by adolescents and youth, sizeable proportions preferred to access services from the private sector, including pharmacists and informal providers. These findings call for promotion of public-private partnerships in meeting the health service needs of adolescents and youth. Models, using different health care provider payment mechanisms or demand side financing options such as vouchers, may be pilot tested. Likewise, a dedicated social marketing/franchising programme for adolescents and youth may be considered.

\section{Sensitise influential others in young people's life about their role in supporting adolescents and youth}

Findings show that informal channels such as friends, family members and informal providers were important sources for meeting the information and counselling needs of adolescents and youth, and therefore, sensitising these groups will continue to remain an important part of reaching out to adolescents and youth.

\section{Sensitise and build the skills of health care providers to respond to the needs of all categories of adolescents and youth}

Findings underscore the limited interactions that adolescents and youth had with frontline health workers and community-level workers as well as limited utilisation of services from the AFHCs. They also highlight that young men have fewer choices than young women within the public health system; similarly, unmarried adolescents and youth tend to have limited access to facilities within the public health system. These findings call for increased efforts to sensitise and build the skills of various cadres of health care providers, including frontline health workers and community-level workers, to respond to the needs of all categories of adolescents and youth. Particularly needed are efforts that enable these workers to overcome their inhibitions to provide information and services to adolescents and youth of the opposite sex and the unmarried, and to provide information on sexual and reproductive matters tailored to the age and life stage of the young person. Besides the conventional, cascading training of providers, such options as e-learning based capacity-building programmes that offer providers an opportunity to learn at their own pace may also be attempted.

\section{Raise awareness about the availability of AFHCs widely among adolescents and youth and} influential adults in their life

Findings that awareness of AFHCs among adolescents and youth is rather dismal even in villages that are located close to the AFHCs underscore the need for communication activities to publicise these facilities, including imaginative branding of AFHCs among adolescents, youth and influential adults in their life. In this context, the use of social media in promoting AFHCs may be considered. Part of these efforts should focus on informing communities and adolescents and youth about the services that different cadres of health care providers can offer to adolescents and youth and the kind of services available at each level of the facility. Such efforts will help in reducing the burden on any one particular level of facility (for example, CHCs were the most popular facility for seeking health services among the participants of the current study) and referrals can get streamlined. Likewise, communities and adolescents and youth need to be informed that health care providers such as ASHAs and ANMs are well trained to respond to their health needs.

\section{Improve the quality of service delivery at the AFHCs}

Findings show that adolescents and youth rarely visited the AFHCs; moreover, even when they did so, as in the case of mystery clients, a sizeable number of clients did not receive the service for which they visited the AFHC. Further, service providers were often prescriptive in the advice they offered and conveyed that pre-marital sex is undesirable. 
Occasionally, the advice given was incorrect and not likely to be helpful to the young person (for example, the Counsellor advising the client who sought advice for anxiety about nocturnal emission that he should study, play, eat food on time and should not look at vulgar things, or the Medical Officer suggesting that AIDS can be cured in the initial stage). These findings call for increased efforts to improve the quality of service provision at the AFHCs. Efforts are needed to make the AFHCs one-stop clinics for meeting the needs of adolescents and youth. Comprehensive, quality information and services should be made available to young people who seek services at the AFHC. Findings that young people's right to privacy and to confidential and non-judgemental services are not always respected call for improving the quality of facilities designated as AFHCs to ensure privacy for services as well as sensitising and strengthening further the skills of all health care staff to provide services in non-judgemental and sensitive ways. Also needed are efforts to standardise the services provided through AFHCs.

\section{Ensure effective monitoring and evaluation of the AFHCs}

Given that AFHCs will be one of the major pillars of the RKSK programme, efforts are necessary that monitor and evaluate concurrently the functioning of the AFHCs and their role in enabling adolescents and youth to access services and support, and thereby make informed and responsible decisions related to their health and well-being. The methodology used in our study for gaining insights by using mystery clients and exit interviews of genuine clients may be considered as a means through which regular third party audits of AFHCs may be conducted. 


\section{References}

Boyce, C. and P. Neale. 2006. Conducting In-Depth Interviews: A Guide for Designing and Conducting In-Depth Interviews for Evaluation Input, Monitoring and Evaluation-2. USA: Pathfinder International.

Centre for Operations Research and Training (CORT). 2009. Assessment of Adolescent Reproductive and Sexual Health (ARSH) Centres in Gujarat. Vadodara: CORT.

International Institute of Health Management Research (IIHMR). 2010. Evaluation study on Adolescent Friendly Health Clinics in Maharashtra. Jaipur: IIHMR.

International Institute for Population Sciences (IIPS) and Population Council. 2010. Youth in India: Situation and Needs, 2006-2007. Mumbai: IIPS.

International Institute for Population Sciences (IIPS). 2010. District Level Household and Facility Survey (DLHS-3), 2007-08: India. Mumbai: IIPS.

Jejeebhoy, S. J., K. G. Santhya, S. K. Singh et al. 2014. Provision of reproductive and sexual health services to adolescents and youth in India: The perspectives of health care provider. New Delhi: Population Council.

Kumar, R. 2014. Overview of Rashtriya Kishor Swasthya Karyakram. Presentation made at the launch of Rashtriya Kishor Swasthya Karyakarm and National Consultation on Adolescent Health, New Delhi, January 2014.

Ministry of Health and Family Welfare (MOHFW). 2006a. Implementation Guide on RCH II Adolescent Reproductive and Sexual Health Strategy for State and District Programme Managers, New Delhi: Ministry of Health and Family Welfare, Government of India.

Ministry of Health and Family Welfare (MOHFW). 2006b. Orientation Programme for Medical Officers to Provide AdolescentFriendly Reproductive and Sexual Health Services: Facilitator's Guide. New Delhi: Ministry of Health and Family Welfare, Government of India.

Ministry of Health and Family Welfare (MOHFW). 2006c. Orientation Programme for ANMs/LHVs to Provide Adolescent-Friendly Reproductive and Sexual Health Services: Facilitator's Guide. New Delhi: Ministry of Health and Family Welfare, Government of India.

Ministry of Health and Family Welfare (MOHFW). 2006d. Reading material for ASHA, Book \# 3, Family Planning, RTI/STIs and HIV/ AIDS and ARSH. Accessed on 4 July, 2011 at http://www.mohfw.nic.in/NRHM/Documents/ASHA_Book_No_3.pdf.

Ministry of Health and Family Welfare (MOHFW). 2009. National Rural Health Mission, Reproductive and Child Health Programme Phase 2, 6th Joint Review Mission Aide Memoire. New Delhi: Ministry of Health and Family Welfare, Government of India.

Ministry of Health and Family Welfare (MOHFW). 2012. Update on the ASHA Programme. New Delhi: Ministry of Health and Family Welfare, Government of India.

Ministry of Health and Family Welfare (MOHFW). 2014. National Rural Health Mission, Rashtriya Kishor Swasthya Karyakram (RKSK). New Delhi: Ministry of Health and Family Welfare, Government of India.

Ministry of Statistics and Programme Implementation (MOSPI). 2008. New Series (1999-2000) Statement: Gross State Domestic Product at Current Prices. New Delhi: Ministry of Statistics and Programme Implementation, Government of India.

Office of the Registrar General and Census Commissioner, India. 2011. Provisional Population Totals, Paper 1 of 2011 : Census of India 2011, Series I-India. New Delhi: Office of the Registrar General, India.

Planning Commission. 2011. Mid-Term Appraisal Eleventh Five Year Plan 2007-2012. New Delhi: Oxford University Press.

Santhya, K.G., S.J. Jejeebhoy and S. Ghosh. 2007. Addressing the sexual and reproductive health needs of young people: Perspectives and experiences of stakeholders from the health and non-health sectors. New Delhi: Population Council.

Santhya, K.G., S. J. Jejeebhoy and A. J. Francis Zavier. 2011. Implementing the Janani Suraksha Yojana: Perspectives and experiences of Accredited Social Health Activists in Rajasthan. New Delhi: Population Council.

Santhya, K. G., S. J. Jejeebhoy, R. Acharya et al. 2011. Effects of the Janani Suraksha Yojana on maternal and newborn care practices: Women's experience in Rajasthan. New Delhi: Population Council. 


\section{Authors}

K G Santhya, Associate II, Population Council, New Delhi

Ravi Prakash, formerly Programme Officer, Population Council, New Delhi

Shireen J. Jejeebhoy, Senior Associate, Population Council, New Delhi

Santosh Kumar Singh, Assistant Programme Officer, Population Council, Patna, Bihar 


\section{List of investigators}

Babita Bansod

Rajesh Manik Bhivsene

Kalyani D Bhure

Pankaj Bhuyar

Rahul Chaudhari

Pawan Chaudhari

Sarita Ramdas Deshbhratar

Md. Tasnim Faruque

Neeta Bhanudas Fulzele

Komal Pyarelal Gupta

Reena Pyarelal Gupta

Anju Abhay Karketa

Nasim Kousar

Brajesh Kumar

Deepak Kumar

Kamlesh Kumar

Pratibha Kumari

Shailender Kumar

Yashoda Kumari

Prerana Hiramanji Malwe

Marium Minz

Hrishikesh Pandey

Anil Phapale

Ashish Ranjan

Rajeshri Keshavrao Rathod

Rajnikant

Brahmanand Saraswati

Md. Shakil

Ismail Sharif

Meena Shinde

Munni Tigga

Jai Shankar Tiwari

Dinesh Uke 
Printed at :

systemsvision@gmail.com 
Zone 5A, Ground Floor POPULATION India Habitat Centre, Lodi Road New Delhi, India 110003 Phone: 91-11-24642901 Email: info.india@popcouncil.org

Ideas. Evidence. Impact. 